\title{
Gesetzliche Schuldverhältnisse
}

\author{
Inhaltsübersicht
}
A. Einleitung
B. Deliktsrecht
I. Grundstrukturen des BGB-Deliktsrechts
II. Verkehrspflichten
1. Haftung für Unterlassen im BGB
2. Entwicklung der Verkehrspflichten durch die Rechtsprechung
3. Literatur bis 1945
4. Entwicklung nach dem Zweiten Weltkrieg: Unmittelbare und mittelbare Verletzungen
5. Das Deliktsrecht bei Mertens: Legislative und judizielle Konzeption des $\S 823$ Abs. 1 BGB
6. Auf dem Weg zu einem einheitlich strukturierten Delikt

III. Persönlichkeitsverletzungen

1. Legislatorische Anerkennung des Rechts am eigenen Bild

2. Vom Attentismus des RG zum Aktionismus des BGH

3. Geldersatz für Persönlichkeitsverletzungen

4. Patrimoniales Persönlichkeitsrecht

IV. Reine Vermögensschäden

1. Gesetzliche Ausgangslage

2. Korrektur durch das UWG

3. Recht am eingerichteten und ausgeübten Gewerbebetrieb

4. Inflation der Vertragshaftung

5. Die große Lösung: Verkehrspflichten zum Schutz fremden Vermögens

6. Perspektiven deliktischen Vermögensschutzes

V. Gefährdungshaftung

1. Verschuldensdogma des BGB

2. Aktivitäten des Gesetzgebers

3. Reformbemühungen

VI. Produkthaftung

1. Produkthaftung zwischen Vertrag und Delikt

2. ProdHaftG

VII. Europäisierung des Deliktsrechts

C. Bereicherungsrecht

I. Streit der Gelehrten und Konstanz der Judikatur

II. Historische Grundlagen

III. Einheitslehre vs. Typenbildung

1. Erste Jahrhunderthälfte

2. Trennungslehre

3. Moderne Einheitslehren

IV. Streit um den Leistungsbegriff

1. Unmittelbarkeit der Vermögensverschiebung

2. Moderner Leistungsbegriff 
3. Kritik der Einheitstheoretiker

4. Kritik von Canaris

5. Leistungsbegriff bei Reuter/Martinek

6. Zum heutigen Stand der Lehre von der Leistungskondiktion

a) Zweipersonenbeziehungen

b) Mehrpersonenverhältnisse
aa) Dissonanzen
bb) Anweisungslagen
cc) Lösung bei von Caemmerer
dd) Konstruktion von Reuter/Martinek
ee) Einheitslehre
ff) Redogmatisierung

V. Umfang des Bereicherungsanspruchs und die Saldotheorie

1. Gegenstand des Bereicherungsanspruchs

2. Saldotheorie
a) Zweikondiktionen- vs. Saldolehre
b) Entwicklung der Saldotheorie in der Rechtsprechung des RG
c) Literatur in der ersten Hälfte des 20. Jahrhunderts
d) Nachkriegsliteratur
e) Zum heutigen Stand der Saldotheorie

VI. Europäisierung des Bereicherungsrechts

D. Geschäftsführung ohne Auftrag

I. Ein Rechtsinstitut ohne feste Grundlage

II. Dogmatische Alternativentwürfe

III. Wertungsjurisprudenz im Recht der GoA

IV. Das ,auch-fremde“ Geschäft

1. Selbst verpflichteter Geschäftsführer

2. Geschäftsführung ohne Auftrag durch Verwaltungsträger

V. Hilfe in Notlagen und Selbstaufopferung im Straßenverkehr

VI. Ausdehnung der $\S \S 683,670$ BGB auf Schadensersatz

VII. Europäisierung

\section{A. Einleitung}

Die Verfasser des BGB haben das Schuldrecht nicht in die zwei traditionellen Abteilungen Vertragsrecht und Deliktsrecht eingeteilt und diese dann um das Bereicherungsrecht zu einer Trias erweitert. Statt dessen wurde zwischen allgemeinem Schuldrecht und besonderem Schuldrecht differenziert, Teile des allgemeinen Vertragsrechts in das erste Buch, den Allgemeinen Teil, verwiesen und das Deliktssowie das Bereicherungsrecht an den Schluß des 8. Abschnitts des zweiten Buchs gestellt, der den ,Einzelnen Schuldverhältnissen“ gewidmet ist. Die Geschäftsführung ohne Auftrag wiederum ist zwar der Sache nach ein Annex des Bereicherungsrechts, doch wurde sie im Anschluß an das Auftragsrecht geregelt, weil in den $\S \S 677 \mathrm{ff}$. BGB relativ häufig auf die $\$ \S 661 \mathrm{ff}$. BGB verwiesen wird. So kommt es, daß 125 Paragraphen zwischen den Vorschriften über die negotiorum gestio und denjenigen über das Bereicherungsrecht liegen, die ihrerseits wiederum einzelnen Vertragstypen gewidmet sind, darunter Verwahrung, Gesellschaft, Gemeinschaft, Bürgschaft und Schuldversprechen. 
Die Regelungstechnik des BGB ist kurz in Erinnerung zu rufen, damit deutlich wird, daß es das Delikts- und das Bereicherungsrecht mit der Kodifikation nicht leicht hatten. ${ }^{1}$ Im Kontext der Systematik des BGB ist zwar nichts dagegen einzuwenden, wenn das Deliktsrecht auf dieselbe Stufe gestellt wird wie der Verwahrungsvertrag, doch die Sachprobleme und die dazugehörigen Lösungsstrukturen werden durch eine solche Regelungstechnik eher verdeckt als erhellt. Vielleicht auch deshalb hat sich im Laufe des 20. Jahrhunderts der Begriff der „Gesetzlichen Schuldverhältnisse“ als Klammer für die drei Rechtsgebiete etabliert. Deutlichstes Zeichen für diese Entwicklung im Programm des Beck-Verlages ist das in der JuSSchriftenreihe erschienene Werk von Medicus über „Gesetzliche Schuldverhältnisse" und das im Schwesterverlag publizierte, umfangreichere Lehrbuch von Schwarz/ Wandt. ${ }^{2}$ Nicht zuletzt ist es einem didaktischen Bedürfnis entsprungen, nachdem viele Fakultäten dazu übergegangen waren, das Schuldrecht nicht mehr in den Vorlesungen „Schuldrecht Allgemeiner Teil“ und „Schuldrecht Besonderer Teil“ zu behandeln, sondern Veranstaltungen über „Vertragsschuldverhältnisse“ und über „Gesetzliche Schuldverhältnisse“ anzubieten. Eine solche Organisation des akademischen Unterrichts hat den unschätzbaren Vorteil, das Vertragsrecht in einem Guß präsentieren zu können, doch darf darüber nicht übersehen werden, daß sich ein vergleichbarer Vorteil im Bereich der gesetzlichen Schuldverhältnisse nicht einstellt. Geschäftsführungs-, Bereicherungs- und Deliktsrecht haben miteinander nicht viel mehr gemein als den negativen Umstand, daß sie nicht auf Vertrag beruhen. Zwar existieren Beziehungen zwischen der Geschäftsführung ohne Auftrag und dem Bereicherungsrecht und Bezüge des Deliktsrechts zur Eingriffskondiktion einerseits und zur Geschäftsanmaßung gemäß $\S 687$ Abs. 2 BGB andererseits. Eine einheitliche normative und dogmatische Grundlage für die drei Abteilungen existiert jedoch nicht; die Leistungskondiktion, um ein Beispiel zu nennen, steht dem Vertragsrecht nahe und hat mit unerlaubten Handlungen überhaupt nichts zu tun, und das Deliktsrecht muß im Zusammenhang mit den Tatbeständen der Gefährdungshaftung gesehen werden, die sich immer noch ganz überwiegend außerhalb des BGB finden.

Außer dem erwähnten Werk von Medicus finden sich auch im Programm des Hauses Beck keine weiteren Titel, die die gesetzlichen Schuldverhältnisse zum Gegenstand haben. Statt dessen werden die einschlägigen Materien in einer Vielzahl von Darstellungen und Kommentierungen des BGB bzw. des Besonderen Schuldrechts mitbehandelt, wie sie jedem Juristen geläufig sind. Darüber hinaus hat der Verlag im Laufe des 20. Jahrhunderts eine Vielzahl von Spezialpublikationen insbesondere zum Delikts- bzw. Haftpflichtrecht - in geringerem Umfang auch zum Bereicherungsrecht - herausgebracht. Insofern entsprach die Verlagspolitik durchaus den gegebenen rechtlichen Strukturen und Zusammenhängen. Diesen zu folgen, muß deshalb auch für die folgende Darstellung das Gebot sein, die sich also das Delikts-, Bereicherungs- und Geschäftsführungsrecht jeweils gesondert vornimmt.

${ }^{1} \mathrm{Zu}$ der Regelungstechnik des BGB und dem sogenannten „Pandektensystem“ ausführlich Zimmermann, The Law of Obligations, 1990/1993, S. $29 \mathrm{ff}$.; zu den Schwierigkeiten, das Bereicherungsrecht einzuordnen a.a. O., S. $837 \mathrm{f}$.

2 Medicus, Gesetzliche Schuldverhältnisse, 1. Aufl. 1977; 5. Aufl. 2007; Schwarz/Wandt, Gesetzliche Schuldverhältnisse, 2. Aufl. 2006. 


\section{B. Deliktsrecht}

\section{Grundstrukturen des BGB-Deliktsrechts}

Das Deliktsrecht des BGB versucht bekanntlich einen Spagat zwischen der deliktischen Generalklausel nach dem Muster der Art. 1382, 1383 Code civil und der Enumeration einzelner Deliktstypen, die für das klassische römische Recht ebenso kennzeichnend war wie für das gemeine Recht, auch wenn in der Praxis die Haftung aufgrund der lex Aquilia im Vordergrund stand. ${ }^{3}$ Der Vorentwurf zum Obligationenrecht von Franz Philipp von Kübel wollte dem französischen Vorbild folgen und eine Generalklausel einführen, und diesem Ansatz folgte auch die Erste Kommission. ${ }^{4}$ Die $\S \S 704,705$ des Ersten Entwurfs sind den $\S \S 823,826$ BGB zwar durchaus ähnlich, doch die Ähnlichkeit täuscht, weil der Erste Entwurf eine Beschränkung der allgemeinen deliktischen Fahrlässigkeitshaftung auf die Verletzung absoluter subjektiver Rechte nicht kannte. Zwar enthielt auch der Erste Entwurf in seinem $\S 704$ Abs. 2 eine dem heutigen $\S 823$ Abs. 1 BGB entsprechende Regelung, doch diese hatte lediglich die Funktion, den Geschädigten durch Vorverlegung des Verschuldensbezugs auf die Rechtsgutsverletzung zu privilegieren. Entscheidend war, daß der dem späteren $\S 823$ Abs. 2 BGB entsprechende $\$ 704$ Abs. 1 des Ersten Entwurfs jedweden Verstoß gegen eine Rechtsnorm ausreichen ließ, also noch nicht auf Schutzgesetze beschränkt war, und zudem in der Parallelnorm zum heutigen $§ 826$ BGB das Vorsatzerfordernis fehlte. Gemäß $\S 705$ des Ersten Entwurfs war ,widerrechtlich auch die kraft der allgemeinen Freiheit an sich erlaubte Handlung, wenn sie einem anderen zum Schaden gereicht und ihre Vornahme gegen die guten Sitten verstößt".

Das Deliktsrecht des Ersten Entwurfs wurde von der Zweiten Kommission als viel zu weitreichend empfunden. Anders als in anderen Teilen des Ersten Entwurfs setzte die Zweite Kommission dessen Deliktsrecht kein ,soziales Öl“ zu, ${ }^{5}$ sondern zog das vorhandene heraus. Die Einführung einer Generalklausel nach französischem Vorbild wurde abgelehnt, eine Kanalisierung der Deliktsansprüche auf unmittelbar in eigenen Rechten verletzte Personen angestrebt und eine allgemeine culpa-Haftung für jedweden Vermögensschaden ausgeschlossen. ${ }^{6}$ „Die Schaffung einer allgemeinen actio culpae könne zu großem Mißbrauch und zu einer erheblichen Gefährdung des Verkehrslebens führen", heißt es in den Protokollen der Zweiten Kommission. ${ }^{7}$ Zur Erreichung dieser Regelungsziele hat die Zweite

3 Ausführlich: MünchKommBGB-Wagner, Bd. 5, 4. Aufl. 2004, Vor $§ 823$ Rn. 7 ff.; ders., in: Zimmermann (Hrsg.), Grundstrukturen des Europäischen Deliktsrechts, 2003, S. 189, $201 \mathrm{ff}$.

${ }^{4}$ Motive zu dem Entwurfe eines Bürgerlichen Gesetzbuches, Bd. II, 1896, S. 725.

5 Vgl. Gierke, Die soziale Aufgabe des Privatrechts, 1889, S. 13; zu dieser Metapher Wieacker, Privatrechtsgeschichte der Neuzeit, 2. Aufl. 1967, S. 470; Repgen, Die soziale Aufgabe des Privatrechts, 2001, S. 4.

${ }^{6}$ Protokolle der Kommission für die zweite Lesung des Entwurfs des Bürgerlichen Gesetzbuchs, Bd. II, 1898, S. $570 \mathrm{ff}$.

7 Prot. II (Fn. 6) S. 574. 
Kommission den Tatbestand der Rechtsgutsverletzung an der Spitze des Deliktsrechts plaziert ( $\$ 823$ Abs. 1 BGB) und auf eine haftungsbeschränkende Funktion umgestellt, indem sie den Tatbestand der Gesetzesverletzung um das Erfordernis eines Schutzgesetzes ergänzt ( $\$ 823$ Abs. 2 BGB) und $\S 826$ BGB auf vorsätzliche Schädigungen beschränkt hat.

Ohne Übertreibung läßt sich sagen, daß das Deliktsrecht des 20. Jahrhunderts den Großteil seiner Problemstellungen den Eingriffen der Zweiten Kommission verdankt. Die vergangenen 100 Jahre Rechtsentwicklung im Bereich des Rechts der unerlaubten Handlungen präsentieren sich als die Geschichte des Bemühens, die den $\S \S 823 \mathrm{ff}$. BGB eingezogenen Restriktionen wieder rückgängig zu machen, d.h. die drei „,kleinen“ Generalklauseln der $\S \S 823$ Abs. 1, Abs. 2, 826 BGB so fortzubilden, daß in der Summe eben doch eine ,große“ Generalklausel herauskommt. Daß dies angesichts der in der deutschen Justiztradition besonders betonten Gesetzesbindung des Richters nicht vollständig gelingen konnte, liegt auf der Hand. Gleichwohl sind im Laufe des 20. Jahrhunderts wichtige Brücken hin zu einer großen Generalklausel gebaut worden: Das Allgemeine Persönlichkeitsrecht (dazu unten B. III.), das Recht am eingerichteten und ausgeübten Gewerbebetrieb und die Moderierung des Vorsatzerfordernisses des $\$ 826$ BGB (dazu unten B. IV. 3, 6.f). Sämtliche Kommissionen, die an der Vorbereitung des BGB beteiligt waren, müssen sich zudem den Vorwurf gefallen lassen, das im Bereich des Haftungsrechts drängendste soziale Problem ihrer Zeit ignoriert zu haben, obwohl es offen zutage lag, nämlich die Gefährdungshaftung (unten B. V.). Zunächst ist allerdings auf ein Problem einzugehen, das im BGB nicht angelegt war, sondern von der Dogmatik erst herbeigeredet werden mußte, nämlich die Verkehrspflichten (unten B. II.).

Der Fairness halber sei vorausgeschickt, daß der eben skizzierte Rundgang durch die Deliktsrechtsentwicklung des vergangenen Jahrhunderts mit Ausnahme der Überlegungen zur Gefährdungshaftung mehr oder weniger denselben Weg abschreitet, den von Caemmerer in seinem Beitrag über ,,Wandlungen des Deliktsrechts" in der Festschrift zum hundertjährigen Bestehen des Deutschen Juristentags gegangen ist. ${ }^{8}$ Obwohl die Gutachten und Sitzungsberichte des Deutschen Juristentags im Verlag C. H. Beck erscheinen, gilt dies nicht für diese Festschrift; der Juristentag hatte sich insoweit an den Verlag C. F. Müller gewandt.

\section{Verkehrspflichten}

\section{Haftung für Unterlassen im $B G B$}

In $§ 704$ Abs. 1 des Ersten Entwurfs zum BGB wurde der Begriff der ,widerrechtlichen Handlung “ durch einen in Parenthese gesetzten Zusatz dahingehend erläutert, daß es sich bei der Handlung um ,Thun oder Unterlassen“ handeln könne. Diese Erläuterung wurde von der Zweiten Kommission gestrichen, die es allerdings für selbstverständlich hielt, daß man ,,bei seinem Thun und Lassen auf

8 von Caemmerer, FS 100 Jahre DJT, Bd. II, 1960, S. 49 bis 136. 
die rechtlich geschützten Interessen der Anderen [insoweit zu achten habe], als man bei Anwendung ordnungsgemäßer Sorgfalt erkennen müsse, daß dieselben dadurch gefährdet werden können“. ${ }^{9}$ Die Reichweite der Haftung für Unterlassen wird in den $\S \S 823 \mathrm{ff}$. BGB offen gelassen, wie überhaupt noch kein Gesetzgeber daran gegangen ist, die Unterlassungshaftung im Detail zu regeln. Selbst das moderne, dem Grundsatz nulla poena sine lege scripta verpflichtete Strafrecht begnügt sich in $\S 13$ StGB mit einer Generalklausel.

\section{Entwicklung der Verkehrspflichten durch die Rechtsprechung}

Vor diesem Hintergrund kann es nicht verwundern, daß die sogenannten Verkehrspflichten, wie sie in der ersten Hälfte des 20. Jahrhunderts in der Rechtsprechung des $R G$ entwickelt wurden, kaum jemanden aufgeregt haben. In seiner grundlegenden Entscheidung vom 30. Oktober 1902 hatte das RG einen Umkehrschluß aus $\$ 836$ BGB abgelehnt und folgerichtig auch dem Eigentümer bzw. Besitzer anderer Sachen als Gebäuden eine Verpflichtung zu Sicherheitsmaßnahmen im Interesse des Schutzes der Rechtsgüter Dritter auferlegt. ${ }^{10}$ Die immense Bedeutung, die dieser Entscheidung für die Praxis des Haftungsrechts zukam, zeigt ein Blick in das Handbuch zum Haftungsrecht von Geigel, das 1934 zum ersten Mal im Verlag C.H. Beck unter dem Titel „Der Haftpflichtprozeß - mit Einschluß des materiellen Haftpflichtrechts“ erschienen ist. Der Autor hält sich bei der Darstellung der „Anwendungsfälle des § 823 Abs. 1 BGB“ erst gar nicht mit der dogmatischen Struktur der Norm oder mit der Erläuterung der verschiedenen Fallgruppen der Rechtsgutsverletzung auf, sondern beginnt direkt mit der Erläuterung der „Verkehrspflicht“. ${ }^{11}$ An die Spitze seiner Ausführungen stellt der Autor einen Satz, den man in der späteren Literatur nicht immer in dieser Klarheit findet: ,Jeder ist dafür verantwortlich, daß die ihm gehörigen oder von ihm benützten beweglichen und unbeweglichen Sachen den ordnungsgemäßen menschlichen Verkehr nicht gefährden“. Der Autor fügt die Klarstellung an: „Man nennt das Verkehrspflicht", und setzt hinzu, bei unbeweglichen Sachen kleide man diesen Rechtssatz auch in die Worte, wer auf einem Grundstück einen Verkehr eröffne, müsse für die Verkehrssicherheit haften. ${ }^{12}$

\section{Literatur bis 1945}

Das Werk von Geigel ist ein Handbuch für den Haftpflichtpraktiker, das sich bis heute großer Beliebtheit erfreut. ${ }^{13}$ Die von dem heutigen Herausgeber Schlegelmilch selbst verfaßte Darstellung der Haftung gemäß $§ 823$ Abs. 1 BGB beginnt immer noch direkt mit den ,Verkehrspflichten“, doch an die Stelle der knappen Sätze von Geigel sind relativ umfangreiche Ausführungen über die Legitimität und Rechtsnatur der Verkehrspflichten sowie ihre Verankerung im Gefüge der beiden

\footnotetext{
9 Prot. II (Fn. 6) S. 569.

10 RGZ 52, 373, $375 \mathrm{ff}$.

11 Geigel, Der Haftpflichtprozeß, 3. Aufl. 1939, S. $74 \mathrm{ff}$.

12 Geigel (Fn. 11) S. $74 \mathrm{ff}$.

13 Vgl. zuletzt Geigel, Der Haftpflichtprozeß, hrsgg. von Günter Schlegelmilch, 24. Aufl. 2004.
} 
Absätze des $\S 823$ BGB getreten. ${ }^{14}$ Tatsächlich sind die Verkehrspflichten erst nach 1945 als Problem entdeckt worden. Zwar ist bereits im Jahre 1929 eine Polemik von Hofacker über ,Die Verkehrssicherungspflicht“ publiziert worden, doch der Autor ärgert sich eigentlich nur darüber, daß das $R G$ es sich ,angemaßt“ hat, nachlässiges Verhalten des Staates bei der Verwaltung öffentlicher Straßen als widerrechtliche Handlung im Sinne des $§ 823$ Abs. 1 BGB zu qualifizieren. ${ }^{15}$ Einen Startschuß für die moderne Diskussion setzte allerdings Josef Esser in seiner 1941 publizierten Schrift über „Grundlagen und Entwicklung der Gefährdungshaftung“, deren erste Auflage zum großen Teil beim Verlag C. H. Beck durch Kriegsereignisse zerstört worden und im Jahre 1969 in zweiter, unveränderter Auflage herausgebracht worden war. ${ }^{16}$ Ein Grundmotiv dieses ebenso polemischen wie mitreißenden Essays ist die These, die von der Rechtsprechung ,unter weitester Ausschaltung aller Entlastungsmöglichkeiten aufgestellten ,Verkehrssicherungspflichten' [seien nur] eine Form, die außerhalb der Haftpflichtgesetze bestehenden Betriebs- und Anstaltsgefahren auf dem Wege einer Unrechtsfeststellung dem Urheber und Nutznießer des Wagnisses zuzuteilen“. Die Verkehrspflichten begründeten demnach keine Haftung für Unrecht, sondern für Unglück, für ,einwandfreien ,casus fortuitus “". ${ }^{17}$ Aus der Sicht Essers sind diese zwar die praktisch wichtigste Abteilung des $§ 823$ Abs. 1 BGB, jedoch ,, aus wilder Wurzel entsprungen“ und ein ,illegitimes Kind“ des Deliktsrechts, weil sie der Sache nach eine Einbruchstelle der Haftung ohne Verschulden im Rahmen der zivilgesetzlichen Verschuldenstatbestände darstellten. ${ }^{18}$

\section{Entwicklung nach dem Zweiten Weltkrieg: Unmittelbare und mittelbare Verletzungen}

Der damit formulierten Illegalitätsthese, nach der die Verkehrspflichten vom RG „genau genommen contra legem“ entwickelt worden sind, wie von Bar in seiner viel beachteten Habilitationsschrift formuliert hat, ${ }^{19}$ ist Larenz in seinen - in der Beck'schen Reihe „Große Lehrbücher“ erschienenen - populären Schuldrechtslehrbüchern, die ganze Studentengenerationen beeinflußt haben, nicht gefolgt. ${ }^{20}$ Statt dessen suchte er die Verkehrspflichten in den Tatbestand des $§ 823$ Abs. 1 $\mathrm{BGB}$ zu integrieren, und zwar mit Hilfe der Unterscheidung zwischen vorsätzlichen und unmittelbar-fahrlässigen Eingriffen einerseits sowie bloß mittelbar den Verletzungserfolg herbeiführenden Fahrlässigkeitsdelikten andererseits. ${ }^{21}$ Mit dieser Zweiteilung der Deliktsrechtsdogmatik konnte zugleich der Angriff abgewehrt

\footnotetext{
14 Geigel-Schlegelmilch, (Fn. 13) Kap. 14 Rn. 1 ff.

${ }^{15}$ Hofacker, Die Verkehrssicherungspflicht, 1929, S. 14 und passim.

16 Esser, Grundlagen und Entwicklung der Gefährdungshaftung, 2. Aufl. 1969, S. V.

17 Esser (Fn. 16), S. 28; genauso ders., JZ 1953, 129.

18 Esser, JZ 1953, 129, 132; vgl. auch ders., Schuldrecht, 2. Aufl. 1960, S. $866 \mathrm{ff}$.

19 von Bar, Verkehrspflichten, 1980, S. 25.

${ }^{20}$ Dies gilt jedenfalls dann, wenn man von einem „Ausrutscher“ in der FS Dölle (Fn. 21) absieht; dazu unten B. IV. 5) sowie Fn. 110.

${ }^{21}$ Larenz, Lehrbuch des Schuldrechts, Bd. II, Besonderer Teil, 12. Aufl. 1981, S. 607 f.; ders., FS Dölle, Bd. I, 1963, S. $192 \mathrm{ff}$.
} 
werden, den Nipperdey in einem in der NJW publizierten Beitrag gegen das traditionelle Deliktsrecht geführt hatte. ${ }^{22}$ Ausgehend von der finalen Handlungslehre Welzels forderte Nipperdey auch vom Zivilrecht den Übergang zum Handlungsunrecht, also zu der Auffassung, daß Vorsatz und Fahrlässigkeit bereits den Unrechtstatbestand konstituieren und nicht erst das Verschulden. In Reaktion darauf entwickelte Larenz die Unterscheidung zwischen unmittelbaren und mittelbaren Eingriffen, die dem Handlungsunrecht mit den Verkehrspflichten den Löwenanteil des Deliktsrechts überließ, ohne den dogmatischen Ausgangspunkt beim Erfolgsunrecht aufzugeben. Mit diesem Kompromiß gewann er die herrschende Meinung nach 1945 für sich; insbesondere die - beide ebenfalls bei Beck erscheinenden - in der juristischen Ausbildung überaus beliebten Lehrbücher von Brox und von Medicus folgten Larenz und machten die Unterscheidung zwischen unmittelbaren und mittelbaren Eingriffen zum Allgemeingut junger Juristen. ${ }^{23}$

\section{Das Deliktsrecht bei Mertens: Legislative und judizielle Konzeption des $§ 823$ Abs. 1 BGB}

Ohne Übertreibung läßt sich feststellen, daß die Verkehrspflichten als Forschungsobjekt und Gegenstand intensiver wissenschaftlicher Diskussion ihren Zenit mit dem Erscheinen des ersten Großkommentars zum BGB aus dem Hause Beck erreichten. Die 1980 erstmals publizierte Kommentierung des Deliktsrechts im Münchener Kommentar zum BGB von Mertens war ein „Paukenschlag“, da hier der Versuch unternommen wurde, die dogmatische Tradition mit der deliktsrechtlichen Moderne zu versöhnen. ${ }^{24}$ Das Mittel zu diesem Zweck war die Unterscheidung zwischen einer legislativen und einer judiziellen Konzeption des $§ 823$ Abs. 1 BGB. ${ }^{25}$ Wie der Name bereits nahe legt, soll die legislative Konzeption des $\S 823$ Abs. 1 BGB das Konzept des historischen Gesetzgebers abbilden. Dieses beruhe auf der Prämisse, ,daß es keine tatbestandsmäßig rechtswidrige Handlung im Sinne des $§ 823$ Abs. 1 gibt, die nicht auch ohne diese Vorschrift rechtswidrig wäre". Tatbestandsmäßigkeit in diesem Sinne soll erfordern, daß die Handlung den Verletzungserfolg herbeiführt, ohne daß noch eine weitere Handlung vorgenommen werden muß. ${ }^{26}$ Ist dies der Fall, wird die Rechtswidrigkeit indiziert, und die Indikation kann nur durch einen Rechtfertigungsgrund ausgeräumt werden, wobei der vom Großen Senat für Zivilsachen entwickelte „Rechtfertigungsgrund verkehrsrichtigen Verhaltens “ nicht in Betracht kommt. ${ }^{27}$ Im Gegensatz dazu steht die judizielle Konzeption des $§ 823$ Abs. 1 BGB, also dasjenige, was die Gerichte aus dem Tatbestand gemacht haben. Nach dieser Konzeption reduziert sich der

\footnotetext{
22 Nipperdey, NJW 1957, 1777; eingehend zum Streit um Handlungs- und Erfolgsunrecht MünchKommBGB-Wagner (Fn. 3), § 823 Rn. $5 \mathrm{ff.}$

${ }_{23}$ Brox/Walker, Besonderes Schuldrecht, 30. Aufl. 2006, § 41 III Rn. 47 ff.; Medicus, Schuldrecht II, Besonderer Teil, 13. Aufl. 2006, Rn. $748 \mathrm{ff}$.

${ }^{24}$ MünchKommBGB-Mertens, Bd. 3, 2. Hbd. (\$§ 657-853), 1. Aufl. 1980.

25 MünchKommBGB-Mertens (Fn. 24), § 823 Rn. $13 \mathrm{ff}$.

26 MünchKommBGB-Mertens (Fn. 24), § 823 Rn. 13.

27 MünchKommBGB-Mertens (Fn. 24), § 823 Rn. 13; zu BGHZ 24, 21.
} 
Tatbestand auf die Verursachung einer Rechtsgutsverletzung, also auf die beiden Elemente Erfolgseintritt und Kausalität. ${ }^{28}$ Einem derart reduzierten Tatbestand fehlt dann gewissermaßen die normative Kraft zur Indikation der Rechtswidrigkeit; das Unrecht bedarf hier der positiven Begründung, und die dabei anfallende Begründungslast tragen wiederum die Verkehrspflichten. ${ }^{29}$ In der Sprache eines dogmatischen Grundlagenstreits ausgedrückt, bestimmt die legislative Konzeption die Rechtswidrigkeit bei $\S 823$ Abs. 1 BGB im Sinne der Erfolgsunrechtslehre, während die judizielle Konzeption der Lehre vom Handlungsunrecht folgt. ${ }^{30}$

Die von Mertens vorgeschlagene Spaltung der Dogmatik zu § 823 Abs. 1 BGB ist bei Canaris auf deutliche Ablehnung gestoßen. ${ }^{31}$ Es sei wenig überzeugend, dem Gesetzgeber zu unterstellen, er habe mittelbare Verletzungen gänzlich aus dem Normprogramm des $\S 823$ Abs. 1 BGB ausklammern wollen. Wenn jemand eine mit Gift gefüllte Bierflasche herumstehen oder eine Handgranate im Spielbereich von Kindern liegen lasse, könne vernünftigerweise nicht an einer Haftung auf der Grundlage der deliktsrechtlichen Zentralnorm gezweifelt werden. Wie eng oder weit der historische Gesetzgeber die Haftung für Unterlassen auch immer intendiert haben möchte, habe das $R G$ in der oben zitierten Entscheidung in ,,methodologisch völlig korrekter Weise“ eine autonome Bestimmung der Garantenpflichten vorgenommen. ${ }^{32}$ Canaris hält somit an der bereits bei Larenz angelegten Differenzierung zwischen unmittelbaren und mittelbaren Rechtsgutsverletzungen fest: Für unmittelbare Rechtsgutsverletzungen gilt die Erfolgsunrechtslehre, d.h. die Verursachung des Verletzungserfolgs indiziert ohne weiteres die Rechtswidrigkeit; die Sorgfaltspflichtverletzung spielt erst im Rahmen des Verschuldens eine Rolle. Unterlassungen und bloß mittelbar einen Verletzungserfolg herbeiführende Handlungen sind hingegen die Domäne der Lehre vom Handlungsunrecht; sie sind nur rechtswidrig, wenn der Schädiger gegen eine Sorgfaltspflicht - eben eine Verkehrspflicht - verstoßen hat. Die Verkehrspflicht soll allerdings mit der Sorgfaltspflicht, deren Verletzung in $§ 276$ Abs. 2 BGB als Fahrlässigkeit bezeichnet wird, nicht identisch sein, sondern über diese noch hinausgehen. Konsequenterweise müßte man dann die Sorgfaltswidrigkeit der Handlung im Rahmen des Verschuldens erneut prüfen und dabei einen reduzierten Standard anlegen.

\section{Auf dem Weg zu einem einheitlich strukturierten Delikt}

In der vierten Auflage des Münchener Kommentars zum BGB hat der Verfasser dieses Berichts die von Mertens vorgeschlagene Dogmatik zweier unterschiedlicher Konzeptionen des $\S 823$ Abs. 1 BGB ebenso aufgegeben wie die von Canaris in ein ausgefeiltes System gebrachte Differenzierung zwischen unmittelbaren und mittelbaren Verletzungshandlungen. ${ }^{33}$ Der Haupteinwand gegen das legislative Konzept im Sinne von Mertens besteht darin, daß dieses sich gerade nicht auf die

${ }_{28}$ MünchKommBGB-Mertens (Fn. 24), § 823 Rn. 15.

${ }^{29}$ MünchKommBGB-Mertens (Fn. 24), § 823 Rn. 16.

30 MünchKommBGB-Mertens (Fn. 24), § 823 Rn. $21 \mathrm{f}$.

31 Larenz/Canaris, Lehrbuch des Schuldrechts, Bd. II/2, 13. Aufl. 1994, S. $404 \mathrm{ff}$.

32 Larenz/Canaris (Fn. 31), S. 404.

33 MünchKommBGB-Wagner (Fn. 3), § 823 Rn. 51 ff. 
Gesetzesmaterialien stützt, sondern auf die in den siebziger Jahren des 20. Jahrhunderts erschienene Bonner Dissertation von Fraenkel. ${ }^{34}$ Die dort ausgebreitete Polemik gegen die ,herrschende Meinung“ zu $§ 823$ Abs. 1 BGB ist gegen Erfolgs- und Handlungsunrecht gleichermaßen gerichtet ${ }^{35}$ und wird weder in den Materialien zum BGB abgestützt noch in der gemeinrechtlichen Praxis, die den Gesetzesverfassern vor Augen stand und die zwischenzeitlich von Kleindiek in seiner Habilitationsschrift über „Deliktshaftung und juristische Person“ aufgearbeitet worden ist. ${ }^{36}$

In der Tat zeigt ein Blick in die Judikatur des 19. Jahrhunderts, daß dasjenige, was wir heute „Verkehrspflichten“ zu nennen gewohnt sind, bereits unter der gemeinrechtlichen Praxis voll entfaltet war. So wurde die Haftung nach der lex Aquilia bejaht, ${ }^{37}$ wenn bei Holzfällarbeiten Passanten durch herabstürzende Bäume geschädigt wurden, ${ }^{38}$ beim Abreißen einer Mauer Steine auf das Nachbargrundstück fielen und dort Schaden anrichteten, ${ }^{39}$ wenn hochexplosiver Sprengstoff einem Bauunternehmer überlassen wurde, der ihn seinerseits an einen unkundigen Dritten weitergab, ${ }^{40}$ oder ein Hauseigentümer es versäumt hatte, Flure und Treppenhäuser zu beleuchten. ${ }^{41}$ In den Materialien zum BGB findet sich keinerlei Anhalt dafür, daß die Verfasser diese Judikatur zurückschneiden oder ihr gar völlig die Grundlage entziehen wollten. Mit vollem Recht hatte das RG in seiner grundlegenden Entscheidung zur Verkehrssicherungspflicht darauf hingewiesen, daß die Haftung nach römischem Recht keineswegs so restriktiv war, wie nunmehr geltend gemacht wurde, und daß es , unmöglich der Sinn der neuesten Gesetzgebung“" sein könne, das deutsche Deliktsrecht noch hinter den im 19. Jahrhundert bereits erreichten Standard zurückfallen zu lassen. ${ }^{42}$ Wie Canaris treffend formuliert hat, sollte man ,,der Rechtsprechung daher nicht aufzureden versuchen, sie habe mit der Entwicklung der Verkehrspflichten das gesetzliche System des Deliktsrechts in mehr oder weniger revolutionärer Weise durchbrochen". ${ }^{43}$

Aber auch ganz unabhängig von der Legalität der Verkehrspflichten verdient die Unterscheidung zweier verschiedener Konzeptionen des $\S 823$ Abs. 1 BGB genauso den Abschied wie die Unterscheidung zwischen unmittelbaren und mittelbaren Eingriffen. Es ist einfach nicht zu erklären, aus welchem sachlichen Grund die Rechtswidrigkeit bei gestreckten Kausalverläufen - mittelbaren Eingriffen von einer Sorgfaltspflichtverletzung abhängen soll, bei unmittelbaren Eingriffen aber nicht. Mit der Unterscheidung von Tun und Lassen lassen sich derart weit-

34 Vgl. MünchKommBGB-Wagner (Fn. 3), § 823 Rn. 56.

35 Fraenkel, Tatbestand und Zurechnung bei $§ 823$ Abs. 1 BGB, 1979.

36 Kleindiek, Deliktshaftung und juristische Person, 1997, S. $41 \mathrm{ff}$.

37 Vgl. MünchKommBGB-Wagner (Fn. 3), § 823 Rn. 52.

38 Obertribunal Stuttgart, SeuffA 15, Nr. 129 (1862).

39 Oberappellationsgericht München, SeuffA 30 Nr. 144 (1868).

40 RG SeuffA 42 Nr. 299 (1887).

41 OLG Darmstadt, SeuffA 46 Nr. 96 (1890); OLG Celle, SeuffA 55 Nr. 399 (1899). Vgl. auch BGH NJW 1994, 945, 946; NJW-RR 1990, 409, 410; VersR 1961, 1119, 1120.

42 RGZ 52, 373, $378 \mathrm{f}$.

43 Canaris, FS Larenz II, 1983, S. 27, 79; Larenz/ders. (Fn. 31), § 76 III 2, S. 404 f.; MünchKommBGB-Wagner (Fn. 3), § 823 Rn. $51 \mathrm{ff.}$ 
reichende dogmatische Konsequenzen jedenfalls nicht erklären, denn die Funktion der Verkehrspflichten geht weit darüber hinaus, das Unterlassen zum Zwecke der Haftungsbegründung mit Handlungspflichten zu unterlegen: „Es geht auch darum, daß Handlungen, die einen Gefahrzustand herbeifuhren, verboten sind“. ${ }^{4}$ Einer Sonderdogmatik allein für unmittelbar drohende Eingriffe bedarf es ebenfalls nicht, auch nicht in dem von Larenz angeführten Beispiel einer gutgläubigen Krankenschwester, die dabei ist, einem Patienten ein tödlich wirkendes Gift zu verabreichen, ohne dies erkennen zu können. ${ }^{45}$ Das von Larenz mit vollem Recht angestrebte Ergebnis, daß der Patient oder auch ein Dritter berechtigt ist, der Krankenschwester die Spritze aus der Hand zu schlagen und sie dabei zu verletzen, ${ }^{46}$ ergibt sich ganz zwanglos aus $\$ 34$ StGB, der - anders als die Notwehr gerade keinen ,rechtswidrigen“ Angriff voraussetzt. ${ }^{47}$ Schließlich verträgt auch der Vorsatz keine Sonderbehandlung, denn mittelbar zu Rechtsgutsverletzungen führende Kausalverläufe, die sich innerhalb des erlaubten Risikos halten, begründen auch dann keine Haftung, wenn der Handelnde die Folgen vorhersieht: Wer Motorräder herstellt oder vertreibt, weiß ganz genau, daß es zu tödlichen Unfällen kommen wird, und trotzdem haftet er nicht, wenn sie sich realisieren. ${ }^{48}$

In der vierten Auflage des Münchener Kommentars zum BGB wird die judizielle Konzeption von Mertens bzw. die von Larenz für Unterlassungsdelikte und mittelbaren Eingriffe anerkannte handlungsunrechtliche Lehre für sämtliche Deliktstypen verallgemeinert. ${ }^{49}$ Das Ergebnis ist ein einheitlich strukturiertes Delikt mit einer Dogmatik, die nicht zwischen Vorsatztaten und unmittelbar-fahrlässigen Eingriffen sowie mittelbar-fahrlässigen Eingriffen und Unterlassungen zu differenzieren braucht und dadurch nicht zuletzt den Anschluß an die europäischen Nachbarrechtsordnungen findet. ${ }^{50}$ In einem solchen Modell können die Verkehrspflichten als das angesprochen werden, was sie seit jeher waren, nämlich als deliktische Sorgfaltspflichten, d.h. als ,,routinemäßig von der Rechtsprechung festgestellte Konkretisierungen der in $§ 276$ (Abs. 2) vorausgesetzten allgemeinen Sorgfaltspflicht".${ }^{51}$ Die Verkehrspflichten sind identisch mit der von $\S 823$ Abs. 1 BGB erforderten und in $\S 276$ Abs. 2 BGB definierten Fahrlässigkeit, und der Sorgfaltspflichtverstoß ist bei $\S 823$ Abs. 1 BGB nur ein einziges Mal zu prüfen - im Rahmen des Handlungsunrechts. Da es sich um eine ordinäre deliktische Sorgfaltspflicht handelt, hängt die Entstehung einer Verkehrspflicht auch nicht davon ab, daß eine „Gefahrenquelle“ geschaffen, kontrolliert oder zugänglich gemacht wird. ${ }^{52}$ Wie Geigel in seinem „Haftpflichtprozeß“ richtig gesehen hat, verpflichten sie vielmehr dazu, die eigene Sphäre, insbesondere die eigenen Sachen, von vorn-

\footnotetext{
44 von Caemmerer, FS DJT II (Fn. 8), S. 74.

45 Larenz (Fn. 21), S. 610.

46 Larenz (Fn. 21), S. 610.

${ }^{47}$ MünchKommBGB-Wagner (Fn. 3), § 823 Rn. 12.

48 MünchKommBGB-Wagner (Fn. 3), § 823 Rn. $21 \mathrm{f}$.

${ }^{49}$ MünchKommBGB-Wagner (Fn. 3), § 823 Rn. 4-24.

50 Dazu unten Fn. 215.

51 Esser/Weyers, Schuldrecht II/2, 8. Aufl. 2000, § 55 V, S. 178.

52 MünchKommBGB-Wagner (Fn. 3), § 823 Rn. 230.
} 
herein in einem Zustand $\mathrm{zu}$ erhalten, daß vermeidbare Gefahren gar nicht erst entstehen. ${ }^{53}$

\section{Persönlichkeitsverletzungen}

\section{Legislatorische Anerkennung des Rechts am eigenen Bild}

Im Rechtsgüterkatalog des $§ 823$ Abs. 1 BGB fehlt die „Ehre“, und auch sonstige Persönlichkeitsinteressen, die sich nicht auf die physische Integrität beziehen, sind nicht erwähnt. Der Gesetzgeber selbst hat diese Entscheidungen in Teilbereichen korrigiert, indem er 1909 das KunstUrhG erlassen hat, das in den bis heute fortgeltenden $\S \S 22 \mathrm{f}$. KunstUrhG das Recht am eigenen Bild als absolutes subjektives Recht anerkannt und damit den Weg zum Deliktsschutz im Rahmen von $§ 823$ Abs. 1 BGB geebnet hat. Die Grundsätze des Bildnisschutzes darf heute in keiner anspruchsvollen Darstellung des Persönlichkeitsschutzes fehlen; im Münchener Kommentar zum BGB werden die $§ \S 22$ ff. KunstUrhG nahezu ebenso eingehend kommentiert ${ }^{54}$ wie in den Beck'schen Kommentaren zum Urheberrecht, ${ }^{55}$ und der eilige Leser erhält im „Palandt“ einen verläßlichen Überblick über die aktuelle Rechtsprechung. ${ }^{56}$ In den Zeitschriften des Beck-Verlages lösen neue Entscheidungen oberster Gerichtshöfe nicht selten eine Flut von Publikationen aus, mit denen das Urteil eingeordnet, überprüft, kritisiert und in seinen Konsequenzen ausgelotet wird. Ein aktuelles Beispiel ist das Urteil des Europäischen Gerichtshofs für Menschenrechte im Fall Caroline von Hannover, mit dem die in Deutschland seit langem im Rahmen von $\S 23$ Abs. 1 Nr. 1 KunstUrhG geläufige Unterscheidung zwischen absoluten und relativen Personen der Zeitgeschichte verworfen wurde. ${ }^{57}$

\section{Vom Attentismus des RG zum Aktionismus des BGH}

Das RG ist immer wieder mit den Defiziten des BGB im Bereich des Persönlichkeitsschutzes konfrontiert worden und hat mitunter punktuelle Notlösungen gefunden, wenn es beispielsweise den Briefen von Friedrich Nietzsche Urheberrechtsschutz gewährte (RGZ 69, 401), denjenigen von Richard Wagner aber vorenthielt ( $R G Z 41,43)$, oder die Berichterstattung über eine fast 20 Jahre zurückliegende strafgerichtliche Verurteilung des Klägers als vorsätzlich-sittenwidrige Schädigung qualifizierte (RGZ 115, 416). Der Durchbruch hin zur Anerkennung eines Allgemeinen Persönlichkeitsrechts gelang jedoch erst nach dem Zweiten Weltkrieg, als der $B G H$ für naturrechtlich-wertfundierte Argumente besonders aufgeschlossen war und das GG mit seiner emphatischen Proklamation in Art. 1

53 Vgl. oben Fn. 11.

54 MünchKommBGB-Rixecker, Bd. 1, 5. Aufl. 2006, § 12 Anh. Rn. 30 ff.

$55 \mathrm{Vgl}$. die Kommentierung der $\$ \S 22 \mathrm{ff}$. KunstUrhG von Gerstenberg/Götting, in: Schricker, Urheberrecht, 2. Aufl. 1999, Anhang zu $§ 60 \mathrm{UrhG}$; weiter Dreier/Schulze, Urheberrechtsgesetz, 2004, S. $1541 \mathrm{ff}$.

56 Palandt-Sprau, 66. Aufl. 2007, § 823 Rn. 112a f.

57 EGMR NJW 2004, 2647, 2650 Nr. 72ff.; dazu Heldrich, NJW 2004, 2634; Mann, NJW 2004, 3220; Mayer-Ladewig/Petzold, NJW 2005, 15. 
Abs. 3 GG, die Grundrechte seien für alle Staatsgewalt ,unmittelbar geltendes Recht", einen zuvor nicht vorhandenen Ansatzpunkt für richterliche Rechtsfortbildung geliefert hatte. In der Leserbrief-Entscheidung wurde das Allgemeine Persönlichkeitsrecht als Gewährleistung der Art. 1 Abs. 1, 2 Abs. 1 GG und uno actu auch als deliktsrechtlich geschütztes Rechtsgut im Sinne des $§ 823$ Abs. 1 BGB anerkannt. ${ }^{58}$

Wie reagierte die Literatur auf die Rechtsfortbildung des BGH? Esser und Larenz zeigten sich in ihren Schuldrechts-Lehrbüchern gegenüber der Promotion des Allgemeinen Persönlichkeitsrechts zu einem Schutzgut des $§ 823$ Abs. 1 BGB sehr skeptisch. ${ }^{59}$ Eine notwendig auf Abwägung der konfligierenden Interessen angelegte Generalklausel passe nicht in den Reigen der gegenständlich faßbaren, leicht erkennbaren und wohl bestimmten Rechte des $\$ 823$ Abs. 1 BGB, deren Verletzung das Unrecht indiziere. Die Verfassung vermöge der Privatrechtsordnung bloß die Richtung, nicht aber den dogmatischen Weg vorzugeben, und der richtige Weg sei die vorsichtige Erweiterung des Rechtsgüterkatalogs des $§ 823$ Abs. 1 BGB um hinreichend konkrete ,,besondere“ Persönlichkeitsrechte wie die Ehre und das Recht auf Achtung der persönlichen Geheimsphäre. Diese Kritik gleicht in verblüffender Weise der gegenwärtig in England geführten Diskussion um die Anerkennung eines allgemeinen ,right of privacy“ in der Folge des Human Rights Act 1998:

„There seems to me a great difference between identifying privacy as a value which underlies the existence of a rule of law (and may point the direction in which the law should develop) and privacy as a principle of law in itself. The English common law is familiar with the notion of underlying values - principles only in the broadest sense which direct its development. [...] [Likewise], no one has suggested that freedom of speech is in itself a legal principle which is capable of sufficient definition to enable one to deduce specific rules to be applied in concrete cases. That is not the way the common law works“. .00

Solche Plädoyers zugunsten eines inkrementalen Ansatzes haben die Rechtsprechung bekanntlich nicht zu beeindrucken vermocht, und sie müssen heutzutage als obsolet gelten. Auch Canaris teilt diese Einschätzung, wenn er auch die methodischen Bedenken aufrechterhält. ${ }^{61}$ Tatsächlich dürfte der Unterschied zwischen dem Allgemeinen Persönlichkeitsrecht als konkretisierungsbedürftiges und abwägungsoffenes Rahmenrecht und als regulatorisches Rechtsprinzip nicht allzu groß sein. Speziell für das deutsche Recht ist insoweit zu bedenken, daß auch bei einer Zurückstufung des Persönlichkeitsschutzes zu einem Hintergrundprinzip über jeder letztinstanzlichen Entscheidung der Zivilgerichte das Damoklesschwert verfas-

\footnotetext{
58 Apodiktisch $B G H Z$ 13, 334, 338; deutlicher und ausfuihrlicher $B G H Z$ 24, 72, 76 f.

59 Esser, Schuldrecht (Fn. 18), S. 847; Larenz, Lehrbuch des Schuldrechts, Bd. II, Besonderer Teil, 2. Aufl. 1957, S. 336f.; ders., NJW 1955, 521; der BGH antwortet auf diese Kritik in BGHZ 24, 72, $77 \mathrm{ff}$.

${ }^{60}$ Lord Hoffmann, in: Wainwright v. Home Office [2004] 2 AC 406, 424 (HL(E) 2003). Gegen einen neuen ,,blockbuster tort" namens privacy auch Lord Mummery für die Vorinstanz: Wainwright v. Home Office [2002] 3 W. L. R. 405, 419 (C.A. 2001).

61 Larenz/Canaris (Fn. 31), S. 493.
} 
sungsgerichtlicher Kontrolle am Maßstab der Art. 1 Abs. 1, 2 Abs. 2 GG schweben würde - nicht umsonst wimmelt es in den Fußnoten der Darstellung des Persönlichkeitsschutzes im Münchener Kommentar nur so von Entscheidungen des BVerfG. ${ }^{62}$ Angesichts dieser institutionellen Rahmenbedingungen ist es besser, wenn die Zivilgerichte das Allgemeine Persönlichkeitsrecht unmittelbar anerkennen, um den verfassungsrechtlichen Schutzgeboten ohne dogmatische Verbiegungen Rechnung tragen zu können. Die Aufgabe der Rechtsdogmatik besteht demgegenüber darin, aus dem von der Rechtsprechung produzierten Fallmaterial spezielle Persönlichkeitsrechte herauszudestillieren, um diese mit wohl definierten Schutzbereichen und konkreten Prärogativen für die Abwägung von Gegeninteressen auszustatten. ${ }^{63}$

\section{Geldersatz für Persönlichkeitsverletzungen}

Bekanntlich ist der $B G H$ bei der Anerkennung des Allgemeinen Persönlichkeitsrechts als Schutzgut des $\S 823$ Abs. 1 BGB nicht stehen geblieben, sondern er ist noch einen Schritt weiter gegangen und hat dem Verletzten unter bestimmten Voraussetzungen einen Anspruch auf Geldersatz gewährt. Diese Rechtsfortbildung war noch wesentlich schwerer zu legitimieren, weil der frühere $\S 847$ BGB das Allgemeine Persönlichkeitsrecht - natürlich - nicht nannte und § 253 BGB a.F. ausdrücklich klarstellte, Geldersatz wegen eines Nichtvermögensschadens könne „,nur in den durch das Gesetz bestimmten Fällen gefordert werden“. Schließlich konnte angesichts der Materialien zum BGB nicht der leiseste Zweifel daran bestehen, daß der Gesetzgeber auch gemeint, was er gesagt hatte, denn man wollte ganz bewußt die „Mißstände“ der gemeinrechtlichen actio iniuriarum beseitigen ${ }^{64}$ und hielt es im übrigen für nicht ehrenvoll, sich Beleidigungen durch Geld abkaufen zu lassen. ${ }^{65}$ Auch und gerade aus rechtshistorischer Sicht war der Standpunkt des BGB durchaus radikal, und er hat sich auf Dauer nicht aufrecht erhalten lassen, wie Reinhard Zimmermann in seinem zunächst in dem südafrikanischen Verlag Juta, dann auch bei Beck und schließlich in Oxford als Taschenbuch publizierten großen Werk ,,The Law of Obligations“ bemerkte:

„These very rigorous provisions have, however, not stood the test of time. Thrown out by the front door, the actio iniuriarum has managed to sneak in through the back window in the guise and under the cover of the general right of personality" .66

Die Rückkehr durch das rückwärtige Fenster begann mit dem Herrenreiter-Urteil, in dem der I. Zivilsenat alle gesetzlichen und methodischen Hürden übersprang und dem Kläger, einem Kölner Lokalhonoratior, dessen Bildnis zur Werbung für ein Potenzmittel verwendet worden war, einen Anspruch auf Ausgleich des erlit-

62 Vgl. MünchKommBGB-Rixecker (Fn. 54), § 12 Anh.

${ }^{63}$ Larenz/Canaris (Fn. 31), S. 498 f.; MünchKommBGB-Wagner (Fn. 3), § 823 Rn. 172.

${ }_{64}^{64}$ Prot. II (Fn. 6), S. 641.

${ }^{65}$ Kommissionsbericht, Mugdan, Die gesammten Materialien zum Bürgerlichen Gesetzbuch für das Deutsche Reich, Bd. II, Berlin 1899, S. 1297.

66 Zimmermann, The Law of Obligations, Kapstadt et al. 1990, München 1993, Oxford 1996, S. 1092. 
tenen immateriellen Schadens in Geld gewährte. ${ }^{67}$ Das Gericht hielt dafür, der „Schutz der ,inneren Freiheit“ (sei) ohne das Recht auf Ersatz immaterieller Schäden weitgehend unwirksam", und versuchte, diese Prärogative dogmatisch beim Freiheitsbegriff des $\S 847$ BGB a.F. zu verankern. ${ }^{68}$ Obwohl der BGH natürlich sah, daß mit „Freiheit“ in den $\S \S 823$ Abs. 1, 847 BGB a.F. nur die Fortbewegungsfreiheit gemeint war, wurde die Verletzung des Allgemeinen Persönlichkeitsrechts als ,Freiheitsberaubung, im Geistigen“ “ apostrophiert und damit eine analoge Anwendung des $§ 847$ BGB a. F. gerechtfertigt. ${ }^{69}$

Diese Begründung war natürlich ,,alles andere als überzeugend“ und „,methodisch unstatthaft", wie Larenz bemerkte, ${ }^{70}$ und sie wurde vom $B G H$ auch nicht wiederholt. In der ersten Stellungnahme des VI. Zivilsenats in Sachen GinsengWurzel rekurrierte das Gericht nicht auf $\S 847$ BGB a.F., sondern direkt auf die Art. 1 Abs. 1, 2 Abs. 1 GG $;^{71}$ ein Ansatz der in der Folgezeit zu dem Satz ausgebaut wurde, der Geldersatz bei Persönlichkeitsverletzungen sei ,im eigentlichen Sinn nicht ein Schmerzensgeld nach $\$ 847$ BGB“, sondern ein Anspruch sui generis, der ,auf den Schutzauftrag aus Art. 1 und 2 Abs. 1 GG zurückgeh(e)“.72 Auch diese Begründung hat Larenz nicht überzeugt, der dem $B G H$ vorhielt, er argumentiere rechtspolitisch und betreibe ,,richterliche Gesetzeskorrektur“ ${ }^{73}$ Diese Kritik war verständlich, die Gesetzeskorrektur aber fällig und sowohl dank der durch das Grundgesetz veränderten rechtlichen Rahmenbedingungen als auch wegen der durch das Erstarken der Massenmedien gegebenen Gefährdung immaterieller Persönlichkeitsinteressen gerechtfertigt. ${ }^{74}$ Sie hat deshalb auch den Segen des BVerfG erhalten, das in seiner Soraya-Entscheidung ausgeführt hat:

„Das Recht ist nicht mit der Gesamtheit der geschriebenen Gesetze identisch. [...] Der Richter ist nach dem GG nicht darauf verwiesen, gesetzgeberische Weisungen in den Grenzen des möglichen Wortsinns auf den Einzelfall anzuwenden. [...] Richterliche Tätigkeit besteht nicht nur im Erkennen und Aussprechen von Entscheidungen des Gesetzgebers. Die Aufgabe der Rechtsprechung kann es insbesondere erfordern, Wertvorstellungen, die der verfassungsmäßigen Rechtsordnung immanent, aber in den Texten der geschriebenen Gesetze nicht oder nur unvollkommen zum Ausdruck gelangt sind, in einem Akt des bewertenden Erkennens, dem auch willenhafte Elemente nicht fehlen, ans Licht zu bringen und in Entscheidungen zu realisieren. Der Richter muß sich dabei von Willkür freihalten; seine Entscheidung muß auf rationaler Argumentation beruhen. Es muß einsichtig gemacht werden können, daß das geschriebene Gesetz seine Funktion, ein Rechtsproblem gerecht zu lösen, nicht erfüllt. Die richterliche Entscheidung schließt dann diese

67 BGHZ 26, 349, $354 \mathrm{ff}$.

68 BGHZ 26, 349, 356.

69 BGHZ 26, 349, 356.

${ }^{70}$ Larenz, Lehrbuch des Schuldrechts, Bd. II, 5. Aufl. 1962, S. 369; ders., Anmerkung zum Herrenreiter-Urteil, NJW 1958, 827, 829

71 BGHZ 35, 363, 367,

72 BGHZ 128, 1, 15 - Caroline von Monaco; kritisch dazu H. P. Westermann, Geldentschädigung bei Persönlichkeitsverletzung - Aufweichung der Dogmatik des Schadensrechts?, in: Koller/Hager et al. (Hrsg.): Einheit und Folgerichtigkeit im Juristischen Denken, Symposion zu Ehren von C.-W. Canaris, 1998, S. 125, 132: es werde „,beständig mit den als kleine Münze in den Verkehr gebrachten Grundrechten geklimpert".

73 Larenz (Fn. 70), S. 370.

74 So im Ergebnis auch Larenz/Canaris (Fn. 31), S. $494 \mathrm{f}$. 
Lücke nach den Maßstäben der praktischen Vernunft und den fundierten allgemeinen Gerechtigkeitsvorstellungen der Gemeinschaft" ${ }^{\text {"75 }}$

Die Abkoppelung des Geldersatzanspruchs bei Persönlichkeitsverletzungen vom bürgerlichen Recht und seine Verankerung im Himmel des Verfassungsrechts ${ }^{76} \mathrm{er}^{\mathrm{H}}$ klärt schließlich auch, warum es sich der Gesetzgeber leisten konnte, den $§ 847$ $\mathrm{BGB}$ a.F. zu streichen und seinen Regelungsinhalt nahezu unverändert in $\S 253$ Abs. 2 BGB n.F. zu überführen, ohne die Gelegenheit wahrzunehmen, dem Anspruch endlich zu einer positiv-rechtlichen Grundlage zu verhelfen. Ausweislich der Gesetzesmaterialien sollte dadurch an der etablierten Judikatur nicht ein Jota geändert werden. ${ }^{77}$ Der legislatorische Quietismus verdankt sich wohl ausschließlich der Furcht vor der Macht der Medien, an deren Widerstand Reformprojekte im Bereich des Persönlichkeitsschutzes leicht scheitern können. Hier zeigt sich ein Phänomen des modernen Verfassungsstaats, daß nämlich dem demokratischen Prozeß mitunter die Kraft fehlt, sachgerechte Regelungen gegen den Widerstand einzelner Interessengruppen durchzusetzen, und - wenn die Mißstände groß genug sind - die Gerichte in die Bresche springen. Dies mag nicht nur die Judikatur des $B G H$ zum Persönlichkeitsschutz erklären, sondern beispielsweise auch die Rechtsprechung des BVerfG im Steuer- und Sozialversicherungsrecht, deren Reichweite in diametralem Gegensatz zur Breite ihrer verfassungsrechtlichen Grundlage steht.

\section{Patrimoniales Persönlichkeitsrecht}

Der Geldersatzanspruch bei Persönlichkeitsverletzungen ist von Anfang an vor allem mit präventiven Erwägungen begründet worden: In der Ginseng-Entscheidung heißt es, der zivilrechtliche Persönlichkeitsschutz bleibe ,lückenhaft und unzureichend, wenn eine Verletzung des Persönlichkeitsrechts keine der ideellen Beeinträchtigung adäquate Sanktion auslösen würde“. Die Präventionsfunktion des Geldersatzanspruchs hat in einem der zu Caroline von Monaco ergangenen Urteile noch eine besondere Akzentuierung erfahren: Anders als beim konventionellen Schmerzensgeld stehe hier nicht der Schadensausgleich im Vordergrund, sondern die Prävention. Bei der Bemessung der zu zahlenden Entschädigung müsse deshalb berücksichtigt werden, daß von ihr ein ,echter Hemmungseffekt“ für die unautorisierte Vermarktung der Persönlichkeit der Klägerin ausgehen solle. ${ }^{78}$ In der Folge sind die Prominenten zugesprochenen Ersatzbeträge deutlich in die Höhe gegangen, etwa auf 180000 DM im Schlußurteil des OLG Hamburg in dem genannten Caroline-Fall. ${ }^{79}$

Mit der Heraufsetzung der Entschädigung für Persönlichkeitsverletzungen ist eine Diskrepanz zu den Fällen ,gewöhnlicher“ Körper- und Gesundheitsverlet-

75 BVerfGE 34, $269=$ NJW 1973, 1221, 1225.

76 Vgl. oben Fn. 72.

77 BT-Drs. 14/7752, S. 25; auch abgedruckt in Wagner, Das neue Schadensersatzrecht, 2002, S. $135 \mathrm{f}$.

78 BGHZ 128, 1, $15 \mathrm{f}$.

79 OLG Hamburg, NJW 1996, 2870. 
zungen entstanden, die dem $B G H$ eine Reihe kritischer Stellungnahmen und schließlich eine Verfassungsbeschwerde eingetragen hat. ${ }^{80}$ Das BVerfG ist dem Vorwurf, der $B G H$ privilegiere immaterielle Persönlichkeitsbelange gegenüber dem Interesse an physischer Integrität, nicht gefolgt. Zwischen Körper- und Gesundheitsschäden und Verletzungen des Allgemeinen Persönlichkeitsrechts durch Massenmedien bestünden ,sachlich begründete Unterschiede, die eine unterschiedliche Behandlung als verfassungsrechtlich gerechtfertigt erscheinen lassen". ${ }^{81}$ - Doch worin bestehen diese Unterschiede? Die Präventionsfunktion für sich allein genommen ist als Differenzierungskriterium ungeeignet, denn niemand wird behaupten wollen, bei schweren Körperverletzungen oder bei einem Martyrium mit mehrfachen grausamsten Vergewaltigungen könne man auf Prävention verzichten. ${ }^{82}$ Die entscheidende Besonderheit der Fälle nach dem Muster der Klagen der Caroline von Monaco bzw. Hannover bestehen vielmehr allein darin, daß das verletzte Persönlichkeitsgut einen Vermögenswert hat, der es ermöglicht, aus rechtswidrigen Eingriffen Gewinn $\mathrm{zu}$ schlagen. Wenn dem aber so ist, dann liegt es nahe, bei der Ausbeutung der Persönlichkeitsrechte Prominenter nicht mehr allein auf den Immaterialschadensersatz ( $\$ 253$ BGB) zu setzen, sondern die Lösung im Rahmen des Vermögensschadensersatzes (§§ 249, 251 BGB) zu suchen. ${ }^{83}$

Der Weg dorthin ist geebnet worden durch Entscheidungen des I. Zivilsenats zu einer weiteren berühmten Frau, nämlich Marlene Dietrich. In den zugrundeliegenden Fällen waren Name, Vita und Bildnis von Marlene Dietrich ohne Zustimmung ihrer Tochter und Alleinerbin u.a. für Merchandising- und Werbezwecke genutzt worden. Der $B G H$ erkannte erstmals ausdrücklich einen patrimonialen Schutzbereich des Allgemeinen Persönlichkeitsrechts an; letzteres diene zwar ,in erster Linie dem Schutz ideeller Interessen, insbesondere dem Schutz des Wertund Achtungsanspruchs der Persönlichkeit“, doch es schütze darüber hinaus ,,auch vermögenswerte Interessen der Person“". ${ }^{84}$ Soweit der vermögensrechtliche Schutzbereich des Allgemeinen Persönlichkeitsrechts verletzt ist, wird es gleich einem Immaterialgüterrecht behandelt, was der geschädigten Person bzw. ihren Angehörigen den Zugang zu dem Instrumentarium der dreifachen Schadensberechnung eröffnet. ${ }^{85}$ Wurde das patrimoniale Persönlichkeitsrecht unrechtmäßig angeeignet, kann folgerichtig nicht nur der konkret erlittene und bezifferte Vermögensschaden verlangt werden, sondern alternativ derjenige Betrag, der sich bei Lizensierung der Rechtenutzung auf dem Markt hätte erzielen lassen. Schließlich stehen dem Geschädigten Ansprüche auf Auskunft und Rechnungslegung über den erzielten Gewinn und sodann auf dessen Auskehrung zu. Anders als der Anspruch auf Aus-

80 Seitz, NJW 1996, 2848; Däubler, NJW 1999, 1639; Canaris, FS Deutsch, 1999, S. 85, 106.

81 BVerfG NJW 2000, 2187, unter 1 b.

82 Vgl. etwa den erschütternden Fall LG Frankfurt/Main, NJW 1998, 2294.

83 Ausführlich Wagner, ZEuP 2000, 200, $220 \mathrm{ff}$; ders., VersR 2000, 1305 ff.; de lege ferenda ders., in: Verhandlungen des 66. DJT, Bd. 1, 2006, S. A $83 \mathrm{ff}$.

${ }^{84}$ BGHZ 143, 214, 218f. = GRUR 2000, 709 mit zust. Anm. Wagner $=$ JZ 2000, 1056 mit abl. Anm. Schack.

${ }^{85}$ BGHZ 143, 214, 232 BGH NJW 2000, 2201, 2202; ähnlich bereits, aber beschränkt auf das Recht am eigenen Bild BGHZ 20, 345, 353 ff. - Paul Dahlke. 
gleich immaterieller Beeinträchtigungen setzt der Anspruch auf Vermögensschadensersatz einen schwerwiegenden, nicht anders auszugleichenden Eingriff in das Persönlichkeitsrecht nicht voraus. ${ }^{86}$

Die Konsequenzen der Marlene-Dietrich-Entscheidungen für den Schadensausgleich bei Persönlichkeitsverletzungen sind noch nicht in vollem Umfang gezogen worden. Bedenkt man, daß auch die dreifache Schadensberechnung bei Verletzungen von Immaterialgüterrechten $\mathrm{zu}$ dem Zweck erfunden wurde, eine wirksame Prävention bei der rechtswidrigen Aneignung fremder Rechtspositionen zu gewährleisten, wird das hier schlummernde Potential auch für Fallgestaltungen nach dem Muster der Herrenreiter- und Caroline von Monaco-Fälle deutlich. Der VI. Zivilsenat des $B G H$ könnte der Kritik an seiner Rechtsprechung den Wind aus den Segeln nehmen, wenn er den „Hemmungseffekt“ bei vorsätzlicher Aneignung der Persönlichkeitsrechte von Prominenten nicht im Rahmen des Immaterialschadensersatzes $\mathrm{zu}$ gewährleisten suchte, sondern durch Anerkennung eines Eingriffs in das patrimoniale Persönlichkeitsrecht, der mit einer Ehrverletzung allerdings durchaus zusammenfallen kann. ${ }^{87}$

\section{Reine Vermögensschäden}

\section{Gesetzliche Ausgangslage}

Neben den Verletzungen nicht-physischer Persönlichkeitsinteressen bleiben auch reine Vermögensinteressen aus dem Schutzbereich der allgemeinen deliktischen Fahrlässigkeitshaftung gemäß $\S 823$ Abs. 2 BGB ausgeklammert. Wiederum sind es $\S 823$ Abs. 2 BGB iVm Schutzgesetzen nach Art der $\S \S 263$ ff., 266 ff. StGB sowie - in letzter Linie - $\$ 826$ BGB, die den deliktischen Schutz von Vermögensinteressen gewährleisten. Die einzige Ergänzung, die der historische Gesetzgeber für erforderlich hielt, betraf den Schutz der sogenannten Geschäftsehre vor falschen Tatsachenbehauptungen, für die $\$ 824$ BGB eine Fahrlässigkeitshaftung statuiert. Damit wollte der Gesetzgeber dem Umstand Rechnung tragen, daß Verletzungen der persönlichen Ehre durch falsche Tatsachenbehauptungen in $\S 186$ StGB bereits dann sanktioniert werden, wenn die Tatsache nicht erweislich wahr ist, während es bei Verletzungen der Geschäftsehre gemäß $§ 187$ StGB darauf ankommt, daß der Täter um die Unrichtigkeit der von ihm behaupteten Tatsache gewußt hat. Nach dem Willen der Zweiten Kommission sollte $§ 824$ BGB „für die privatrechtlichen Folgen den $§ 186$ des StGB gewissermaßen aus $§ 187$ ergänze(n)“" ${ }^{88}$

\section{Korrektur durch das UWG}

Aus verschiedenen, hier nicht näher darzustellenden Gründen kann es in der Tat nicht in Betracht kommen, Rechtsgutsverletzungen und reine Vermögensschäden einander gleichzustellen und das Vermögen umfassend vor pflichtwidrigen Eingrif-

\footnotetext{
86 BGHZ 143, 214, 228.

87 Ausführlich dazu Wagner, ZEuP 2000, 200, 223 f.; ders., VersR 2000, 1305, 1309 f.

88 Prot. II (Fn. 6), S. 638.
} 
fen zu schützen. ${ }^{89}$ Der beschränkte Schutz von Vermögensinteressen liegt einer marktwirtschaftlich verfaßten Wirtschaftsordnung geradezu als Prämisse zugrunde, denn der Wettbewerb basiert gerade darauf, daß ein jeder seine eigenen (Vermögens-) Interessen zu wahren und zu mehren sucht und dabei weiß oder doch wissen kann, daß dies nur auf Kosten der Vermögensinteressen anderer möglich ist. Gerade dieses Beispiel ist jedoch auch Beleg dafür, daß die Zweite Kommission zu weit gegangen ist, als sie den heutigen $§ 826$ BGB um ein Vorsatzerfordernis anreicherte. Bereits neun Jahre nach Inkrafttreten des BGB korrigierte der Gesetzgeber sich selbst bzw. die Zweite Kommission, indem er mit $\S 1$ UWG für den praktisch wichtigsten Bereich des Vermögensschutzes - das Wettbewerbsrecht den $§ 705$ des Ersten Entwurfs wiederherstellte und eine Fahrlässigkeitshaftung für die Verletzung reiner Vermögensinteressen im wirtschaftlichen Wettbewerb aufstellte, die freilich über den in der Tat unverzichtbaren Filter der Sittenwidrigkeit verfügte..$^{90}$ Seit der Reform des Jahres 2004 findet sich die wettbewerbsrechtliche Generalklausel in $§ 3$ UWG, nach dem allerdings nun nicht mehr ,sittenwidrige“, sondern „unlautere“ Wettbewerbshandlungen sanktioniert werden. Wie man bei Köhler in dem Beck'schen Standardkommentar zum Wettbewerbsrecht nachlesen kann, hat man die Terminologie umgestellt, um den heute antiquiert wirkenden und falsche Assoziationen weckenden Begriff der Sittenwidrigkeit durch eine moderne Formulierung zu ersetzen und damit die Kompatibilität mit dem Europarecht $\mathrm{zu}$ verbessern. ${ }^{91}$

\section{Recht am eingerichteten und ausgeübten Gewerbebetrieb}

Anders als beim Persönlichkeitsschutz suchte und fand bereits das $R G$ den Weg zu einer Fahrlässigkeitshaftung für reine Vermögensschäden, indem es ein „Recht am eingerichteten und ausgeübten Gewerbebetrieb“ proklamierte. Während der Palandt diese Rechtsprechung brav referierte und damit seine Leser in dem Glauben wog, es handele sich hier tatsächlich um ein „,sonstiges Recht“ im Sinne des $\S 823$ Abs. 1 BGB, ${ }^{92}$ übte Larenz Kritik an der Unbestimmtheit und generalklauselartigen Weite des Instituts, ${ }^{93}$ und Esser formulierte, das Recht am eingerichteten und ausgeübten Gewerbebetrieb führe im Ergebnis ,,zur Aufgabe der Lehre von der Unrechtsindikation des Tatbestandes“. ${ }^{94}$ Diese Kritik wurde bei von Caemmerer bestätigt und auf den Punkt gebracht: „Ein echtes absolutes Recht ist das sogenannte Recht am eingerichteten und ausgeübten Gewerbebetrieb damit freilich nicht geworden. [...] Man hat das ,Recht' am Gewerbebetrieb kreiert, um den vermißten Schutz gegen fahrlässige Schädigungen jeder Art nach $§ 823$ Abs. 1

\footnotetext{
${ }^{89}$ Ausführlich dazu MünchKommBGB-Wagner (Fn. 3), § 826 Rn. 11 ff.; ders., in: Zimmermann (Fn. 3), S. $230 \mathrm{ff}$.

90 Zur Geschichte des Wettbewerbsrechts Beater, Unlauterer Wettbewerb, 2002, § 3 insbes. Rn. $77 \mathrm{f}$.

${ }_{91}$ Hefermehl/Köhler/Bornkamm, Wettbewerbsrecht, 25. Aufl. 2007, § 3 Rn. 3; vgl. auch Schünemann, in: Harte-Bavendamm/Henning-Bodewig (Hrsg.), UWG, 1. Aufl. 2004, § 3 Rn. $52 \mathrm{f}$.

92 Palandt-Pinzger, 2. Aufl. 1939, § 823 Anm. 6 g.

93 Larenz (Fn. 59), S. $338 \mathrm{ff}$.

${ }^{94}$ Esser, Schuldrecht (Fn. 18), S. 849.
} 
BGB gewähren zu können. Es fehlen diesem Recht aber alle Merkmale sonstiger Herrschaftsrechte“. ${ }^{95}$ Trotz dieser vernichtenden Worte ging von Caemmerer nicht so weit, das Recht am eingerichteten und ausgeübten Gewerbebetrieb in Bausch und Bogen zu verwerfen; vielmehr scheint er die Ergänzung des deutschen Deliktsrechts um eine solche „Generalklausel“ für nötig oder zumindest vertretbar gehalten zu haben. ${ }^{96}$

Die Literatur hat sich diesem Standpunkt angeschlossen, das Recht am eingerichteten und ausgeübten Gewerbebetrieb also als beschränkte Generalklausel entlarvt, ohne es deswegen aus dem Kanon der ,sonstigen Rechte“ in $\S 823$ Abs. 1 BGB zu verabschieden. So läßt sich etwa der Standpunkt von Medicus beschreiben, wobei offen bleiben mag, ob er auf Überzeugung beruht oder sich lediglich den Zwängen verdankt, denen ein Lehrbuchautor unterliegt. ${ }^{97}$ Kreative Unruhe in diesen Winkel des Deliktsrechts hat erst Canaris gebracht, der die Analyse von Caemmerers teilt, aber andere Konsequenzen aus ihr zieht, nämlich die Forderung erhebt, das Recht am eingerichteten und ausgeübten Gewerbebetrieb auf den „Müllhaufen der Rechtsgeschichte“ zu werfen. ${ }^{98}$ In der Tat schien sich das Blatt im Jahre 2004 in die von Canaris vorgezeichnete Richtung zu wenden, als nämlich der I. Zivilsenat des BGH den Großen Zivilsenat anrief, um sich das Plazet für eine Umwidmung der unberechtigten Schutzrechtsverwarnung von einem Fall des $\S 823$ Abs. 1 BGB in einen solchen des $\$ 3$ UWG geben zu lassen. Hätte der Große Zivilsenat diesem Verlangen nachgegeben, wäre eine der beiden Säulen weggebrochen, auf der das Recht am eingerichteten und ausgeübten Gewerbebetrieb seit der Entscheidung des RG in Sachen Juteplüsch aus dem Jahr 1904 ruht. ${ }^{99}$ Der Große Zivilsenat hat die Frage des I. Zivilsenats jedoch in vollem Umfang verneint, statt dessen die Sonderstellung der unberechtigten Schutzrechtsverwarnung bestätigt und das Recht am eingerichteten und ausgeübten Gewerbebetrieb auf diese Weise erneut anerkannt ${ }^{100}$. Auf absehbare Zeit dürfte es also beim status quo bleiben, nämlich bei einer Enklave der Fahrlässigkeitshaftung für reine Vermögensschäden im Rahmen der rechtsgutsbezogenen und eben deshalb „kleinen“ Generalklausel des $§ 823$ Abs. 1 BGB.

\section{Inflation der Vertragshaftung}

Auch abgesehen vom Recht am eingerichteten und ausgeübten Gewerbebetrieb hat die Rechtsprechung weitere Breschen der Fahrlässigkeitshaftung in § 826 BGB geschlagen, indem sie die Vertragshaftung auf Fallgruppen ausgedehnt hat, in denen auf den ersten Blick kein Vertrag zu sehen ist und in denen unsere Nachbarrechtsordnungen auch keinen Vertrag erkennen würden. Ein schönes Beispiel da-

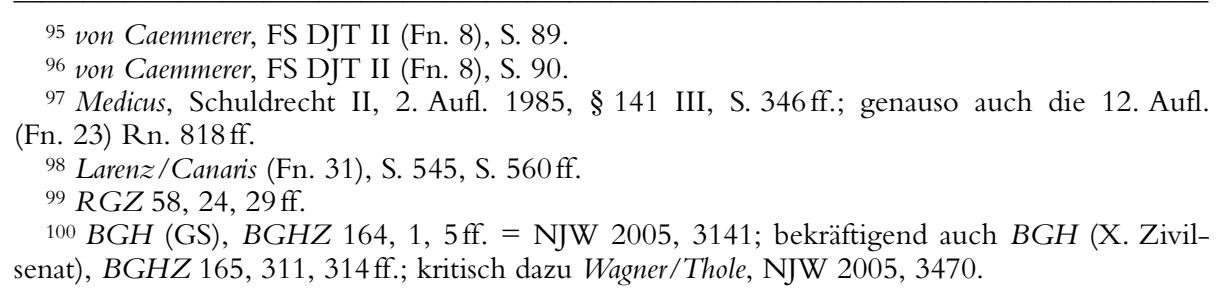


für liefern die Fälle, in denen ein Rechtsanwalt es versäumt, rechtzeitig vor dem Tod seines Mandanten ein Testament aufzusetzen oder ein Testament entwirft, das rechtlicher Prüfung nicht oder nicht mit dem vom Erblasser intendierten Ergebnis standhält. Das Problem der enttäuschten Putativerben besteht darin, daß sie sich auf den Anwaltsvertrag nicht berufen können, weil sie nicht dessen Partei geworden sind, und ihnen $§ 826$ BGB nichts nützt, weil es am Vorsatz fehlt. ${ }^{101}$ Soll diese Rechtslage wirklich dazu führen, daß den um ihr Erbe gebrachten Destinatären keinerlei Anspruch gegen den Anwalt zusteht, mit der Folge, daß dessen Pflichtverletzung sanktionslos bleibt und er sich allenfalls um die Beeinträchtigung seines guten Rufs sorgen muß? Der BGH hat die Frage verneint, die Putativerben in den Schutzbereich des Anwaltsvertrags einbezogen und sich so in den Hafen der Vertragshaftung gerettet, die zwischen Rechtsgutsverletzungen und reinen Vermögensschäden keinen Unterschied macht. ${ }^{102}$ Die englischen Gerichte kamen nach voller Würdigung der „German experience“ zum selben Ergebnis, aber auf dem Weg des Deliktsrechts, indem sie den Tatbestand der negligence auf der Grundlage des Prinzips in Hedley Byrne auf reine Vermögensschäden erstreckten. ${ }^{103}$

Enttäuschte Erben sind nicht die einzigen Personen, die von der Bereitschaft der Gerichte profitieren, die Vertragshaftung auszudehnen, um das Terrain des $\S 826$ BGB zu verkleinern und einen angemessenen Vermögensschutz zu gewährleisten. Ein anderes Beispiel ist die Auskunftserteilung einer Bank über die Bonität eines Kunden; obwohl es in $\S 675$ Abs. 2 BGB ( $\$ 676$ BGB aF) klipp und klar heißt, wer einem anderen einen Rat oder eine Empfehlung gebe, sei zum Schadensersatz nicht verpflichtet, bejaht der $B G H$ in ständiger Rechtsprechung einen konkludent geschlossenen Auskunftsvertrag und verpflichtet die Bank eben doch zum Schadensersatz. ${ }^{104}$ Würde das Gericht genauso verfahren, wenn es das Vorsatzerfordernis in $\$ 826$ BGB nicht gäbe? Dieselbe Frage stellt sich mit Blick auf die Haftung von Grundstückssachverständigen, Wertgutachtern und Wirtschaftsprüfern, die den Verkehrswert eines Grundstücks, eines Unternehmens oder auch eines Kunstwerks zu hoch ansetzen bzw. Daten liefern, die eine Überbewertung zur Folge haben, und damit eben nicht ihren Auftraggebern, sondern dem Erwerber des Grundstücks, Kunstwerks oder Unternehmens einen Vermögensschaden zufügen. ${ }^{105}$ Auch hier operiert der BGH mit dem Vertrag mit Schutzwirkung zugunsten Dritter, doch die Nähe dieser Konstruktion zum Deliktsrecht springt ge-

101 Bei notariellen Testamenten, die sich als nichtig erweisen oder nicht rechtzeitig aufgesetzt werden, ist die Sachlage identisch, doch die Rechtslage verschieden: Gemäß $\S 19$ BNotO trifft den Notar eine $\$ 839$ BGB nachgebildete Haftung für Amtspflichtverletzungen, deren persönlicher Schutzbereich nicht auf die „Beteiligten“ des Amtsgeschäfts beschränkt ist, sondern uU auch Dritte erfaßt, wie etwa den intendierten Erben; vgl. BGHZ 27, 274, 275; Hirte, Berufshaftung, 1996, S. 84.

102 BGH NJW 1965, 1955, 1956f.; 1995, 51, 52; 1995, 2551, 2552; 1997, 2327, 2328; MünchKommBGB-Gottwald, Bd. 2, 4. Aufl. 2001, § 328 Rn. 134; ablehnend Kegel, FS Flume, Bd. I, 1978, 545.

103 White v. Jones [1995] 2 A. C. 207, 262ff. (H.L.(E.) 1995); Ross v. Caunters [1980] Ch. 297, $302 \mathrm{ff}$. (1979); wohl zustimmend Zimmermann, ZEuP 1996, 672, $676 \mathrm{ff}$.

104 MünchKommBGB-Wagner (Fn. 3), § 826 Rn. 55 m.w. N.

$105 \mathrm{Zu}$ dieser Fallgruppe MünchKommBGB-Wagner (Fn. 3), § 826 Rn. 58 ff. m. w. N. 
radezu ins Auge, wenn das Gericht dem beklagten Experten die Berufung auf eine von seinem Vertragspartner, dem Veräußerer, begangene Täuschung versagt. Im Kontext des selbst gewählten Ansatzes müßte der BGH eine solche Einwendung akzeptieren, doch das Gericht hält $§ 334$ BGB für „,konkludent abbedungen“. ${ }^{106}$

\section{Die große Lösung: Verkehrspflichten zum Schutz fremden Vermögens}

Die komplizierte Gemengelage aus einem inflationierten Vertragsrecht, fragmentarischem Vermögensschutz über Schutzgesetze gemäß $\S 823$ Abs. 2 BGB und einer Enklave des Vermögensschutzes innerhalb von $\S 823$ Abs. 1 BGB unter dem Deckmantel des Rechts am eingerichteten und ausgeübten Gewerbebetrieb ließe sich gewissermaßen auf einen Schlag bereinigen, wenn man mit Mertens dazu bereit wäre, Verkehrspflichten zum Schutz fremden Vermögens anzuerkennen. ${ }^{107}$ Maßgebend für diesen weitreichenden Vorschlag war die - zutreffende - Einsicht, daß sich $\S 826$ BGB als zu eng erwiesen und die Rechtsprechung deshalb allerlei Wege gesucht und gefunden hat, um eine Fahrlässigkeitshaftung für reine Vermögensschäden begründen zu können. ${ }^{108}$ Die Anerkennung von Verkehrspflichten zum Schutz fremden Vermögens würde sämtliche Schleichwege um § 826 BGB herum überflüssig machen und dem deliktischen Vermögensschutz im Rahmen des $§ 823$ Abs. 1 einen sicheren Platz verschaffen.

Das bloße Bedürfnis nach einem erweiterten Vermögensschutz schafft indessen noch keine Anspruchsgrundlage. Als solche käme allenfalls $\S 823$ Abs. 2 BGB in Betracht, dessen Funktion ja gerade darin besteht, den Rechtsgüterschutz nach $\S 823$ Abs. 1 BGB um einen selektiv gewährten Vermögensschutz zu ergänzen. ${ }^{109}$ In der Tat hat Larenz in seinem Beitrag für die Festschrift Dölle mit der Idee geliebäugelt, die Verkehrspflichten bei $\S 823$ Abs. 2 BGB anzusiedeln, also richterliche und gesetzliche Verhaltensgebote einander gleichzustellen, ${ }^{110}$ ohne diesen Ansatz in sein Lehrbuch zu übernehmen. ${ }^{111}$ Von Bar hat die These jedoch in seiner Habilitationsschrift ausgearbeitet und die Verkehrspflichten als richterrechtliche Schutzgesetze in den Tatbestand des $\S 823$ Abs. 2 BGB überführt. ${ }^{12}$ Damit wechseln sie nicht nur die Anspruchsgrundlage, sondern streifen auch die Beschränkung auf den Schutz der Rechtsgüter des $§ 823$ Abs. 1 BGB ab, so daß Verkehrspflichten zum Schutz fremden Vermögens möglich werden. ${ }^{113}$

Nun sollte es auf der Hand liegen, daß das Hin- und Herschieben der Verkehrspflichten zwischen den beiden Absätzen des $§ 823$ BGB nicht über den Um-

106 BGHZ 127, 381, 385 ff.; zur Kritik Canaris, ZHR 163 (1999), 206, 220 ff.; ders., JZ 1995, 441; ders., JZ 1998, 603; Hopt, AcP 183 (1983), 608, 658 ff., 710 ff.; Picker, FS Medicus, 1999, S. 397, 400 ff.; Schäfer, AcP 202 (2002), 808, 827 f.

107 MünchKommBGB-Mertens (Fn. 24), § 823 Rn. $469 \mathrm{ff}$.

108 MünchKommBGB-Mertens (Fn. 24), § 823 Rn. $471 \mathrm{ff}$.

109 Canaris, FS Larenz II (Fn. 43), S. 27, 47 ff.; Larenz/Canaris (Fn. 31), S. 431 f.; MünchKommBGB-Wagner (Fn. 3), § 823 Rn. 319.

110 Larenz, FS Dölle (Fn. 21), S. 169, $189 \mathrm{ff}$.

111 Larenz (Fn. 21), S. 611 ff.; vgl. auch Larenz/Canaris (Fn. 31), S. 405 mit Fn. 119, sowie oben, Fn. 20 f.

112 von Bar, Verkehrspflichten, 1980, S. $145 \mathrm{ff}$.

113 So von Bar (Fn. 112), S. 204 ff.; genauso K. Huber, FS von Caemmerer (1978), S. 359, $377 \mathrm{ff}$. 
fang des deliktischen Vermögensschutzes entscheiden kann. Diese zentrale Problematik muß normativ überzeugend beantwortet werden und nicht durch dogmatisch-systematische Arbeit am Begriff (Schutz-"Gesetz") und an der Systematik. Dementsprechend hat Mertens auch gar nicht ernsthaft versucht, §823 Abs. 2 BGB als Grundlage für vermögensbezogene Verkehrspflichten auszuschlachten, sondern seine Konzeption ganz offen auf einen ,ungeschriebenen $§ 823$ Abs. 3“ gestützt. ${ }^{114}$ Auch dieses Zugeständnis im Interesse der Methodenehrlichkeit vermag den zentralen Einwand gegen Verkehrspflichten zum Schutz fremden Vermögens allerdings nicht auszuräumen: Es war von Anfang an ein Mißverständnis, wenn von Caemmerer seine zutreffende Analyse der richterlich entwickelten Verkehrspflichten mit der Bemerkung abgeschlossen hat, wir hätten ,damit auch im deutschen Recht eine Generalklausel, daß jeder die vernünftigerweise zu erwartende Sorgfalt anzuwenden hat, um Schädigungen anderer zu vermeiden “. ${ }^{115}$ Die Rede von der Generalklausel suggeriert nämlich, als hätte die Rechtsprechung mit den Verkehrspflichten den Rechtsgutsbezug des $§ 823$ Abs. 1 BGB aufgegeben oder auch nur aufgeweicht - und genau dies ist nicht der Fall. Die Gerichte haben durchweg an dem Grundsatz festgehalten, daß das Vermögen kein Schutzgut des $\S 823$ Abs. 1 BGB ist, und sie haben in keinem einzigen Fall eine Verkehrspflicht zum Schutz fremden Vermögens aufgestellt. ${ }^{116}$ Die Verkehrspflichten haben die Funktion, den Schutz der Rechtsgüter in Gefahrenlagen zu gewährleisten, indem sie denjenigen mit Sorgfaltspflichten belasten, der die Möglichkeit zur Gefahrsteuerung hat und Verantwortung für die Gefahrenquelle trägt. Mit der Ausweitung bzw. Sprengung des Katalogs enumerierter Rechtsgüter in $\S 823$ Abs. 1 BGB haben sie nichts zu tun.

Es ist auch nicht zu erkennen, wie man das Vermögen in den Schutzbereich des $\S 823$ BGB einbeziehen kann, ohne Konzept und Systematik des deutschen Deliktsrechts völlig zu zerstören. ${ }^{117}$ So sehr man bedauern muß, daß die Zweite Kommission den heutigen $\S 826$ BGB mehr oder weniger unreflektiert auf Vorsatztaten beschränkt hat, so läßt sich dieser Fehler doch nicht dadurch korrigieren, daß man das Vermögen de facto in den rechtsgutsbezogenen Tatbestand des $\S 823$ Abs. 1 BGB einschmuggelt.

\section{Perspektiven deliktischen Vermögensschutzes}

Was bleibt nach diesem ernüchternden Befund an Perspektiven des deliktischen Vermögensschutzes?

Zum einen die Erkenntnis, daß der Schutz des Vermögens im deutschen Recht primär eine Aufgabe des Gesetzgebers ist. Ohne daß dies bewußt geworden wäre, hat sich eine Aufgabenverteilung zwischen Rechtsprechung und Gesetzgebung eingespielt, die den Gerichten den Vortritt läßt, dem Parlament aber das letzte

\footnotetext{
114 Mertens, AcP 178 (1978), 227, $231 \mathrm{ff}$.

115 von Caemmerer, FS DJT II (Fn. 8), S. 80 (Hervorhebung im Original).

116 Ständige Rechtsprechung seit RGZ 51, 92, 93; vgl. MünchKommBGB-Wagner (Fn. 3), $\S 823$ Rn. 176 m.w. N.

117 MünchKommBGB-Wagner (Fn. 3), § 823 Rn. 177 f.
} 
Wort vorbehält. Ein klassisches Beispiel dafür ist das Kartellrecht, dessen Zelt das RG im berühmten Benrather Tankstellenfall noch in $\$ 826$ BGB aufschlagen mußte, ${ }^{118}$ bis dann der Gesetzgeber 1957 selbst tätig geworden ist und die Ersatzansprüche von Personen, die durch Mißbrauch von Marktmacht geschädigt worden sind, im GWB geregelt hat (vgl. heute $\$ \S 33 \mathrm{ff}$. GWB). Aktuell zeichnet sich eine ganz ähnliche Entwicklung im Bereich der Kapitalmarkthaftung ab: Dem $B G H$ blieb bei der Bewältigung der Schadensersatzklagen, die infolge des Zusammenbruchs der Infomatec $A G$ und anderer Unternehmen des sogenannten Neuen Marktes wegen falscher ad-hoc-Mitteilungen der jeweiligen Vorstände erhoben worden waren, wenig anderes übrig als der Rekurs auf § 826 BGB. ${ }^{119}$ Insoweit hat der $B G H$ mit Recht klargestellt, daß der Risikocharakter einer Vermögensanlage kein Freibrief zur bewußten Irreführung und Übervorteilung anderer ist, wie das OLG München gemeint hatte, ${ }^{120}$ daß für $§ 826$ BGB selbstverständlich dolus eventualis genügt und die Vorschrift im übrigen nicht voraussetzt, daß der Schädiger sein Opfer vor der schädigenden Handlung individualisiert und identifiziert hat. ${ }^{121}$ Trotz dieser zustimmungswürdigen Klarstellungen bleibt die Haftung aus $\S 826$ BGB auf Extremfälle zugeschnitten, weshalb es zu begrüBen ist, wenn die Bundesregierung eine gesetzliche Regelung der Haftung für fehlerhafte Kapitalmarktinformationen anstrebt. ${ }^{122}$ Würde dieses Vorhaben realisiert, hätte sich wieder einmal eine Fallgruppe des $§ 826$ BGB in ein Sondergesetz verabschiedet. ${ }^{123}$

Die angestammte Domäne des Gesetzgebers ist natürlich die Haftung für Schutzgesetzverletzung gemäß $§ 823$ Abs. 2 BGB. Letztere hat unter den Rahmenbedingungen einer durch- oder gar überregulierten Gesellschaft durchaus das Zeug dazu, ein erhebliches Niveau an Vermögensschutz zu gewährleisten. Zwar kommt es vor, daß sich das Gesetz selbst die Schutzeigenschaft ausdrücklich vorenthält - ein Beispiel ist $\S 15$ Abs. 6 S. 1 WpHG a.F. (ähnlich $\S 15$ Abs. 6 S. 1 WpHG n.F.) $)^{124}$ - oder in den Gesetzesmaterialien gesagt wird, die Norm solle kein Schutzgesetz sein, wie im Fall des früheren $\S 88$ BörsG, ${ }^{125}$ doch diese Fälle sind selten. In aller Regel bleibt es der Rechtsprechung überlassen, autonom über die Schutzgesetzeigenschaft einer Norm zu entscheiden. Der BGH ist sich der darin liegenden Verantwortung vollauf bewußt und formuliert in ständiger Rechtsprechung, die an einen Normverstoß gemäß $§ 823$ Abs. 2 BGB

118 RGZ 143, 342; vgl. dazu Behrens, in: Kötz/Schäfer, Judex oeconomicus, 2003, S. $78 \mathrm{ff}$. m. w. N.

119 Vgl. BGH NJW 2004, 2971; NJW 2004, 2664 sowie 2668; zu dieser Trilogie Fleischer, DB 2004, 2031.

120 OLG München, NJW 2003, 144.

121 BGH NJW 2004, 2971, 2972 ff.; MünchKommBGB-Wagner (Fn. 3), § 826 Rn. 63.

$122 \mathrm{Vgl}$. den ersten, wieder zurückgezogenen Entwurf eines „Kapitalmarktinformationshaftungsgesetzes - KapInHaG“, abgedruckt in NZG 2004, 1042.

123 Zum Kommen und Gehen der Fallgruppen des $\$ 826$ BGB MünchKommBGB-Wagner (Fn. 3), § 826 Rn. 42 aE.

124 Dazu BGH NJW 2004, 2665, 2665.

125 BVerfG NJW 2003, 501, 502; BGH NJW 2004, 2664, 2665 mit Hinweis auf BT-Drs. 10/ 318 , S. $45 \mathrm{f}$. 
geknüpfte Haftung müsse, ,im Lichte des haftpflichtrechtlichen Gesamtsystems tragbar" erscheinen. ${ }^{126}$ So richtig dieser bewußt-skrupulöse Ansatz auch ist, so fragt sich doch, ob es der $B G H$ mit der Zurückhaltung nicht manchmal übertreibt. Ein aktuelles Beispiel betrifft einen Bauunternehmer, der aufgrund entsprechender Ermächtigung durch die zuständige Behörde Halteverbotsschilder aufstellt, um alsbald mit Straßenbauarbeiten beginnen zu können. Wird das Halteverbot von den Anwohnern ignoriert und der für die Baustelle benötigte Raum mit Fahrzeugen zugeparkt, stellt sich die Frage, ob der Bauunternehmer die durch die Verzögerung erlittenen, nicht unerheblichen Vermögensschäden von den Falschparkern ersetzt verlangen kann. Dies wäre der Fall, wenn $\S \S 12$ Abs. 1 Nr. 6a, 45 StVO als Schutzgesetz zu qualifizieren wären. Nun dient die StVO insgesamt nicht nur der Leichtigkeit des Verkehrs, sondern auch dessen Sicherheit und damit der Vermeidung von Schäden an Leben, Körper und Eigentum. ${ }^{127}$ All dies nützt dem Bauunternehmer hier aber nichts, denn nach Auffassung des $B G H$ liegen reine Vermögensschäden jenseits des sachlichen Schutzbereichs der StVO. ${ }^{128}$ Sicherlich kann eine pauschale Einbeziehung von Vermögensinteressen in den Schutzbereich der StVO nicht in Betracht kommen, denn sonst haftete der Verursacher eines Verkehrsunfalls auf einer Autobahn für die Nachteile, die den Tausenden von Autofahrern entstehen, die hinter der Unfallstelle im Stau stehen. Im speziellen Fall des $§ 12$ Abs. 1 Nr. 6a StVO fragt sich allerdings, warum der $B G H$ diejenigen schützt, die unter flagranter Mißachtung von Verkehrsvorschriften und in rücksichtsloser Weise ihrer eigenen Bequemlichkeit nachgeben und damit einem Dritten - dem Bauunternehmer einen Schaden zufügen, gegen den er sich anders als durch die Beschilderung nicht schützen kann.

Die Rechtsprechung sollte auch nicht den Forderungen aus der Literatur nachgeben und die Anforderungen an Vorsatz und Sittenwidrigkeit in $§ 826$ BGB verschärfen. ${ }^{129}$ Das Sittenwidrigkeitsmerkmal hat nichts mit sozialethischer Verwerflichkeit zu tun, sondern dient allein der sachgerechten Begrenzung des Ersatzes reiner Vermögensschäden durch Vermeidung einer uferlosen Haftung gegenüber einem unbeschränkten Kreis potentiell aktivlegitimierter Personen - die berühmte ,liability in an indeterminate amount for an indeterminate time to an indeterminate class" im Sinne des amerikanischen Richters Cardozo. ${ }^{130}$ Auch die Anforderungen an das Vorsatzerfordernis werden in der zivilrechtlichen Literatur mitunter weit überschätzt und dabei übersehen, daß der Vorsatz keine böse Absicht erfor-

126 BGHZ 66, 388, 390; 106, 204, 207; MünchKommBGB-Wagner (Fn. 3), § 823 Rn. 318, 343.

127 BGH NJW 1983, 1326; 1991, 292.

128 BGH NJW 2004, 356, 357 f.; LG München I, NJW 1983, 288; a. A. AG Waiblingen, NJWRR 2002, $895 \mathrm{f}$.

129 Larenz/Canaris (Fn. 31), S. 454f.; Honsell, JuS 1976, 621, 628; ders., FS Medicus, 1999, S. $211,215 \mathrm{f}$.

130 Ultramares Corp. v. Touche, 255 N. Y. $174=174$ N.E. 441, 444 (1931 Cardozo, C. J.), mit Blick auf die Haftung von Wirtschaftsprüfern gegenüber einem Kreditgeber des geprüften Unternehmens. Ausführlich zur funktionalen Interpretation des Sittenwidrigkeitserfordernisses: MünchKommBGB-Wagner (Fn. 3), § 826 Rn. 10 ff. 
dert und nach moderner strafrechtlicher Auffassung wenig mehr erfordert als das Bewußtsein der Möglichkeit der Schadensverursachung. ${ }^{131}$

Die große Lösung, die den gordischen Knoten durchhauen würde, könnte nur der Gesetzgeber liefern. Dazu würde der buchstäbliche Federstrich genügen, nämlich die Streichung des Wortes ,vorsätzlich“ in $\S 826$ BGB, wahlweise auch die Hinzufügung von ,oder fahrlässig“. Nicht zuletzt ließe sich damit eine Binnenharmonisierung mit dem Vermögensschutz nach Maßgabe der Sonder-Deliktsrechte herstellen, denn weder nach $\S 3$ UWG noch gemäß $\S 33$ GWB ist die Haftung für reine Vermögensschäden auf vorsätzliche Verstöße gegen die Regeln fairen Leistungswettbewerbs beschränkt.

\section{Gefährdungshaftung}

\section{Verschuldensdogma des $B G B$}

Die Zweite Kommission als Schöpferin des BGB-Deliktsrechts war stolz darauf, durchgängig am Verschuldensprinzip festgehalten $\mathrm{zu}$ haben, wenn man von der Tierhalterhaftung des heutigen $\S 833$ S. 1 BGB einmal absieht. Das Verschuldensprinzip sei ,das Ergebnis einer höheren Kulturentwicklung“ und „,von entscheidender Bedeutung für die Abgrenzung der Rechtskreise der Einzelnen, innerhalb derer sie ihre Individualität entfalten dürfen“" ${ }^{132}$ - Diese Worte klingen gut, wurden aber bereits der wirtschaftlichen und sozialen Wirklichkeit zum Ende des 19. Jahrhunderts nicht gerecht. Die Arbeitsunfälle waren damals ein ebenso drängendes wie politisch brisantes Problem, ${ }^{133}$ und Eisenbahnen wurden schon damals unter einer Gefährdungshaftung betrieben, die kein geringerer als von Savigny eingeführt hatte. ${ }^{134}$ Wenn Jhering gleichwohl 1868 einflußreich ausrief, nicht der Schaden verpflichte zum Ersatz, sondern (allein) die Schuld, ${ }^{135}$ hatte der sonst so „lebensnah“ denkende Jurist die Zeichen der Zeit grob verkannt. ${ }^{136}$ Dementsprechend heftig fiel die Kritik von von Gierke am BGB aus: Es sei ,eine Verkennung der sozialen Aufgabe des Privatrechts, wenn die gesammte Ordnung des Schadensersatzrechtes auf den Deliktsbegriff gebaut werden soll“; denn: „Mag den Urheber der Rechtsverletzung ein eigentliches Verschulden nicht treffen, so ist doch der Geschädigte noch unschuldiger" ${ }^{\prime 37}$ Der Einzelne müsse für den Schaden einstehen, der durch die besondere Gefährlichkeit seines Besitztums anderen erwachse; andernfalls wäre es gestattet, , alle Vortheile aus einem die Mitmenschen gefährdenden Eigenthum zu genießen, ohne das entsprechende Risiko zu tragen“ “. ${ }^{138}$

\footnotetext{
131 Ausführlich: MünchKommBGB-Wagner (Fn. 3), § 826 Rn. 19 ff.

132 Prot. II (Fn. 6), S. 569.

133 Stolleis, Geschichte des Sozialrechts, 2003, S. $52 \mathrm{ff}$.

134 Baums, SZGerm 104 (1987), 277; weitere Nachweise bei MünchKommBGB-Wagner (Fn. 3), vor $\$ 823$ Rn. 16.

135 von Jhering, Das Schuldmoment im römischen Privatrecht (1867), in: ders., Vermischte Schriften juristischen Inhalts, 1879, S. 155, 199.

136 Diederichsen, in: Behrends (Hrsg.), Privatrecht heute und Jherings evolutionäres Rechtsdenken, 1993, S. 37, 65.

137 Gierke (Fn. 5), S. 33.

138 Gierke (Fn. 5), S. 33.
} 


\section{Aktivitäten des Gesetzgebers}

Die Kritiker des BGB sollten auf ganzer Linie Recht behalten, denn der Gesetzgeber ist ihren Forderungen nachgekommen, wenn auch nur schrittweise, indem er Sondergesetz auf Sondergesetz geschichtet hat. Damit erhielt die Gefährdungshaftung doch noch Einzug in die Schuldrechts-Lehrbücher, und darüber hinaus etablierte sich eine Gattung von Spezialliteratur zu den jeweiligen Sondergesetzen, wobei die erzielten Auflagen von der praktischen Bedeutung der jeweiligen Materie und damit von der Häufigkeit und Schwere der jeweils vorkommenden Unfälle abhängen. Im folgenden werden nur die dogmatisch und praktisch wichtigsten Gebiete der Gefährdungshaftung erwähnt; wer vollständige Dokumentation und Information sucht, findet sie etwa im bereits erwähnten, von Geigel begründeten Erläuterungswerk zum Haftpflichtprozeß. ${ }^{139}$

Eröffnet wurde der Reigen von Sondergesetzen zur Gefährdungshaftung - wie bereits erwähnt - durch $\S 25$ des preußischen Gesetzes über die Eisenbahnunternehmungen, nach der ein Eisenbahnunternehmer zum Ersatz allen Personen- und Sachschadens verpflichtet war, welcher ,bei der Beförderung auf der Bahn“ entstand. Diese Regelung diente als Vorbild für das Reichshaftpflichtgesetz von 1871 und findet sich heute in $\S 1$ HPflG. Der Standardkommentar zu diesem Gesetz stammt aus dem Hause Beck und befindet sich in den guten Händen von Filthaut. ${ }^{140}$

Das Jahr 1908 markiert die erstmalige Einführung einer Gefährdungshaftung zu Lasten von Fahrzeughaltern; die damalige Regelung in $\S 7$ KraftVG über die Schadensersatzpflicht des Kraftfahrzeughalters für Personen- und Sachschäden, die „,bei dem Betrieb eines Kraftfahrzeugs“ verursacht werden, findet sich heute in $\S 7$ StVG. Das Standard-Erläuterungswerk zum Straßenverkehrsrecht ist von dem Rechtsanwalt beim Reichsgericht Floegel begründet worden, der im Vorwort zur 3. Auflage seines Werks ausrief „Ein Volk, ein Wille, ein Recht!“. ${ }^{141}$ Im Vorwort zur 8. Auflage 1953 - der ersten nach dem Zweiten Weltkrieg - informierte der neue Bearbeiter des Kommentars, der pensionierte Reichsgerichtsrat Hartung, die Leser über den Tod Floegels in einem ,,russischen Konzentrationslager“ ${ }^{142}$ Nachdem der Kommentar zeitweise von Jagusch betreut wurde, zeichnete über viele Jahre Hentschel für ihn verantwortlich; die aktuelle 38. Auflage stammt aus dem Jahr 2005 und ist mit den meisten anderen „Kurz-Kommentaren“ aus dem Hause Beck im Umfang stark gewachsen, nämlich auf über 1600 Seiten im Lexikonformat. ${ }^{43}$ Was die Gliederung des Kommentars anlangt, so ist das Haftungsrecht vom Ende der Darstellung ganz an den Anfang gerückt. In diesen Veränderungen spiegelt sich auch die stark angestiegene Zahl der Straßenverkehrsunfälle, ein Anstieg, der seinerseits auf einer immer vollkommeneren Motorisierung der Bevölkerung und einer immensen Zunahme der Verkehrsbewegungen beruht. So kann man ein

139 Geigel (Fn. 13), Kapitel 22 bis 32.

140 Filthaut, HPflG, 6. Aufl. 2003.

141 Floegel, Straßenverkehrsrecht, 3. Aufl. 1935, S. III.

142 Floegel/Hartung, Straßenverkehrsrecht, 8. Aufl. 1953, S. III.

143 Hentschel, Straßenverkehrsrecht, 38. Aufl. 2005. 
Schmunzeln kaum unterdrücken, wenn Hartung im Vorwort zur 9. Auflage 1954 des Straßenverkehrsrechts die ,,immer noch fortschreitende Motorisierung des StraBenverkehrs “ beklagt. ${ }^{144}$ Rückblickend erscheinen die Verhältnisse auf Deutschlands Straßen im Jahr 1954 als pure Idylle.

Trotz aller Veränderungen sind die Sachprobleme des Straßenverkehrsunfallrechts in den vergangenen siebzig Jahren weitgehend dieselben geblieben. Schon Floegel kämpfte in seiner Erläuterung des $§ 7$ KraftVG mit dem Erfordernis, daß die Rechtsgutsverletzung ,beim Betrieb“ des Kraftfahrzeugs entstanden sein muß und schildert die Rechtsprechung des RG, die sich zwischen maschinen- und verkehrstechnischer Auffassung dieses Erfordernisses nicht recht zu entscheiden wußte. ${ }^{145}$ Bei Hentschel findet sich zu dieser Frage natürlich noch weit mehr Material, doch die Grenzen der Gefährdungshaftung werden nicht klarer, wenn formuliert wird, maßgebend sei die Verletzung beim „Fahrbetrieb oder einer seiner Folgewirkungen, naher zeitlicher und örtlicher Zusammenhang mit Betriebsvorgängen oder Betriebseinrichtungen des Kraftfahrzeugs" ${ }^{146}$ Für den Rechtsanwender kommt diese Formulierung einer Anleitung zum Unglücklichsein gleich. Das in der zitierten Formulierung schlummernde Problem des ,ruhenden Verkehrs“ ist kürzlich in ganz unvermutetem Zusammenhang wieder aktuell geworden: Der BGH hat die Erstreckung des $\S 828$ Abs. 2 BGB auf Kollisionen zwischen Kindern und ordnungsgemäß geparkten Autos abgelehnt und ist damit jedenfalls im Rahmen dieses Haftungsprivilegs zur maschinentechnischen Auffassung zurückgekehrt. ${ }^{147}$

Im Jahr 1943 wurde in das damalige Reichshaftpflichtgesetz eine Bestimmung eingefügt, die zum Modell für den haftungsrechtlichen Umweltschutz durch Gefährdungshaftung der Betreiber von Industrieanlagen werden sollte. ${ }^{148} \mathrm{Nach}$ der heute in $\S 2$ HPflG enthaltenen Regelung haftet der Inhaber einer Energieanlage für Personen- und Sachschäden, die ,durch die Wirkungen von Elektrizität, Gasen, Dämpfen oder Flüssigkeiten“ verursacht werden. Die gleiche Verpflichtung trifft seit Inkrafttreten des WHG 1957 auch den Inhaber einer zur Herstellung, Verarbeitung, Förderung, Lagerung oder Fortleitung von Stoffen bestimmten Anlage, der gemäß $\S 22$ Abs. 2 WHG dafür aufzukommen hat, wenn Stoffe aus der Anlage in ein Gewässer - darunter fallen nicht nur Flüsse, Bäche, Teiche und Seen, sondern auch das Grundwasser - gelangt sind und dadurch Schaden angerichtet worden ist. $\S 22$ Abs. 1 WHG bringt darüber hinaus eine vom Betrieb einer Anlage unabhängige Gefährdungshaftung zu Lasten von jedermann, der in ein Gewässer Stoffe einbringt oder einleitet, die die Beschaffenheit des Wassers derart verändern, daß dadurch einem anderen ein Schaden entsteht. Der Tatbestand spielt zwar in der Praxis keine allzu große Rolle, doch aus theoretischdogmatischer Sicht ist er kaum zu unterschätzen, weil hier die strikte Haftung von ihrer Anknüpfung an das Halten einer technischen Gefahrenquelle gelöst und auf

\footnotetext{
144 Floegel/Hartung, Straßenverkehrsrecht, 9. Aufl. 1954, S. III.

145 Floegel (Fn. 141), § 7 KraftVG Anm. 3 a.

146 Hentschel (Fn. 143), § 7 StVG Rn. 10; vgl. auch a. a. O. Rn. 5 a ff.

147 BGHZ 161, 180, 183 ff.; BGH NJW 2005, 356.

$148 \mathrm{Vgl}$. dazu den Überblick bei MünchKommBGB-Wagner (Fn. 3), § 823 Rn. 624f.; Wagner, in: Handwörterbuch des Umweltrechts I, 1994, Stichwort Haftung.
} 
gefährliche Handlungen erstreckt worden ist, die prinzipiell von jedermann vorgenommen werden können. Entsprechend intensiv wird die Vorschrift in der schuldrechtlichen Literatur diskutiert. ${ }^{149}$ Eine aktuelle Darstellung des WHG findet sich im Programm des Beck-Verlages in der Kommentierung von Czychowski/Reinhardt. ${ }^{150}$

Einen vorläufigen Höhepunkt erreichte der Umweltschutz durch Gefährdungshaftung mit Inkrafttreten des UmweltHG am 1. Januar 1991. Das Gesetz unterwirft die Inhaber bestimmter umweltgefährdender Anlagen einer verschuldensunabhängigen Haftung auch bei Schäden infolge sogenannten Normalbetriebs ( $\$ 1$ UmweltHG), führte erstmals eine gesetzliche Kausalitätsvermutung ein ( 6 UmweltHG), gewährt dem Geschädigten Auskunftsansprüche sowohl gegenüber der Genehmigungsbehörde als auch gegenüber dem Anlagenbetreiber und vice versa (\$§ 8-10 UmweltHG) und begründet schließlich für besonders gefährliche Anlagen eine Verpflichtung zur Deckungsvorsorge ( $\$ 19$ UmweltHG). Angesichts dieser Neuerungen war es nicht verwunderlich, daß das UmweltHG eine Fülle von Kommentaren gebar - gerade auch im Programm des Verlages C. H. Beck. ${ }^{151}$ Die Praxis hat das Gesetz indessen nicht erreicht, denn 14 Jahre nach seinem Inkrafttreten kann Salje in der 2. Auflage seines Kommentars von lediglich vier Gerichtsentscheidungen berichten, von denen bloß eine einzige vom $B G H$ stammt und die durchweg wenig spektakuläre Fälle betreffen. ${ }^{152}$ Auch aus der Pflicht- und Haftpflichtversicherung ist die Luft heraus, denn die zur Implementierung der Verpflichtung gemäß $§ 20$ UmweltHG zu erlassende Deckungsvorsorgeverordnung ist bis heute nicht ergangen und wird wohl auch nicht mehr erlassen werden, nachdem die Verweisung des $\$ 19$ Abs. 1 UmweltHG auf die StörfallVerordnung nach der Änderung der 12. BImSchV ins Leere stößt. ${ }^{153}$ Dieser Befund muß nicht unbedingt beunruhigen; vielleicht zeigt er nur, wie sicher umweltgefährdende Anlagen in Deutschland zwischenzeitlich geworden sind.

Die bis zum 30. April 2007 umzusetzende Umwelthaftungs-Richtlinie der EG beschäftigt sich ausschließlich mit der Vermeidung und der Sanierung von Umweltschäden im engeren Sinne, den in der deutschen Dogmatik sogenannten ökologischen Schäden. ${ }^{154}$ Sie läßt die Haftung aufgrund des UmweltHG gänzlich unberührt, denn nach ihrem Art. 3 Abs. 3 haben „Privatparteien gemäß dieser Richtlinie keinen Anspruch auf Schadensersatz infolge eines Umweltschadens

149 Larenz, VersR 1963, 593, 603; ders. (Fn. 21), S. $731 \mathrm{ff}$; anders jetzt aber Larenz/Canaris (Fn. 31), S. 631 ff.; vgl. auch Medicus (Fn. 23), Rn. 896.

150 Czychowski/Reinhardt, WHG, 8. Auflage 2003.

151 Rehbinder/Hager, Kommentar zum UmweltHG, in: Landmann/Rohmer, GewO, Bd. III; Salje, UmweltHG, 1. Aufl. 1993; vgl. weiter Landsberg/Lülling, Umwelthaftungsrecht, 1991; Schmidt-Salzer, Umwelthaftungsrecht, 1992; Paschke, Umwelthaftungsgesetz, 1993; vgl. auch G. Hager, NJW 1991, 134; Wagner, VersR 1991, 249.

152 Salje/Peter, UmweltHG, 2. Aufl. 2005, §§ 1, 3 Rn. 139 ff.; vgl. auch Salje, VersR 1998, 797.

153 Salje/Peter (Fn. 152), § 20 Rn. 2, § 19 Rn. 6 ff.

154 Richtlinie 2004/35/EG des Europäischen Parlaments und des Rates über Umwelthaftung zur Vermeidung und Sanierung von Umweltschäden vom 21. April 2004, AB1.EG L 143/56; dazu Wagner, VersR 2005, 177. 
oder der unmittelbaren Gefahr eines solchen Schadens“. Dem Zurechnungsprinzip der Gefährdungshaftung folgt Art. 3 Abs. 1 der Richtlinie nur mit Blick auf besonders gefährliche Tätigkeiten, insbesondere, aber nicht nur, den Betrieb umweltgefährdender Anlagen, während es im übrigen bei der Verschuldenshaftung bleibt. ${ }^{155}$ Es ist geplant, die Richtlinie im Kontext des öffentlichen Umweltverwaltungsrechts umzusetzen und nicht etwa das UmweltHG um Ersatzansprüche zugunsten von Behörden zu ergänzen. ${ }^{155 a}$

\section{Reformbemühungen}

Die um die Wende zum 19. Jahrhundert geäußerte Kritik Gierkes hat Esser Ende der vierziger Jahre wieder aufgegriffen und in seiner bereits erwähnten Monographie über „Grundlagen und Entwicklung der Gefährdungshaftung“ ausgearbeitet, die sich als ein flammendes Pläydoyer für den Ausbau dieses Rechtsinstituts liest. ${ }^{156}$ Seine besondere Note erhält das Werk dadurch, daß Esser die Verschuldenshaftung als Korrelat einer liberal-freiheitlichen Gesellschaftsordnung charakterisiert, ${ }^{157}$ um dieser die auf die Herstellung von Verteilungsgerechtigkeit orientierte Gefährdungshaftung gegenüberzustellen. ${ }^{158}$ Die Gefährdungshaftung sei „eine Methode des Sozialschutzes [durch] Abwendung bestimmter Zwangsrisiken [...] von dem sozial hierauf Angewiesenen“, ${ }^{159}$ die auf der ,Grundansicht“ beruht, ,„daß man für die Sonderrechte, die man genießt, durch Übernahme des hierbei entstehenden Unglücks aufzukommen hat"“. ${ }^{160}$

Obwohl niemand bestreiten wird, daß diese Gesichtspunkte bei der Gefährdungshaftung eine Rolle spielen, blieb die Wirkung des Buchs diffus, was wohl darauf zurückzuführen ist, daß Esser den Adressaten seines Plädoyers nicht nannte. Unklar blieb, ob er sich an den Gesetzgeber wandte, um diesen zur Reform des Haftungsrechts in Richtung auf die Gefährdungshaftung aufzufordern, oder ob er die Rechtsprechung dazu ermuntern wollte, von der ,weiteren Zersetzung des zivilrechtlichen Deliktsbegriffs" durch Überspannung der Verkehrspflichten abzulassen ${ }^{161}$ und statt dessen ihrerseits die Gefährdungshaftung auszudehnen. Sollte letzteres die Absicht Essers gewesen sein, so ist ihr der Erfolg versagt geblieben, denn der $\mathrm{BGH}$ ist stets der ständigen Rechtsprechung des $R G$ gefolgt, daß die Gefährdungshaftungstatbestände keine analoge Anwendung auf solche Gefahrenquellen vertragen, die nicht explizit von ihnen erfaßt werden. ${ }^{162}$ An diesem Standpunkt hat der BGH auch über die sechziger und siebziger Jahre des 20. Jahrhun-

155 Vgl. Wagner, VersR 2005, 177, 180.

155a Vgl. den Regierungsentwurf eines Umweltschadensgesetzes, BT-Drs. 16/3806, S. 7 ff.

156 Esser, Grundlagen und Entwicklung der Gefährdungshaftung, 2. unveränderte Aufl. 1969; vgl. das Zitat aus Gierke (Fn. 5), S. 16f. auf S. III.

157 Esser (Fn. 156), S. 51.

158 Esser (Fn. 156), S. $80 \mathrm{ff}$.

159 Esser (Fn. 156), S. 90.

160 Esser (Fn. 156), S. 97.

161 Esser (Fn. 156), S. 106, $23 \mathrm{ff}$.

162 RGZ 78, 171, 172; 99, 96, 98f.; 147, 353, 355 f.; BGHZ 55, 229, 234 = NJW 1971, 607, 608f.; BGHZ 63, 234, 237 = NJW 1975, 117, 118; BGH VersR 1958, 194; NJW 1960, 1345, 1346; NJW 1993, 2173, 2174. 
derts hinaus festgehalten, obwohl er damals von vielen Autoren dazu aufgefordert wurde, die Kompetenz zur Rechtsfortbildung auch in diesem Bereich wahrzunehmen. ${ }^{163}$ Vor allem aus diesem Grund stellte Erwin Deutsch seinen Rückblick auf die Rechtsprechung des BGH zur Gefährdungshaftung unter den Titel: „Die Geschichte eines Abstoßungsprozesses" “. ${ }^{164}$

Rückblickend wird man für die Hartleibigkeit der Rechtsprechung einiges Verständnis aufbringen. Die Erfahrungen des österreichischen Rechts mit Analogieschlüssen im Bereich der Gefährdungshaftung sind ernüchternd; obwohl eine Haftungsbegründung per analogiam in Österreich für zulässig gehalten wird, ${ }^{165}$ hat der OGH diesen Weg kaum einmal beschritten. ${ }^{166}$ Das verwundert nicht, denn wenn der Gesetzgeber Landfahrzeuge zwei verschiedenen Regimen der Gefährdungshaftung unterwirft, je nach dem, ob sie auf Schienen oder auf Straßen fahren $(\S 1$ HPflG, § 7 StVG), kann der BGH ein Binnenschiff ${ }^{77}$ oder einen Schlepplift guten Gewissens weder dem einen noch dem anderen Regime zuordnen. ${ }^{168}$ Besonders deutlich wird die Problematik von Analogieschlüssen bei den geradezu willkürlichen Grenzziehungen des Katalogs umweltgefährdender Anlagen nach Anhang 1 zu § 1 UmweltHG, wenn beispielsweise Anlagen zum Halten von Schweinen mit mehr als 1700 Mastschweine- oder 500 Sauenplätzen der Gefährdungshaftung unterworfen werden, solche mit 1699 Mastschweinen oder 499 Sauen aber nicht. ${ }^{169}$

Im internationalen Vergleich scheint selbst das vorzugswürdige Modell einer Gesamtanalogie ${ }^{170}$ oder einer gefährdungshaftungsrechtlichen Generalklausel eher auf dem Rückzug denn auf dem Vormarsch zu sein. ${ }^{171}$ Das englische Recht, das mit der "rule in Rylands v. Fletcher" auf dem besten Weg zu einer Generalklausel der strict liability war, hat die gegenteilige Entwicklung genommen und die verschuldensunabhängige Haftung de facto in eine Nische des Nachbarrechts verbannt. Das französische Recht schließlich hat zwar mit Art. 1384 Abs. 1 Code civil eine solche Generalklausel zur Verfügung, doch die Gardien-Haftung gilt für sämtliche Sachen ganz unabhängig davon, ob der konkrete schadensträchtige $\mathrm{Ge}-$ genstand als Quelle besonderer Gefahr anzusprechen ist oder nicht, so daß die Sachhalter- und die Gefährdungshaftung nur partiell und zufällig kongruent sind. Umgekehrt - oder sogar folgerichtig - sind dem französischen Recht sonderge-

163 Kötz, Gefährdungshaftung, S. 1785 ff.; ders., AcP 170 (1970), 1, 41; Deutsch, VersR 1971, 1, $2 \mathrm{ff}$; von Caemmerer, Reform der Gefährdungshaftung, 1971; S. $19 \mathrm{ff}$; Will, Quellen erhöhter Gefahr, 1980, S. 277 f.

164 Deutsch, FS 50 Jahre BGH, Bd. I, 2000, S. $675 \mathrm{ff}$.

$165 \ddot{o} O G H$ JBl. 1993, 113, 114; Koziol, FS Wilburg, 1975, S. $173 \mathrm{ff}$.

166 Vgl. den Überblick bei Canaris, JBl. 1995, 2, 10 ff. m. w. N.; vgl. auch öOGH JB1. 1993, 113, 114; JB1. 1996, 446, 449.

167 Gegen eine analoge Anwendung der für Luft- und Landfahrzeuge geltenden Gefährdungshaftungstatbestände auf Motorboote öOGH ZVR 1986/59, 153.

168 Zum Schlepplift: BGH NJW 1960, 1345, $1346=$ VersR 1960, 642, sowie $\ddot{0} O G H \mathrm{SZ}$ 39/69.

169 MünchKommBGB-Wagner (Fn. 3), Vor $\$ 823$ Rn. 23; vgl. auch Salje/Peter, UmweltHG, 2. Aufl. 2005, $\S 1,3$ Rn. 45 gg) Nr. 64.

${ }^{170}$ Dazu öOGH JB1. 1996, 446, 449; eingehend Koziol, Österreichisches Haftpflichtrecht, Bd. II, 1984, S. $577 \mathrm{ff}$.

171 Zum folgenden eingehend Wagner, in: Zimmermann (Fn. 3), S. $277 \mathrm{ff.}$ 
setzliche Haftungsregime in angestammten Bereichen der Gefährdungshaftung nicht erspart geblieben, unter denen der sogenannten ,loi Badinter“ über den Schadensausgleich bei Straßenverkehrsunfällen die mit Abstand größte Bedeutung zukommt. ${ }^{172}$ Ohne die „Hilfe“ des Gesetzgebers kommt die Gefährdungshaftung also offenbar nirgends aus. Der englische Richter Lord Goff hat diese Gedanken in folgende Worte gekleidet:

„I incline to the opinion that, as a general rule, it is more appropriate for strict liability in respect of operations of high risk to be imposed by Parliament, than by the courts. If such liability is imposed by statute, the relevant activities can be identified, and those concerned can know where they stand. Furthermore, statute can where appropriate lay down precise criteria establishing the incidence and scope of such liability." ${ }^{\text {"173 }}$

\section{Produkthaftung}

\section{Produkthaftung zwischen Vertrag und Delikt}

Die Produkthaftung ist in einer schwer zu definierenden Grauzone zwischen Vertrags-, Delikts- und Gefährdungshaftung angesiedelt. Zwar hatte bereits das RG in mehreren Entscheidungen Warenhersteller auf deliktischer Grundlage zum Schadensersatz verurteilt, ${ }^{174}$ und der $B G H$ hat diese Rechtsprechung fortgeführt. ${ }^{175}$ Erst in der Nachkriegszeit und mit wachsendem Wohlstand brandete jedoch in der Literatur eine Debatte um die richtige Einordnung der Produkthaftung auf. ${ }^{176}$ Ein vorläufiger Höhepunkt war die Zivilrechtliche Abteilung des 47. Deutschen Juristentags 1968, die durch ein Gutachten von Simitis vorbereitet wurde, ${ }^{177}$ dem wiederum die ein Jahr zuvor veröffentlichte Habilitationsschrift von Diederichsen über die „Haftung des Warenherstellers“ vorausgegangen war. ${ }^{178}$

Diederichsen kam nach umfangreichen rechtsvergleichenden, rechtssoziologischen und rechtstheoretischen Überlegung zu dem Ergebnis, daß sich das vertragsrechtliche Relativitätsprinzip nicht überspringen lasse, eine Rekonstruktion der Produkthaftung auf kontraktlicher Grundlage somit ausscheide. ${ }^{179}$ Doch auch das Deliktsrecht erwies sich nach seiner Auffassung als ungeeignet zur Lösung des Problems, weil der individualistische Handlungsbegriff des $§ 823$ BGB nicht auf arbeitsteilig organisierte Prozesse moderner Massenproduktion passe, zudem eine generelle Verantwortlichkeit des Herstellers für Produktfehler wegen des in $\S 831$

172 Dazu Wagner, in: Zimmermann (Fn. 3), S. 284 ff.; von Bar, VersR 1986, 620.

173 Cambridge Water Co.v. Eastern Counties Leather Plc. [1994] 2 A. C. 264, 305 (H.L.(E.) 1993, per Lord Goff of Chieveley).

174 RGZ 87, 1 - Brunnensalz; 163, 21, 25 f. - Bremsen I; RG DR 1940, 1293 - Bremsen II.

175 BGH VersR 1953, 242 - Speiseöl; VersR 1956, 625 - Karussell; weitere Nachweise bei MünchKommBGB-Wagner (Fn. 3), § 823 Rn. 548.

176 Sie wurde mitbegründet von W. Lorenz, FS Nottarp, 1960, S. $59 \mathrm{ff}$.

177 Simitis, Soll die Haftung des Produzenten gegenüber dem Verbraucher durch Gesetz, kann sie durch richterliche Fortbildung des Rechts geordnet werden? In welchem Sinne?, in: Verhandlungen des 47. DJT, Bd. I, 1968, S. C $1 \mathrm{ff}$.

178 Diederichsen, Die Haftung des Warenherstellers, 1967.

179 Diederichsen (Fn. 178), S. $90 \mathrm{ff}$. 
Abs. 1 S. 2 BGB für die Gehilfenhaftung vorgesehenen Entlastungsbeweises auf dem Boden des Deliktsrechts nicht zu begründen sei und eine Verschuldenshaftung auch die sogenannten Ausreißer, also fehlerhafte Stücke einer Serie, deren Aussonderung dem Hersteller beim besten Willen nicht möglich ist, nicht erfassen könne. ${ }^{180}$ Schließlich schied Diederichsen auch die Gefährdungshaftung aus dem Kreis seiner Überlegungen aus, weil industriell hergestellte Produkte keineswegs samt und sonders als „Quellen erhöhter Gefahr“ anzusprechen seien. ${ }^{181}$ Die Lösung des Problems fand er vielmehr in einer auf das Vertrauensprinzip gegründeten und damit jenseits der Dichotomie Vertrag/Delikt angesiedelten gesetzlichen Garantiehaftung für die Folgen fehlerhaft-gefährlicher Produkte. ${ }^{182}$ Der Durchgriff des materiell betroffenen Endverbrauchers gegen den Hersteller unter Überspringen der Vertriebskette legitimiert sich durch das gewährleistungsrechtliche Substrat einer Mehrzahl hintereinander geschalteter Kaufverträge.

Diese Überlegungen haben sich bekanntlich nicht durchgesetzt. Simitis ist ihnen in seinem Gutachten nicht gefolgt, sondern hat für die deliktsrechtliche Lösung optiert, ergänzt um eine vom Gesetzgeber einzuführende Gefährdungshaftung. ${ }^{183}$ So ist es auch gekommen. Der VI. Zivilsenat hat in der Hühnerpest-Entscheidung sämtlichen vertragsrechtlichen oder quasi-vertragsrechtlichen Lösungsansätzen eine Absage erteilt und die Produzentenhaftung nach Maßgabe der damaligen lex lata auf dem Boden des Deliktsrechts etabliert. ${ }^{184}$ In der Folgezeit ist daraus ein imponierendes Gebäude an Richterrecht entstanden, das den $§ 831$ BGB samt der dort vorgesehenen Entlastungsmöglichkeit völlig an die Seite gedrängt und die Produkthaftung als Unternehmenshaftung auf der Grundlage des $\S 823$ Abs. 1 BGB entfaltet hat. ${ }^{185}$ Heute ist die deliktische Produkthaftung eine Verschuldenshaftung bzw. eine Verantwortlichkeit für pflichtwidriges Verhalten nur noch insofern, als es auf die Pflichtwidrigkeit ,des Unternehmens“ ankommt, nicht auf das Fehlverhalten eines Individuums. ${ }^{186}$

\section{ProdHaft G}

Den zweiten Teil des von Simitis unterbreiteten Vorschlags, die Ergänzung der deliktischen Produkthaftung um eine Gefährdungshaftung, ist von der EG-Kommission aufgegriffen worden, die unter der Ägide von Taschner eine Richtlinie über die Produkthaftung erarbeitet hat. Die Richtlinie 85/374/EWG vom 25. Juli 1985 zur Angleichung der Rechts- und Verwaltungsvorschriften der Mitgliedstaa-

\footnotetext{
${ }^{180}$ Diederichsen (Fn. 178), S. $49 \mathrm{ff} ., 81 \mathrm{ff} ., 187 \mathrm{ff}$.

181 Diederichsen (Fn. 178), S. 194, $200 \mathrm{ff}$.

182 Diederichsen (Fn. 178), S. $297 \mathrm{ff} ., 347 \mathrm{ff}$.

183 Simitis (Fn. 177), S. C $30 \mathrm{ff}$., $35 \mathrm{ff} ., 97 \mathrm{f}$.

${ }^{184}$ BGHZ 51, $91=$ NJW 1969 mit Anm. Diederichsen = JZ 1969, 387 mit Anm. Deutsch, mit Besprechung Rehbinder, JuS 1969, 208.

${ }_{185}$ Das Gebäude wird dargestellt von Foerste, in: von Westphalen, Produkthaftungshandbuch, Bd. I, 2. Aufl. 1997, §§ 21 ff.; MünchKommBGB-Wagner (Fn. 3), § 823 Rn. 553 ff.; kritische Würdigungen bei Diederichsen, NJW 1978, 1281; ders., VersR 1984, 797.

186 Zur deliktischen Unternehmenshaftung ausführlich MünchKommBGB-Wagner (Fn. 3), $\S 823$ Rn. 368 ff.; speziell zur Produkthaftung Rn. 608f.
} 
ten über die Haftung für fehlerhafte Produkte ist vom deutschen Gesetzgeber 1989 mit dem Erlaß des ProdHaftG umgesetzt worden. ${ }^{187}$ Nach der Intention ihres Urhebers und nach bis heute verbreiteter Meinung begründet die Richtlinie und damit auch das ProdHaftG eine Gefährdungshaftung, ${ }^{188}$ aber das ist nur richtig, wenn man als Gefahrenquelle allein das fehlerhafte Produkt sieht. Wer so vorgeht, muß sich fragen lassen, nach welchen Kriterien sich denn beurteilt, ob das Produkt fehlerhaft ist. Hierzu heißt es in $\S 3$ Abs. 1 ProdHaftG (Art. 6 Abs. 1 RL), ein Produkt habe einen Fehler, wenn es nicht die Sicherheit biete, die unter Berücksichtigung aller Umstände im Zeitpunkt seines Inverkehrbringens von ihm erwartet werden kann. Zudem fügt $\S 3$ Abs. 2 ProdHaftG (Art. 6 Abs. 2 RL) ausdrücklich hinzu, ein Produkt sei nicht deshalb fehlerhaft, weil später ein besseres Produkt in den Verkehr gebracht werde, und schließlich erlaubt $\S 1$ Abs. 2 Nr. 5 ProdHaftG (Art. 15 Abs. 1 RL) dem Hersteller die Entlastung, wenn der Fehler nach dem Stand der Wissenschaft und Technik im Zeitpunkt des Inverkehrbringens des Produkts nicht erkannt werden konnte. Alle diese Prärogativen zusammen lassen sich zu dem Grundsatz verdichten, daß der Hersteller zumindest für Konstruktions- und Instruktionsfehler nur unter der Voraussetzung einzustehen braucht, daß er die im Verkehr erforderliche Sorgfalt nicht eingehalten hat. ${ }^{189}$ Der Fehlerbegriff des ProdHaftG ,,verschlüsselt“ lediglich die dem Hersteller obliegenden Sorgfaltspflichten. ${ }^{190}$

Wie auch immer man die harmonisierte Produkthaftung dogmatisch einordnet, sie hat dem Produkthaftungsrecht ein weiteres Kapitel hinzugefügt. Die moderne Produkthaftung ist dreispurig angelegt, und diesem Umstand wird von Publikationen wie dem bei Beck erschienenen zweibändigen Produkthaftungshandbuch Rechnung getragen, das sich nicht auf eine Darstellung der deliktischen Haftungsgrundlagen beschränkt, sondern die Vertragshaftung und das ProdHaftG gleichberechtigt daneben stellt. ${ }^{191}$ Darüber hinaus trägt das Produkthaftungshandbuch auch dem Umstand Rechnung, daß die Auslegung des ProdHaftG wegen des Gebots richtlinienkonformer Auslegung der Rückkoppelung mit der Richtlinie bedarf ${ }^{192}$ und diese wiederum die rechtsvergleichende Absicherung der Ergebnisse durch Konsultierung der Umsetzungs- und Anwendungsprobleme anderer EU-Mitgliedstaaten erfordert. Folgerichtig enthält das Handbuch Länderberichte über das Pro-

187 Gesetz v. 15. 12. 1989, BGB1. I, S. 2198.

188 Präambel zur RL 85/374/EWG; Begründung zum ProdHaftG, BT-Drs. 11/2447 S. 8, 11, 13; auf der Qualifikation als Gefährdungshaftung insistiert insbesondere Ficker (= Taschner), FS von Caemmerer, 1978, S. 343 ff.; Taschner, NJW 1986, 611 f.; ders., in: Taschner/Frietsch, Produkthaftungsgesetz und EG-Produkthaftungsrichtlinie, 2. Aufl. 1990, Art. 1 RL Rn. 1 f.; weitere Nachweise bei MünchKommBGB-Wagner (Fn. 3), Einl. ProdHaftG Rn. 15.

189 W. Lorenz, ZHR 151 (1987), 1, 13 ff.; Hager, JZ 1990, 397, 398; Kötz, FS W. Lorenz, 1991, S. 109, 113 ff.; von Bar, FS Hermann Lange, 1992, S. 373, 389; Schlechtriem, FS Rittner, 1991, S. 545, 547 ff.; MünchKommBGB-Wagner (Fn. 3), Einl. ProdHaftG Rn. 16.

190 Treffend Schlechtriem (Fn. 189), S. 545, 546; Brüggemeier, ZHR 152 (1998), S. 511, 517; vgl. auch Diederichsen, NJW 1978, 1281, 1284.

191 von Westphalen (Hrsg.), Produkthaftungshandbuch, Bd. I, 2. Aufl. 1997, 1. Teil, §§ 1 bis 17: Vertragliche Haftung, 2. Teil, $\$ \S 18$ bis 43: Deliktische Haftung; Bd. II, 2. Aufl. 1999, 6. Teil: Produkthaftungsgesetz.

192 MünchKommBGB-Wagner (Fn. 3), Einl. ProdHaftG Rn. 9 m. w. N. 
dukthaftungsrecht der übrigen Staaten der EU, und darüber hinaus werden auch wichtige Drittstaaten einbezogen, soweit sie ein wichtiger Handelspartner der auf den Export angewiesenen deutschen Wirtschaft sind. ${ }^{193}$

\section{Europäisierung des Deliktsrechts}

Die Privatrechte Europas befinden sich in einem Prozeß der Harmonisierung, wobei freilich noch nicht abzusehen ist, ob überhaupt und zu welchem Zeitpunkt das BGB durch ein einheitliches Europäisches Zivilgesetzbuch abgelöst werden wird. Wie auch immer man zu diesem Projekt steht, ist Rechtsvergleichung im europäischen Maßstab das Gebot der Zeit, denn mit dem Europäischen Binnenmarkt intensivieren sich die wirtschaftlichen und sozialen Beziehungen zwischen den Mitgliedstaaten, die Lebensbedingungen gleichen sich immer mehr an und die Zahl grenzüberschreitender Rechtsstreitigkeiten wächst. Diese Entwicklungen zusammengenommen lassen es als dringlich erscheinen, die eigenen juristischen Probleme nicht in Isolation anzugehen, sondern die Erfahrungen der Nachbarrechtsordnungen einzubeziehen. Um diesen Prärogativen Rechnung zu tragen, ist der Stand der Harmonisierungsarbeiten im Bereich des Europäischen Deliktsrechts im Münchener Kommentar zum BGB dokumentiert worden, ${ }^{194}$ und die Kommentierung bemüht sich darum, rechtsvergleichende Erfahrungen an geeigneter Stelle einzubeziehen, soweit es der stets beschränkte Raum erlaubt. So verdankt sich etwa das Bemühen um Vereinheitlichung der dogmatischen Struktur von $§ 823$ Abs. 1 BGB auch rechtsvergleichenden Forschungen, ${ }^{195}$ und gleiches gilt für normative Fundierung der Unterscheidung zwischen Rechtsgutsverletzungen und reinen Vermögensschäden. ${ }^{196}$ Darüber hinaus erfordert die Kommentierung des ProdHaftG die Einbeziehung von Rechtsprechung und Literatur aus anderen Mitgliedstaaten ${ }^{197}$ sowie die stete Beachtung des Gebots richtlinienkonformer Auslegung. ${ }^{198}$

Die seit 1992 im Beck-Verlag erscheinende Zeitschrift für Europäisches Privatrecht $(\mathrm{ZEuP})$ hat bereits eine Vielzahl von Beiträgen zum Europäischen Deliktsrecht veröffentlicht. Beispielhaft $\mathrm{zu}$ nennen sind Arbeiten von Jansen über die Struktur des europäischen Haftungsrechts im Spannungsfeld von Erfolgs- und Handlungsorientierung, ${ }^{199}$ von Thüsing zur Einordnung der deutschen Schadensersatzrechtsreform 2002 in die aktuelle europäische Diskussion ${ }^{200}$, von Feenstra über

193 Produkthaftungshandbuch II (Fn. 191), 9. Teil, $\S \S 130$ bis 144: Mitgliedstaaten der EU; $\S \S 104$ bis 118: Vereinigte Staaten; $\$ \S 145$ bis 147: Wichtige Drittstaaten (Norwegen, Schweiz, Japan).

194 MünchKommBGB-Wagner (Fn. 3), Vor $§ 823$ Rn. 81.

195 Vgl. MünchKommBGB-Wagner (Fn. 3), § 823 Rn. 24; Wagner, in: Zimmermann (Fn. 3), S. $215 \mathrm{ff}$.

196 MünchKommBGB-Wagner (Fn. 3), § 826 Rn. $11 \mathrm{ff.;}$ Wagner, in: Zimmermann (Fn. 3), S. $229 \mathrm{ff}$.

197 Beispiele: MünchKommBGB-Wagner (Fn. 3), § 1 ProdHaftG Rn. 4 mit Fn. 6, Rn. 7 mit Fn. 19 f., Rn. 14 mit Fn. 36, Rn. 49 mit Fn. 142 usw.

198 MünchKommBGB-Wagner (Fn. 3), Einl. ProdHaftG Rn. 9 ff.

199 Jansen, ZEuP 2003, $490 \mathrm{ff}$; ausführlich ders., Die Struktur des Haftungsrechts, 2003.

200 Thüsing, ZEuP 2003, $745 \mathrm{ff}$. 
den Ursprung der deliktischen Generalklausel, ${ }^{201}$ ein Beitrag über Ersatzansprüche wegen reiner Vermögensschäden, ${ }^{202}$ über die persönliche Haftung der Leitungsorgane von Kapitalgesellschaften ${ }^{203}$ sowie mehrere Arbeiten und Entscheidungsrezensionen über das in Deutschland bisher unbekannte Angehörigenschmerzensgeld ${ }^{204}$ und über Abwehransprüche und Geldersatz bei Persönlichkeitsverletzungen. ${ }^{205}$ Erheblicher Gewinn läßt sich überdies aus der Darstellung und Besprechung von Entscheidungen der Obergerichte unserer Nachbarn zu Fragestellungen ziehen, die auch in Deutschland unklar und umstritten sind, etwa die Auskunftshaftung zwischen Vertrag und Delikt, ${ }^{206}$ Schadensersatzansprüche des behindert geborenen Kindes wegen ,wrongful life“"207, die Grenzen der Gehilfenhaftung ${ }^{208}$ oder die Haftung mehrerer Schädiger für Gesundheitsverletzungen infolge Exposition gegenüber Asbest ${ }^{209}$. Nicht zuletzt hat die ZEuP die „Principles of European Tort Law“ der „European Group on Tort Law“ samt eines erläuternden Aufsatzes von Koziol publiziert, ${ }^{210}$ und von Bar hat die Konturen des Deliktsrechtskonzepts der „Study Group on a European Civil Code" vorgestellt. ${ }^{211}$

Der Name von Bar steht aber nicht nur für die Harmonisierungsarbeiten der Study Group, sondern natürlich auch für eine monumentale Monographie zum Gemeineuropäischen Deliktsrecht, die in zwei Bänden 1996 und 1999 bei Beck erschienen ist und im Verlagsprogramm die Reihe ,Jus Commune Europaeum“ begründet hat. ${ }^{212}$ Der erste Band ist gewissermaßen der ,horizontalen“ Rechtsvergleichung gewidmet, denn der Autor untersucht und vergleicht die großen europäischen Rechtsfamilien des kontinentalen Deliktsrechts, des englischen „,common law of torts“ und der skandinavischen Deliktsrechte, freilich nicht ohne ständige Tiefenbohrungen bei interessanten Einzelfragen, wie sie sich entlang des Weges stellen. Der zweite Band ist stärker dogmatisch-systematisch geprägt, da von Bar in diesem die grundlegenden Elemente der europäischen Haftungstatbestände herausarbeitet und rechtsvergleichend verarbeitet. Herausgekommen sind dabei Ausarbeitungen des Schadensbegriffs, von Kausalität und Zurechnung sowie Theorien der Haftung für eigenes Fehlverhalten - in Deutschland herkömmlich Verschuldenshaftung genannt - sowie der Haftung ohne eigenes Fehlverhalten, die man hierzulande herkömmlich Gefährdungshaftung nennt. Am Schluß des zweiten Bandes steht - für deutsche Dogmatiker gänzlich ungewohnt - eine Darstellung der Verteidigungsgründe, deren Anlage sich der englischen Lehre von den „defences“ verdankt.

\footnotetext{
201 Feenstra, ZEuP 2001, 585.

202 Gómez/Ruiz, ZEuP 2004, 908.

203 Coderch/García/Salguero/Puig, ZEuP 2004, 644.

204 Ferrari, ZEuP 1997, 1122; Kadner, ZEuP 2002, 834; Karakostas, ZEuP 2005, 107.

205 Smith, ZEuP 1999, 303; Wagner, ZEuP 2000, 200; Amelung/Vogenauer, ZEuP 2002, 341;

206 Jansen/van der Lely, ZEuP 1999, 229.

207 von Bar, ZEuP 2000, 119; Rebhahn, ZEuP 2004, 794 zum französischen Arrêt Perruche.

208 Wicke, ZEuP 2000, 637; ders., ZEuP 2004, 783.

209 Scherpe, ZEuP 2004, 164 zur berühmten Entscheidung des House of Lords in Sachen Fair-

210 ZEuP 2004, 427 ff., 234 ff.; zuvor bereits Spier/Haazen, ZEuP 1999, 469.

211 von Bar, ZEuP 2001, 515 ff.; vgl. auch Jansen, ZEuP 2001, 30.

212 von Bar, Gemeineuropäisches Deliktsrecht, Bd. I, 1996; Bd. II, 1999.
} child. 
Das englische House of Lords greift gerne auf die beiden Bände zurück, ${ }^{213}$ die seit 1998 bzw. 2000 auch in englischer Übersetzung vorliegen. ${ }^{214}$ Einflüsse des Werks von Bars auf die deutsche Praxis sind bislang nicht auszumachen. Immerhin steht jetzt ein leicht greifbarer Vergleichsrahmen zur Verfügung, der es interessierten Praktikern und Wissenschaftlern erlaubt, die konkret erwogenen Lösungen komparativ abzusichern und zu überprüfen. So wird man etwa schnell gewahr, daß die deutsche Differenzierung zwischen unmittelbaren und mittelbaren Eingriffen bzw. Erfolgs- und Handlungsunrecht in Europa keine Gefolgschaft findet und selbst der österreichische $O G H$ es ablehnt, eine Handlung nur deshalb als rechtswidrig zu bezeichnen, weil sie Ursache für einen Verletzungserfolg war. ${ }^{215}$

\section{Bereicherungsrecht}

\section{Streit der Gelehrten und Konstanz der Judikatur}

Detlef König hat in seinem Gutachten zum Bereicherungsrecht, das er dem Bundesjustizministerium zur Vorbereitung der Schuldrechtsreform erstattet hat, festgestellt, die Rechtsprechung habe die an sie herangetragenen Fälle ,mit eindrucksvoller und vielleicht $\mathrm{zu}$ wenig beachteter Stetigkeit" entschieden. ${ }^{216}$ Mit diesem Befund stimmt überein, daß die großen Fortschritte, die im Bereich des Bereicherungsrechts erzielt wurden, nicht so sehr auf der sachlich-praktischen Ebene liegen, sondern dogmatisch-theoretischer Natur sind. Echte Neuerungen nach Art eines Allgemeinen Persönlichkeitsrechts, des Rechts am eingerichteten und ausgeübten Gewerbebetrieb oder der Produkthaftung kann das Bereicherungsrecht nicht vermelden. Insbesondere nach dem Zweiten Weltkrieg ist jedoch nahezu unermüdlich an seinen dogmatischen und normativen Grundlagen gearbeitet worden. Im Vorwort zu elften Auflage seines SchuldrechtsLehrbuchs stellte Larenz fest, hier sei ,inzwischen so vieles kontrovers, daß man sich fragen muß, ob der Ertrag noch den Aufwand lohnt“. ${ }^{217}$ Die Frage wurde von Canaris im Vorwort zur 13. Auflage desselben Lehrbuchs bejaht: Die Materie sei eine der schwierigsten des Privatrechts, die Diskussion bewege sich auf besonders hohem Niveau und sei die Anstrengung wert, sich in sie hineinzudenken. ${ }^{218}$ Wohlan!

\footnotetext{
213 Vgl. etwa Fairchild v. Glenhaven Funeral Services Ltd. [2002] 3 WLR 89, 110 (HL(E) 2002).

214 von Bar, The Common European Law of Torts, Oxford/New York, Vol. I, 1998, Vol. II, 2000.

215 Vgl. von Bar, Gemeineuropäisches Deliktsrecht, Bd. II (Fn. 212), Rn. 215 m. w. N.

216 König, Bereicherungsrecht, in: Bundesminister der Justiz (Hrsg.), Gutachten und Vorschläge zur Überarbeitung des Schuldrechts, Bd. II, 1981, S. 1578, und passim. Ganz ähnlich Esser/Weyers, Schuldrecht II/2 (Fn. 51), § 47, S. 30: „Bemerkenswert ist [...], daß bei allem heillosem Streit über theoretische Ansätze die jeweils erreichten Ergebnisse, wenn man die Komplexität der faktischen und rechtlichen Sachverhalte berücksichtigt, doch verhältnismäßig wenig streitig erscheinen."

217 Larenz, Lehrbuch des Schuldrechts, Bd. II, Besonderer Teil, 11. Aufl. 1977, Vorwort.

218 Larenz/Canaris (Fn. 31), S. VI.
} 


\section{Historische Grundlagen}

„Iure naturae aequum est neminem cum alterius detrimento et iniuria fieri locupletiorem". ${ }^{219}$

Dieser Satz des Pomponius gilt als klassische Formulierung des Grundprinzips des Bereicherungsrechts: Niemand darf sich mit dem Schaden eines anderen unrechtmäßig bereichern. Damit ist allerdings lediglich ein Grundsatz formuliert, keine einfach zu handhabende und direkt anzuwendende Rechtsregel. Das römische Recht hatte insoweit eine Vielzahl von Klagetypen ausgebildet, die sogenannten condictiones, mit denen die Herausgabe des unrechtmäßig Erlangten gefordert werden konnte. ${ }^{220}$ An diesem Katalog untereinander verwandter Klagearten hielt die Pandektenwissenschaft bis zum Vorabend des BGB fest. ${ }^{221}$ Mit den Arbeiten an der Kodifikation stellte sich dieselbe Frage wie im Bereich des Deliktsrechts: Sollte man der Bereicherungshaftung durch Einführung einer Generalklausel eine allgemeine Grundlage verschaffen, um deren Konkretisierung Rechtsprechung und Wissenschaft zu überlassen oder empfahl es sich statt dessen, einen Katalog von Einzeltatbeständen zu normieren und auf diese Weise einen Teil der notwendigen Weichenstellungen und Konkretisierungen bereits im Gesetz vorzunehmen?222

Überspitzt formuliert, hat sich im Deliktsrecht das Prinzip der Einzeltatbestände durchgesetzt, während im Bereicherungsrecht die Generalklausel realisiert wurde. Ironischerweise verhalten sich auch die beiden Entwürfe zum BGB in den relevanten Passagen komplementär: Während der Erste Entwurf die Generalklausel im Deliktsrecht akzeptierte, ${ }^{223}$ dafür aber im Bereicherungsrecht zu Einzeltatbeständen Zuflucht nahm, ${ }^{224}$ kehrte die Zweite Kommission im Deliktsrecht zu den Einzeltatbeständen zurück und faßte im Bereicherungsrecht den Mut zur Generalklausel. ${ }^{225}$ Die Vorschriften gewönnen , hierdurch wesentlich an Übersichtlichkeit und Klarheit. Auch systematisch sei es richtiger, das allgemeine, die ganze Lehre beherrschende Prinzip an die Spitze zu stellen; jedenfalls verdiene dies vom Standpunkte der Gesetzgebungstechnik den Vorzug“.226

Diese Kontrastierungen sind nicht falsch, aber eben doch überspitzt. Im Deliktsrecht hat man mit den $\S \S 823$ Abs. 1, Abs. 2, 826 BGB drei Gattungstatbestände formuliert, die mit den umfangreichen Katalogen von Einzeldelikten nach Art des Besonderen Teils des StGB fast nichts gemein haben. In diesem Sinne sind die $§ \S 823 \mathrm{ff}$. BGB Ausdruck des Versuchs, zwischen Generalklausel und Einzeltatbestand einen Kompromiß zu finden. Ganz ähnlich liegt es im Bereicherungs-

219 Pomponius, D 50, 17, 206.

220 Zur Geschichte des Bereicherungsrechts: Reuter/Martinek, Ungerechtfertigte Bereicherung, 1983, §§ 1, 2, S. 1 bis 38; Zimmermann (Fn. 66), S. $834 \mathrm{ff.}, 887 \mathrm{ff}$.

221 Windscheid, Lehrbuch des Pandektenrechts, Bd. 2, 7. Aufl. 1891, § 422, S. $534 \mathrm{ff}$.

222 von Caemmerer, FS Rabel, Bd. I, 1954, S. 333, 335.

$223 \S \S 704,705$ Erster Entwurf; dazu eingehend oben, II 1, vgl. auch Fn. 4.

$224 \S \S 737$ bis 748 Erster Entwurf; dazu Mot. II (Fn. 4), S. $829 \mathrm{ff}$; dazu die Kritik von Gierke, Der Entwurf eines bürgerlichen Gesetzbuchs und das deutsche Recht, 1889, S. $272 \mathrm{ff}$.

$225 \S 737$ Zweiter Entwurf, der mit $§ 812$ BGB weitgehend identisch ist; zur Genese Prot. II, S. $681 \mathrm{ff}$.

226 Prot. II, S. 684. 
recht. Neben die „Generalklausel“ des $§ 812$ BGB treten die „Einzeltatbestände“ der $\S \S 813,816,817$ BGB, und der Grundtatbestand selbst - $\S 812$ BGB - formuliert eben kein allgemeines Prinzip, sondern zählt in knapper Diktion eine Fülle von Einzeltatbeständen auf, die sich allerdings in ihren Voraussetzungen und Rechtsfolgen großflächig überschneiden. Da auch der Erste Entwurf in seinem $\S 748$ Abs. 1 den allgemeinen Bereicherungsanspruch als Auffangtatbestand normiert hatte, ${ }^{227}$ ist der Gegensatz zwischen den konkurrierenden Regelungsansätzen im Bereicherungsrecht überwiegend technischer Natur. ${ }^{228} \mathrm{Ob}$ es der Zweiten Kommission einfach nur um eine elegantere Gesetzesfassung ging oder ob sie mit der Adoption einer quasi-Generalklausel sachlich etwas bewirken wollte - und was das sein sollte - bleibt ungewiß. Wie Reinhard Zimmermann treffend formuliert, können die $\$ \S 812$ ff. BGB nicht als „legislative masterpiece“ gelten; ${ }^{229}$ nach dem Urteil von Detlev König sind „Aufbau und Formulierung der $\S \S 812-822$ BGB für die heutigen Schwierigkeiten im Bereicherungsrecht wesentlich mitverantwortlich“ ${ }^{230}$ denn ihnen fehlt in den Worten von Josef Esser ,jede organische Ordnung, die das Verständnis erleichtern könnte. “231

\section{Einheitslehre vs. Typenbildung}

\section{Erste Jahrhunderthälfte}

Der mit dem Inkrafttreten des BGB zunächst hergestellte Kompromiß hielt ein halbes Jahrhundert. Zwar warf Heinrich Lehmann weiterhin die Frage auf, ob die schon aus dem Gesetz ersichtlichen verschiedenen Fälle der Bereicherungsansprüche ,nur als Besonderheiten einer im Grundprinzip einheitlichen Kondiktio oder als in ihrem Wesen verschiedene Ansprüche aufzufassen sind". ${ }^{232}$ Seine Antwort war jedoch eindeutig: ,Das BGB hat jedenfalls in $\S 812$ einen allgemeinen Tatbestand des Bereicherungsanspruchs aufgestellt." ${ }^{233}$ Allerdings unterscheidet der zitierte $§ 812$ Abs. 1 S. 1 klar zwischen Bereicherung ,durch Leistung“ und ,,in sonstiger Weise“, und diese Differenzierung ist selbstverständlich auch der älteren Literatur geläufig. ${ }^{234}$ Den maßgeblichen Unterschied zwischen den beiden Fallgruppen sieht Heinrich Lehmann in der verschiedenen Fassung des Rechtsgrundes bzw. des Fehlens eines solchen: Bei der Leistungskondiktion fehlt der Rechts-

$227 \S 748$ Abs. 1 hatte folgenden Wortlaut: „Derjenige, aus dessen Vermögen nicht kraft seines Willens oder nicht kraft seines rechtsgültigen Willens ein Anderer bereichert worden ist, kann, wenn hierzu ein rechtlicher Grund gefehlt hat, von dem anderen die Herausgabe der Bereicherung fordern." Dazu Mot. II (Fn. 4), S. $851 \mathrm{ff.}$

228 Im Deliktsrecht waren die Eingriffe der Zweiten Kommission keineswegs bloß technischer Natur, weil die Haftung für reine Vermögensschäden und Verletzungen immaterieller Persönlichkeitsinteressen drastisch beschränkt wurde; dazu oben unter B. I.

229 Zimmermann (Fn. 66), S. 887.

${ }^{230}$ König, Bereicherungsrecht, in: Bundesminister der Justiz (Hrsg.), Gutachten und Vorschläge zur Überarbeitung des Schuldrechts, Bd. II, 1981, S. 1520.

231 Esser, Schuldrecht (Fn. 18), S. 776.

232 Enneccerus-Lehmann, Recht der Schuldverhältnisse, 12. Bearb. 1932, § 217 II, S. 722.

233 Enneccerus-Lehmann (Fn. 232), § 217 II, S. 722.

234 Enneccerus-Lehmann (Fn. 232), § 217 II, S. 723. 
grund bei Zweckverfehlung, insbesondere bei Unwirksamkeit des Kausalverhältnisses, bei der Kondiktion in sonstiger Weise fehlt er, wenn sich der Bereicherungsschuldner nicht auf ein Recht zum Eingriff stützen kann. ${ }^{235}$

Diese Lehre paßte insofern gut zum Gesetz, als sie die Existenz eines einheitlichen Begriffs der ungerechtfertigten Bereicherung akzeptierte, dann aber doch zu Typisierungen und daran anschließenden Differenzierungen kam. Sie dominierte das deutsche Bereicherungsrecht bis in die dreißiger Jahre des 20. Jahrhunderts hinein - und wegen des hereinbrechenden Zweiten Weltkriegs de facto bis Anfang der fünfziger Jahre. So hält sich Larenz in seinem Schuldrechtslehrbuch nicht lange mit dem allgemeinen Bereicherungsprinzip auf, sondern betont, es bedürfe der „Entfaltung (,Konkretisierung") nach verschiedenen Richtungen“..236 Zwischen Bereicherung durch Leistung und Bereicherung in sonstiger Weise müsse unterschieden werden, weil die Frage nach dem Rechtsgrund für beide Kondiktionstypen unterschiedlich zu beantworten sei. ${ }^{237}$

\section{Trennungslehre}

In der Nachkriegszeit hat sich das Bild gründlich gewandelt und eine Entwicklung eingesetzt, die schließlich zur Etablierung der heute herrschenden Trennungslehre geführt hat. Der Startschuß wurde allerdings bereits 1934 in Graz abgegeben, und zwar von Walter Wilburg mit seiner Schrift über „Die Lehre von der ungerechtfertigten Bereicherung“. Dem Werk liegt die Einsicht zugrunde, der oben zitierte Satz des Pomponius sei ,als Grundlage des Bereicherungsrechts unzureichend“. ${ }^{238}$ Wilburg fährt fort: „Die Regel ist durchaus klar und findet in vielen Fällen praktische Anwendung. Aber sie enthält einerseits zu viel und andererseits zu wenig. Vor allem $z u$ viel. Niemand dürfe sich mit fremdem Schaden bereichern: In solch allgemeiner Weise ist das Vermögen nicht geschützt. " 239 Wie an dem zuletzt zitierten Diktum deutlich wird, ging es Wilburg - anknüpfend an die Vorarbeiten von Fritz Schul $z^{240}$ - vor allem auch um die Profilierung der Eingriffskondiktion als ein von den übrigen Kondiktionen zu unterscheidender Anspruchstyp.

Worin erblickte Wilburg nun den maßgebenden Unterschied zwischen Leistungs- und Eingriffskondiktion? Wie bei Heinrich Lehmann unterscheiden sich die beiden Kondiktionstypen auch nach Wilburg im Bereich des Rechtsgrunds. Anders als Lehmann greift Wilburg bei der Leistungskondiktion jedoch direkt auf das Kausalverhältnis durch, faßt die causa also objektiv und verzichtet insoweit auf die Kategorie der Zweckverfehlung. Bei der Eingriffskondiktion ist ein Kausalverhält-

235 Enneccerus-Lehmann (Fn. 232), § 219 I, S. 733 ff., § 219 II, S. 736 f.

236 Larenz (Fn. 59), S. 296.

237 Larenz (Fn. 59), S. 296.

238 Wilburg, Die Lehre von der ungerechtfertigten Bereicherung nach österreichischem und deutschem Recht, 1934; die Arbeit ist bei Ernst Rabel entstanden.

239 Wilburg (Fn. 238), S. 6.

240 Schulz, AcP 105 (1909), 1 bis 488. Die Vorstellungen von Schulz zum Bereicherungsrecht waren allerdings viel zu eigenwillig, um anschlußfähig sein zu können; vgl. aaO, S. $473 \mathrm{ff}$., mit der Forderung nach „Auflösung dieser ganzen Anspruchskategorie“. Ablehnend auch Wilburg (Fn. 238), S. $25 \mathrm{ff}$. 
nis mit einem Dritten hingegen kein Rechtsgrund zum Behaltendürfen. In funktionaler Hinsicht sieht Wilburg die Leistungskondiktion als „Leistungsrückgabeanspruch“, als ,,eine Art rechtsgeschäftlicher Anfechtung“, während die Eingriffskondiktion auf dem Gedanken der Rechtsfortwirkung beruhe. ${ }^{241}$ Aus diesen Prämissen zog Wilburg Konsequenzen für die Bestimmung der Parteien des Bereicherungsanspruchs: Das von der älteren Dogmatik entwickelte Kriterium der Unmittelbarkeit der Vermögensverschiebung wurde von Wilburg als Leerformel entlarvt und durch den Leistungsbegriff ersetzt. ${ }^{242}$ Danach steht der Bereicherungsanspruch ganz einfach dem Leistenden gegen den Leistungsempfänger zu, ohne Rücksicht darauf, ob unmittelbar oder mittelbar geleistet worden ist. ${ }^{243} \mathrm{Im}$ Ergebnis genauso liegt es nach Wilburg bei der Eingriffskondiktion; auch bei jener ist die Unmittelbarkeit der Vermögensverschiebung als Anspruchsvoraussetzung entbehrlich. ${ }^{244}$ Die Parteien der Eingriffskondiktion werden vielmehr bereits mit dem Eingriff fixiert: Der Inhaber des verletzten Rechtsguts ist im Rahmen von $\S 812$ Abs. 1 S. 1 Alt. 2 BGB aktivlegitimiert, der Verletzer, der das fremde Gut im eigenen Interesse verwendet hat, passivlegitimiert. ${ }^{245}$

In der Nachkriegszeit nahm von Caemmerer den Ansatz Wilburgs in einem Beitrag für die Festschrift Rabel wieder auf, ${ }^{246}$ der für die Diskussion der folgenden Jahrzehnte ebenso grundlegend werden sollte wie die Darstellung des Bereicherungsrechts auf dem Boden der Trennungslehre im Schuldrechts-Lehrbuch von Josef Esser die Studenten der fünfziger Jahre prägte. ${ }^{247}$ Auch von Caemmerer stellt weder die Bereicherungsformel des Pomponius ${ }^{248}$ noch die Eigenschaft des $\S 812$ BGB als Generalklausel in Frage, hält jedoch eine Konkretisierung für erforderlich, mit dem Ziel, , die Typen der Bereicherungsansprüche“ zu entwickeln. ${ }^{249}$ Dreh- und Angelpunkt der Unterscheidung ist sowohl bei von Caemmerer wie auch bei Esser der Rechtsgrund bzw. das Tatbestandsmerkmal der Rechtsgrundlosigkeit. ${ }^{250}$ Ein wirksamer schuldrechtlicher Vertrag tauge als Rechtsgrund nur im Kontext der Leistungskondiktion, nicht aber auch bei der Bereicherung in sonstiger Weise. ${ }^{251}$

Funktional sieht von Caemmerer die Leistungskondiktion als Annex des Vertragsrechts, und zwar auf einer Stufe mit dem Rücktrittsrecht und der - damals noch existierenden - Wandelung nach Lieferung einer mangelhaften Sache ( $\$ 462 \mathrm{ff}$., 634 BGB a. F.). ${ }^{252}$ Im Vergleich zu ausländischen Rechtsordnungen liege der große

\footnotetext{
241 Wilburg (Fn. 238), S. 49.

242 Siehe C. IV. 2.

243 Wilburg (Fn. 238), S. 113.

244 Wilburg (Fn. 238), S. 114.

245 Wilburg (Fn. 238), S. 114.

246 von Caemmerer, FS Rabel, Bd. I, 1954, S. $333 \mathrm{ff.}$

247 Esser, Schuldrecht, 1. Aufl. 1949, §§ 302ff., S. 432 ff.; 2. Aufl. (Fn. 18), §§ 189 ff., S. 775.

248 von Caemmerer (Fn. 246), S. 339: „Natürlich übt der Satz, daß sich niemand mit dem Schaden eines anderen bereichern dürfe, als allgemeines Prinzip ausgleichender Gerechtigkeit einen Zauber aus, wie er allen allgemeinen Sätzen eigen ist, in denen Prinzipien der Gerechtigkeit in letzter einfacher Form ausgesprochen sind.“

249 von Caemmerer (Fn. 246), S. 337, 340.

250 von Caemmerer (Fn. 246), S. 337, 340; Esser, Schuldrecht, 1. Aufl. (Fn. 247), S. 442 f.

251 von Caemmerer (Fn. 246), S. 337 f.; Esser (Fn. 247), S. 442 f.

252 von Caemmerer (Fn. 246), S. 342.
} 
technische Vorteil des BGB darin, daß es die mannigfachen Gründe für die Unwirksamkeit von Verträgen - vom mangelnden Zustandekommen, über die Anfechtung wegen Willensmängeln über Gesetzes- und Sittenwidrigkeit bis hin zu Rücktritt, Kündigung und einverständlicher Aufhebung - aus dem Bereicherungsrecht herausnehme und ein einheitliches Rückabwicklungsinstrument für sämtliche Unwirksamkeitsfälle zur Verfügung stelle - eben die Leistungskondiktion. ${ }^{253}$

Die Eingriffskondiktion wird demgegenüber in den Zusammenhang des Deliktsrechts und der Geschäftsanmaßung ( $\$ 687$ Abs. 2 BGB) gestellt, so daß sich eine Stufenfolge ergibt: Wer in fremde Rechte ohne Rechtfertigungsgrund eingreift, haftet stets auf Herausgabe der Bereicherung nach Maßgabe der $\$ \S 818$, 819 BGB; ist bei dem Eingriff die im Verkehr erforderliche Sorgfalt außer acht gelassen worden, ergibt sich darüber hinaus eine Schadensersatzpflicht aus $\$ \S 823$ Abs. 1, 249 BGB, und handelt es sich um einen vorsätzlichen Eingriff in fremde Rechte, ist der Täter gemäß $\S 687$ Abs. 2, 681 S. 1, 667 BGB sogar zur Herausgabe des erzielten Gewinns verpflichtet. ${ }^{254}$ Alle diese Ansprüche haben zur gemeinsamen Voraussetzung einen Eingriff in den Zuweisungsgehalt des Eigentums oder einer anderen dem Verletzten zustehenden Rechtsposition.

Die Trennungslehre setzte sich in der Folgezeit durch. Die Rechtsprechung vermied zwar - ihrer Aufgabe gemäß - eine umfassende Festlegung auf ein bestimmtes „System“, rezipierte jedoch den modernen Leistungsbegriff und damit das Herzstück der Trennungslehre. ${ }^{255}$ In der Literatur war Esser der erste und Larenz einer der letzten Lehrbuchautoren, der auf sie eingeschwenkt ist. ${ }^{256}$ Die 1968 erschienene neunte Auflage seines Lehrbuchs zum Besonderen Schuldrecht bewegt sich noch weitgehend in den Bahnen der Darstellung von Heinrich Lehmann aus der Vorkriegszeit. Bereicherung durch Leistung und Bereicherung in sonstiger Weise werden zwar voneinander geschieden, doch wird der maßgebliche Unterschied allein beim Merkmal der Rechtsgrundlosigkeit gesehen. ${ }^{257}$ In der zehnten Auflage aus dem Jahr 1972 heißt es hingegen unter Berufung auf Wilburg und von Caemmerer klipp und klar: „Die verschiedenen Funktionen, die das Bereicherungsrecht im heutigen System der Privatrechtsordnung erfüllt, lassen sich nicht auf eine Formel bringen. ... Daher hat die neuere Lehre und die Rechtsprechung differenziert. Sie erblickt in $\S 812$ Abs. 1 S. 1 nicht eine Anspruchsgrundlage, sondern zwei zu sondernde Anspruchsgrundlagen. Den Ansatz zu dieser Dif-

253 von Caemmerer (Fn. 246), S. 343.

254 von Caemmerer (Fn. 246), S. 352, 359, jeweils mit Hinweis auf die weitergehende Rechtsprechung zum Immaterialgüterrecht, die den Anspruch auf Gewinnherausgabe bereits bei fahrlässigen Eingriffen gewährt; grundlegend $R G Z$ 35, 63, $67 \mathrm{ff}$;; 43, 56, $58 \mathrm{ff}$.; 50, 111, 115.

${ }^{255}$ Vgl. BGHZ 40, 272, 277; 48, 70, 73; 50, 227, 230; 58, 184, 188; weitere Nachweise bei Reuter/Martinek (Fn. 220), § 2 IV, S. 34f.; Schlechtriem, JZ 1984, 509f.; 555 f.; JZ 1988, 854; JZ 1993, 24, 25.

256 Esser (Fn. 247), S. 432 ff.; Esser/Weyers, Schuldrecht II/2 (Fn. 51), § 47 3, S. 34 ff.; vgl. aus der Kommentarliteratur Erman-Westermann, Vor $\S 812$ Rn. 1; Palandt-Sprau (Fn. 56), Vor $\$ 812$ Rn. 1 f., § 812 Rn. 1; Staudinger-Lorenz, Bearb. 1999, § 812 Rn. 1 ff.; aus der Lehrbuch-Literatur Medicus (Fn. 23), Rn. 632; Brox-Walker (Fn. 23), § 36 Rn. 1; aus der Handbuch-Literatur Reuter/Martinek (Fn. 220), § 2 V, S. 38 und passim.

257 Larenz, Lehrbuch des Schuldrechts, Bd. II, Besonderer Teil, 9. Aufl. 1968, S. 364. 
ferenzierung findet sie in dem Wortlaut des Gesetzes selbst. Sie unterscheidet nämlich den Anspruch wegen ungerechtfertigten Erwerbs durch die Leistung eines anderen und den Anspruch wegen ungerechtfertigten Erwerbs, in sonstiger Weise und verlangt nur für letzteren, daß die Bereicherung ,,auf Kosten“ des Bereicherungsgläubigers erlangt worden ist. ${ }^{258} \mathrm{Im}$ Schuldrechts-Lehrbuch von Medicus wird diese Differenzierung auch graphisch sichtbar gemacht. ${ }^{259}$

\section{Moderne Einheitslehren}

Die Gegenbewegung gegen die Trennungslehre ließ nicht auf sich warten. Startschuß für ihre Infragestellung war das Jahr 1973. Damals trug Wilhelm den ersten ausführlich begründeten Angriff vor: Leistungskondiktion und Eingriffskondiktion seien ,,wesensgleiche Ansprüche wegen ungerechtfertigter Bereicherung aus fremdem Vermögen.“ Und weiter: „Sie sind Anwendungsfälle des Prinzips, daß die Vermögensmehrung, die der Schuldner aus dem Vermögen des Gläubigers hat, d.h. die nach den Rechten oder Rechtspositionen des Gläubigers in dessen Vermögen gehört, herauszugeben ist, wenn das Haben des Schuldners nicht durch ein Rechtsgeschäft oder unmittelbar durch eine Norm des objektiven Rechts gerechtfertigt ist. "260 In der Folgezeit hat die Einheitslehre wieder vermehrt Anhänger gefunden. Ganz im Sinne Wilhelms wirft Kupisch der Trennungslehre vor, sie habe den „spezifischen Bereicherungsgedanken“, also die Bereicherung des Schuldners aus dem Vermögen des Gläubigers ,,als selbständigen, obligationserzeugenden Grund aufgegeben“. ${ }^{261}$ Ganz ähnlich formuliert es auch Flume in der Festschrift zum 50-jährigen Bestehen des BGH. ${ }^{262}$ Aus dem Kreis der Kommentatoren hat sich Lieb für den Münchener Kommentar der „Gegenbewegung“ angeschlossen und festgestellt, es gebe ,nur einen Grundtatbestand [...], nämlich den des rechtsgrundlosen Erlangens auf Kosten eines anderen“. 263

Im Jahr 1973 erschien bei Beck auch die erste Festschrift für Larenz mit der groß angelegten Abhandlung von Canaris über den ,Bereicherungsausgleich im Dreipersonenverhältnis“, die in einer Forderung gipfelte, die zum geflügelten Wort werden sollte: „Abschied vom Leistungsbegriff“. ${ }^{264}$ So folgenreich diese Intervention auch gewesen ist, ${ }^{265}$ bleibt an dieser Stelle festzuhalten, daß es Canaris gerade nicht darum ging, die Trennungslehre zu überwinden und zur Einheitsbetrachtung zurückzukehren. Seiner Ansicht nach kann der Ausweg ,nicht in der Aufgabe der Lehre von der Leistungskondiktion liegen, sondern nur in ihrer folge-

${ }^{258}$ Larenz, Lehrbuch des Schuldrechts, Bd. II, Besonderer Teil, 10. Aufl. 1972, S. 403 (Hervorhebungen im Original).

259 Medicus (Fn. 23), Rn. 632.

260 Wilhelm, Rechtsverletzung und Vermögensentscheidung als Grundlagen und Grenzen des Anspruchs aus ungerechtfertigter Bereicherung, 1973, S. 173; vgl. auch ders., JuS 1973, 1.

${ }^{261}$ Kupisch, FS von Lübtow, 1980, 501, 511; vgl. auch ders., Gesetzespositivismus im Bereicherungsrecht, 1978, S. 62 ff. und passim; vgl. auch Pinger, AcP 179 (1979), 301, 312, 314.

262 Flume, FS 50 Jahre BGH Bd. I, 2000, S. 525, 535.

${ }^{263}$ MünchKommBGB-Lieb, Bd. 3, 2. Hbd., 1. Aufl. 1980, § 812 Rn. 7, insoweit unverändert auch in der 4. Aufl. 2004 (Fn. 273).

264 Canaris, FS Larenz, 1973, S. 799, 857.

265 Ausführlich unten, C. III. 4. 
richtigen Fortbildung“. ${ }^{266}$ Daran hat er auch in seinem Lehrbuch zum Besonderen Schuldrecht festgehalten. ${ }^{267}$ Die zentralen Argumente sind vertraut: Die Funktionen von Leistungs- und Eingriffskondiktion sind unterschiedlich, und der Rechtsgrund ist bei den beiden Typen auf je eigene Weise zu bestimmen. ${ }^{268}$

Mehr als das haben aber auch Wilburg und von Caemmerer nicht behauptet: Ausgangspunkt ihrer Lehre war die Einsicht, daß das Fehlen eines schuldrechtlichen Anspruchs, eines Kausalverhältnisses, im Bereich der Bereicherung ,in sonstiger Weise“ nicht ausreicht, um die Rechtsgrundlosigkeit zu begründen, bzw. mit der Rechtsgrundproblematik gar nichts zu tun hat. ${ }^{269}$ Der Differenzierungslehre ging es um Typenbildung innerhalb des allgemeinen Bereicherungsprinzips, nicht um dessen Ersetzung durch eine pluralistische, zwischen mehreren verschiedenen und völlig selbständigen Anspruchsarten unterscheidende Dogmatik. ${ }^{270}$ Ein solcher Ansatz entspricht voll und ganz der gesetzlichen Regelung, die durch die Binnendifferenzierungen des $\S 812$ BGB und durch etliche Sondervorschriften speziell für die Leistungskondiktion gekennzeichnet ist ( $\$ 813$ bis 815,817 BGB).

Allerdings hat besonders von Caemmerer - anders als Esser ${ }^{271}$ - die Leistungskondiktion eng an das Vertragsrecht gerückt und als funktionales Äquivalent zu Rücktritt und Wandelung profiliert, doch dies ist entgegen Flume kein Nachteil, sondern ein Vorzug. ${ }^{272}$ Wie noch zu zeigen sein wird, lassen sich nämlich weder die Dreiecksbeziehungen noch der Haftungsumfang bei der Leistungskondiktion ohne Rückgriff auf zentrale Wertungen des Vertragsrechts - Relativität des Schuldverhältnisses, synallagmatische Verknüpfung der wechselseitigen Ansprüche - in den Griff bekommen, während umgekehrt die Eingriffskondiktion auf die Wertungen des Deliktsrechts - Schutz absoluter Rechte, kein umfassender Vermögensschutz Rücksicht nehmen muß. Diese Zusammenhänge auf den Punkt gebracht zu haben, ist das bleibende Verdienst von Caemmerers. Insgesamt drängt sich somit der Eindruck auf, als hätten sich die neuen Einheitslehren selbst einen Popanz aufgebaut, um ihn anschließend denunzieren zu können. Er wird verstärkt, wenn die Kritiker ihre eigenen Darstellungen ebenfalls anhand des Schemas Leistungs-/ Nichtleistungskondiktion aufbauen, ${ }^{273}$ wie es die Kommentarliteratur seit Inkrafttreten des BGB stets getan hat. ${ }^{274}$

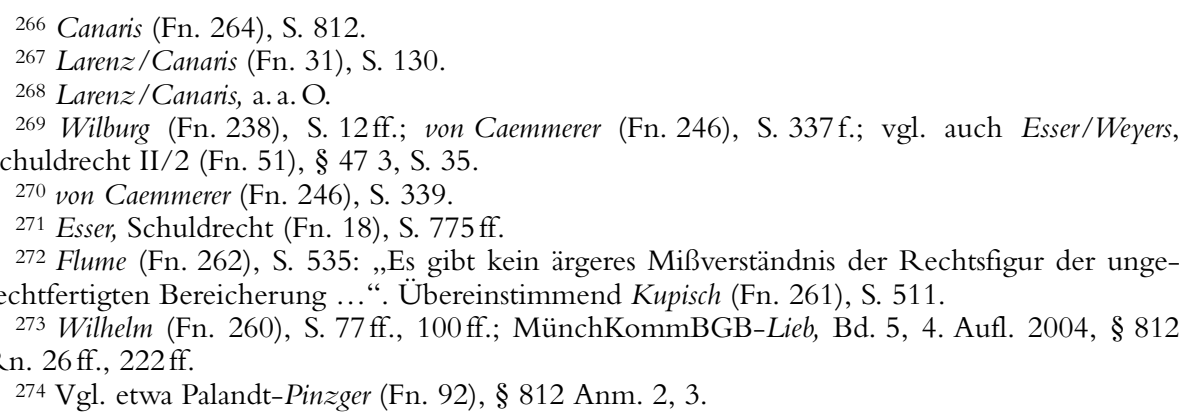




\section{Streit um den Leistungsbegriff}

\section{Unmittelbarkeit der Vermögensverschiebung}

Dem Streit um Einheits- oder Trennungslehren des Bereicherungsrechts sowie um die Leistungsfähigkeit des Leistungsbegriffs liegt eine zentrale Meinungsverschiedenheit darüber zugrunde, auf welche Weise bei Mehrpersonenverhältnissen die Parteien des Bereicherungsanspruchs zu bestimmen sind. Bis nach dem Zweiten Weltkrieg war die Auffassung herrschend, die Fixierung der Parteien des Bereicherungsanspruchs sei mit Hilfe des Merkmals ,auf dessen Kosten“ vorzunehmen. Beispielhaft ist die Behandlung der Problematik im Lehrbuch von EnneccerusLehmann aus dem Jahr 1932: Die Bereicherung müsse „,auf Kosten eines anderen“ erlangt sein, und zwar entweder durch Leistung oder in sonstiger Weise. ${ }^{275}$ Auch die Leistungskondiktion enthält somit dieses Merkmal, und es wird definiert als „Vermögensverschiebung, die sich unmittelbar zwischen den Parteien des Bereicherungsanspruchs vollzogen haben muß““. ${ }^{276}$ Das klingt einfach und klar, ist es aber dann nicht, wenn die Vermögensverschiebung ,,über das Vermögen“ eines Dritten erfolgt. Ein einfaches Beispiel ist der Fall der Durchlieferung: Der Käufer eines Grundstücks übereignet dies an einen Zweitkäufer, an den das Grundstück aufgelassen und der als Rechtsnachfolger des Verkäufers ins Grundbuch eingetragen wird. Erweist sich jetzt der erste Kaufvertrag als unwirksam, sollte der Verkäufer nur von dem Erstkäufer, seinem Vertragspartner, kondizieren dürfen, nicht aber von dem Zweitkäufer. Die bis zum Zweiten Weltkrieg herrschende Lehre erreichte dies über die Figur der ,unmittelbaren Vermögensverschiebung durch mittelbare Zuwendung“. 277

\section{Moderner Leistungsbegriff}

Diese Formulierung lädt zur Kritik geradezu ein und macht verständlich, warum sich die moderne Lehre nach dem Zweiten Weltkrieg so schnell durchsetzen konnte, nachdem Wilburg 1934 die Grundlagen gelegt hatte. ${ }^{278}$ Die Aufgabe, die Parteien des Ausgleichsverhältnisses zu bestimmen, übernimmt bei Wilburg der Leistungsbegriff selbst: „Wer Leistungsempfänger ist, ergibt sich aus dem Inhalt und aus dem Zweck der Leistung. Ein Streit um die Unmittelbarkeit hat hier keinen Sinn. Man kann einem anderen ebenso mittelbar als unmittelbar leisten; die Unterscheidung ist vollkommen bedeutungslos. " 279 Von Caemmerer hat diesen Ansatz nach 1945 aufgenommen, ${ }^{280}$ ohne der Konturierung des Leistungsbegriffs besondere Aufmerksamkeit zu schenken. Sein Ausgangspunkt ist die Feststellung, daß

275 Enneccerus-Lehmann (Fn. 232), § 218 II, S. 726.

276 Enneccerus-Lehmann (Fn. 232), § 218 III, S. 726.

277 Enneccerus-Lehmann (Fn. 232), § 218 III, S. 727.

278 Oben, C. III. 2, mit Fn. 243.

279 Wilburg (Fn. 238), S. 113.

280 Besonders deutlich von Caemmerer, JZ 1962, 385: „Das [...] Erfordernis der Unmittelbarkeit der Bereicherung besagt bei der Leistungskondiktion, daß der Anspruch dem Leistenden zusteht und daß er sich nur gegen den Leistungsempfänger richtet". 
bei der Leistungskondiktion der Empfänger ,,ganz formal gesehen deshalb ungerechtfertigt bereichert [ist], weil das Schuldgeschäft und damit die zu tilgende Forderung nicht bestand“". ${ }^{281}$ Doch auf welches Kausalverhältnis ist die Leistung zu beziehen? Von Caemmerer beantwortet die Frage nicht durch Deduktion aus einem Leistungs-,,Begriff“, sondern mit Hilfe eines ganzen Bündels von Gesichtspunkten, mit denen die ,Zurechnung von Leistungen“ zu dem einen oder dem anderen Kausalverhältnis begründet wird. ${ }^{282}$

\section{Kritik der Einheitstheoretiker}

Mit der Trennungslehre im allgemeinen kam auch der ,,moderne Leistungsbegriff" in den siebziger Jahren des 20. Jahrhunderts unter Beschuß. Die Kritiker sind die Anhänger der Einheitslehre, und sie möchten die Einheit des Bereicherungsrechts dadurch wahren, daß die Parteien des Ausgleichsanspruchs auch bei der Leistungskondiktion mit Hilfe des Merkmals ,auf dessen Kosten“ bestimmt werden. In seiner bereits erwähnten Arbeit aus dem Jahr 1973 setzte Wilhelm das Kriterium der unmittelbaren Vermögensverschiebung wieder in seine angestammte Funktion ein: „Leistung“ im Sinne des $§ 812$ BGB bedeute ganz einfach die Mehrung des Schuldnervermögens aus dem Vermögen des Gläubigers. „Auf diese Festlegung kommt es rechtlich an; daß die Vermögensverschiebung, wenn sie als Leistung willentlich erfolgt, zweckbestimmt ist, ist so selbstverständlich, daß es einer begrifflichen Hervorhebung der Zweckbestimmung im Leistungsbegriff nicht bedarf. ${ }^{283}$ (Auch) die Leistungskondiktion steht dem Gläubiger folglich, ,nicht deshalb zu, weil er die Vermögensmehrung des Schuldners zweckbestimmt verursacht hat, sondern weil der Schuldner aus seinem Vermögen bereichert ist." ${ }^{284}$ Entscheidend ist die Vermögensverschiebung, nicht der Leistungsbegriff. Im Münchener Kommentar zum BGB bekundete Lieb große Sympathie mit der Kritik des Leistungsbegriffs, den er als „Irrweg“ bezeichnete. ${ }^{285}$

\section{Kritik von Canaris}

Bereits die Anhänger der Einheitslehre hatten den Proponenten des modernen Leistungsbegriffs „Begriffsjurisprudenz“ vorgeworfen. ${ }^{286}$ Diese Kritik wird von Canaris in seiner bereits erwähnten Arbeit für die Festschrift Larenz aufgenommen. Die Anhänger des modernen Leistungsbegriffs seien unfähig zu erklären, warum der Angewiesene normalerweise auf die Kondiktion beim Anweisenden beschränkt sei, während bei Fehlen einer zurechenbaren Anweisung eine Direktkondiktion des Angewiesenen bei dem Leistungsempfänger stattfinde. Die Frage, an

281 von Caemmerer (Fn. 246), S. 343.

282 von Caemmerer, JZ 1962, 385, 386.

283 Wilhelm (Fn. 260), S. 103.

284 Wilhelm (Fn. 260), S. 104; vgl. auch S. 173; im wesentlichen genauso Kupisch (Fn. 261), S. $511 \mathrm{f}$.

285 MünchKommBGB-Lieb, 1. Aufl. (Fn. 263), § 812 Rn. 25 ff., 4. Aufl. (Fn. 273), § 812 Rn. $31 \mathrm{ff}$.

286 Wilhelm (Fn. 260), S. 111, 132. 
welche Partei der Angewiesene eine Leistung erbringe - an den Anweisenden oder an den Leistungsempfänger - könne nicht unterschiedlich beantwortet werden, je nach dem, ob die Anweisung wirksam ist oder nicht. Alles andere sei ,eine willkürliche Begriffsmanipulation“.287

Wenn die Abhandlung von Canaris maßgeblichen Einfluß auf die heutige Dogmatik des Bereicherungsrechts gewonnen hat, dann deshalb, weil Canaris nicht bei seiner Kritik stehen geblieben ist, sondern die moderne Lehre von der Leistungskondiktion nicht verabschiedet, sondern fortentwickelt hat. ${ }^{288}$ Statt ,konstruktiver Tricks“ bedürfe es einer „offenen Rechtsfortbildung“. ${ }^{289}$ Seine weiteren Überlegungen widmet er der Herausarbeitung der dafür erforderlichen Wertungsgrundlagen und erblickt sie in den Gedanken des Einwendungsausschlusses, der Risikoverteilung, der Zurechnung, im Abstraktionsprinzip und im Verkehrs- und Vertrauensschutz. ${ }^{290}$ Diese abstrakten Gesichtspunkte werden zu konkreten Maximen verdichtet, die sich heute in dieser oder anderer Form in jedem anständigen Lehrbuch zum Schuldrecht finden: ${ }^{291}$

(1) Erhalt der Einwendungen aus dem fehlerhaften Kausalverhältnis für beide Parteien. Schutz der Parteien des fehlerhaften Kausalverhältnisses vor Einwendungen aus Drittverhältnissen.

(2) Allokation der wechselseitigen Insolvenzrisiken zu den Parteien des jeweiligen Kausalverhältnisses, die einander schließlich ausgesucht haben. Schutz jeder Partei vor dem Risiko der Insolvenz eines Bereicherungsschuldners, den sie sich nicht ausgesucht hat.

(3) Sachgerechte Zuweisung der Parteirollen in einem eventuellen Rechtsstreit an diejenigen Personen, die Parteien des fehlerhaften Kausalverhältnisses sind. ${ }^{292}$

Welche Rückwirkungen hat die Einführung dieser Wertungskriterien auf den Leistungsbegriff? In seiner Abhandlung in der Festschrift für Larenz hatte Canaris, wie bereits erwähnt, den „Abschied vom Leistungsbegriff“" gefordert. ${ }^{293}$ Auch in seinem von Larenz übernommenen Lehrbuch hält Canaris an der Auffassung fest, der Leistungsbegriff sei ,als dogmatisches Zentralkriterium ungeeignet“, ${ }^{294}$ doch dieses harsche Urteil wird anschließend abgeschwächt. Die Rolle eines ,dogmatischen Kürzels" könne der Leistungsbegriff durchaus wahrnehmen; entscheidend blieben jedoch die oben genannten Wertungen. Wie bereits deren Formulierung zeigt, spielt bei allen drei Wertungskriterien das Kausalverhältnis eine zentrale Rolle. Tatsächlich formuliert Canaris drei Hauptentscheidungsregeln, aus denen sich ergibt, daß der Bereicherungsausgleich grundsätzlich zwischen den Parteien des fehlerhaften Kausalverhältnisses durchzuführen ist, wenn nicht ein sogenannter

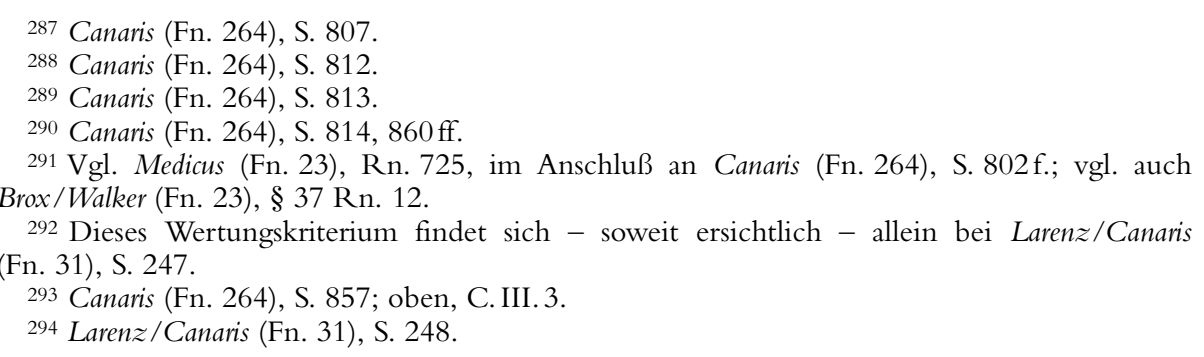


Zurechenbarkeitsmangel vorliegt, also die Anweisung fehlerhaft ist; dann kommt es zur Direktkondiktion. ${ }^{295}$

\section{Leistungsbegriff bei Reuter/Martinek}

Im Jahre 1983 bot sich dem Beobachter der Meinungsstand zum Leistungsbegriff wie folgt dar: Die herrschende Lehre bestimmte die Parteien der Leistungskondiktion mit Hilfe des Leistungsbegriffs. Für diesen hatte Kötter, etwa zeitgleich mit der grundlegenden Abhandlung von Caemmerers, die bis heute in Rechtsprechung und Literatur gültige Formel geprägt, nach der Leistung die zweckgerichtete Mehrung fremden Vermögens ist. ${ }^{296}$ Für die Einheitstheoretiker war der Leistungsbegriff irrelevant, weil nach ihrer Auffassung die Parteien des Rückabwicklungsverhältnisses mit Hilfe des Kriteriums der (unmittelbaren) Vermögensverschiebung zu fixieren sind. Canaris hingegen hatte vorgeschlagen, die Lehre von der Leistungskondiktion durch Rückgriff auf das dem Vertragsrecht zugrundeliegende Grundprinzip der Relativität der Schuldverhältnisse fortzuentwickeln.

In diesen Diskussionstand hinein erschien 1983 das großangelegte Handbuch zum Bereicherungsrecht von Reuter/Martinek. Die Autoren stellten sich auf den Boden der Trennungslehre und unternahmen den Versuch, den Leistungsbegriff dogmatisch scharf zu fassen und mit seiner Hilfe insbesondere die problematischen Dreipersonenverhältnisse in den Griff zu bekommen. ${ }^{297}$ Kernelement des Leistungsbegriffs im Sinne von Reuter/Martinek ist die Tilgungsbestimmung, die als zugangsbedürftige Willenserklärung konzipiert wird. ${ }^{298}$ Dieser Ansatz macht in Dreipersonenverhältnissen komplizierte Konstruktionen erforderlich, weil die Begründung eines Bereicherungsanspruchs aus Leistungskondiktion davon abhängig wird, daß sich der Zugang der rechtsgeschäftlichen Tilgungsbestimmung des Gläubigers beim Schuldner nachweisen läßt. ${ }^{299}$

Die Reaktionen auf das Werk waren gespalten: Die Kritiker des Leistungsbegriffs sahen sich in ihrer Befürchtung bestätigt, unter dem Deckmantel der Leistungskondiktion werde Begriffsjurisprudenz betrieben. ${ }^{300}$ Aber auch die Reaktion der „Freiburger Schule“ in der Tradition von Caemmerers fiel skeptisch aus: Die Bewältigung der Dreipersonenverhältnisse mit Hilfe des dogmatisch im Sinne einer Willenserklärung profilierten Konzepts der Tilgungsbestimmung sei ,höchst diffizil und - vor allem - riskant, weil durch Konfrontation mit unerwarteten Fallkonstellationen und -konsequenzen gefährdet. Zuweilen werden die Ergebnisse selbst als befremdlich [...] gesehen [... ““. ${ }^{301}$ Dementsprechend hat König nicht die

295 Larenz/Canaris (Fn. 31), S. 250f.; die dritte Entscheidungsregel betrifft die Konkurrenz von Leistungs- und Eingriffskondiktion, auf die hier nicht näher eingegangen wird.

296 Kötter, AcP 153 (1954), 193; der BGH bedient sich dieser Formel in ständiger Rechtsprechung, vgl. oben Fn. 255; aus der Literatur vgl. Esser, Schuldrecht (Fn. 18), S. 779; Medicus (Fn. 23), Rn. 634; Brox/Walker (Fn. 23), § 37 Rn. 6.

297 Reuter/Martinek (Fn. 220), § 4 II, S. $80 \mathrm{ff} ., \S \S 10-13$, S. $387 \mathrm{ff}$.

298 Reuter/Martinek (Fn. 220), § 4 II, S. $99 \mathrm{ff}$.

299 Vgl. dazu unten, C. IV. 6 b) dd).

300 Lieb, AcP 186 (1986), $518 \mathrm{ff}$.

301 Schlechtriem, Besprechung des Buchs von Reuter/Martinek in: ZHR 149 (1985), 327, 339. 
konstruktiven Anstrengungen von Reuter/Martinek, wohl aber die von Canaris erarbeiteten Wertungskriterien umstandslos in sein eigenes Konzept des Bereicherungsrechts übernommen. ${ }^{302}$

\section{Zum heutigen Stand der Lehre von der Leistungskondiktion}

Niemand wird bestreiten, daß die intellektuellen Investitionen in die dogmatische Profilierung der Leistungskondiktion im vergangenen Jahrhundert denkbar hoch gewesen sind. Welchen Ertrag haben diese Anstrengungen gebracht?

\section{a) Zweipersonenbeziehungen}

Wird die Analyse auf Zweipersonenverhältnisse beschränkt, so erscheint der Leistungsbegriff in der Tat unverzichtbar. Soweit ersichtlich, wird von niemandem bestritten, daß es der Schuldner in der Hand hat, bei der Erbringung der Leistung selbst zu bestimmen, auf welches Kausalverhältnis er seine Leistung ,,angerechnet“ haben will. In der Tat steht in $§ 366$ Abs. 1 BGB klipp und klar, bei mehrfacher Verpflichtung des Schuldners werde diejenige Schuld getilgt, die der Schuldner „,bei der Leistung bestimmt“ habe. Dementsprechend hält auch Wilhelm den finalen Leistungsbegriff für zutreffend, und zwar gerade auch im Bereicherungsrecht; der „Zusammenhang zwischen Leistung, Leistungszweck und Rückforderbarkeit der Leistung" sei schon im Ersten Entwurf mit Recht anerkannt gewesen. ${ }^{303}$ Der Streit um den „,modernen Leistungsbegriff“ betrifft eben gar nicht den Leistungsbegriff als solchen, der im übrigen auch gar nicht besonders „,modern“ ist, sondern allein seine Funktionalisierung für die Festlegung der Parteien der Leistungskondiktion bei Mehrpersonenverhältnissen: Wogegen Wilhelm sich wendet, ist allein die Mobilisierung des Leistungsbegriffs bzw. der Zweckbestimmung für die Fixierung von Gläubiger und Schuldner der Leistungskondiktion - und nicht bloß für die Feststellung der Rechtsgrundlosigkeit. ${ }^{304}$

\section{b) Mehrpersonenverhältnisse}

aa) Das Mehrpersonenverhältnis ist nicht nur „,cause celèbre“ des Bereicherungsrechts, sondern vor allem auch der funktionale Bezugspunkt des Leistungsbegriffs; hier liegen diejenigen Probleme, ,zu deren Lösung der Leistungsbegriff an sich entwickelt wurde“". ${ }^{305}$ Hat die jahrzehntelange Diskussion hier irgend etwas gebracht außer Verwirrung? Immerhin hat Horst Heinrich Jakobs in der NJW sein lesenswertes Plädoyer für „Die Rückkehr der Praxis zur Regelanwendung“ gegen zwei Besprechungen einer BGH-Entscheidung aus den Federn von Martinek und Canaris gerichtet und mit der Mitteilung des Gerüchts eröffnet, das Landesjustiz-

302 König, Ungerechtfertigte Bereicherung, 1985, S. 181; übereinstimmend Schlechtriem, Schuldrecht Besonderer Teil, 6. Aufl. 2003, Rn. 770; genauso auch Medicus (Fn. 23), Rn. 724 f.

303 Wilhelm (Fn. 260), S. 102.

304 Wilhelm (Fn. 260), S. 103.

305 MünchKommBGB-Lieb (Fn. 273), § 812 Rn. 29; Reuter/Martinek (Fn. 220), § 4 II 5 , S. 111 . 
prüfungsamt in Nordrhein-Westfalen stelle keine Prüfungsaufgaben aus dem Gebiet der bereicherungsrechtlichen Dreiecksverhältnisse. Die Rechtslage sei ,,derart regellos und darum schwierig geworden, daß auch überdurchschnittlich befähigte Kandidaten in ihr eine zensierbare Leistung zu erbringen nicht imstande seien“.306 Am Ende des Beitrags steht daher der Seufzer: „Wer kann dafür sorgen, daß in dieser Materie sich Professoren keine Aufgaben mehr stellen?"“307 Die solcherart Angegriffenen äußerten daraufhin die Sorge, Jakobs habe die „Haare in der Suppe" mitgegessen, ${ }^{308}$ und vermuteten Überforderung. ${ }^{309}$ So hat die Problematik des Bereicherungsausgleichs im Dreipersonenverhältnis dem Publikum eine der heutzutage selten gewordenen Szenen offener polemischer Auseinandersetzung beschert.

bb) Gleichwohl soll der Versuchung nicht widerstanden werden, dem Streitpunkt auf die Spur zu kommen, also zu überprüfen, ob denn die jahrzehntelange Debatte über den Leistungsbegriff nun einen Fortschritt gebracht hat oder nicht. Als Beispiel soll ein denkbar einfacher Fall dienen, nämlich die Anweisung, etwa in Gestalt einer Giroüberweisung. Der Anweisende A erteilt seiner Bank B die Weisung, einen bestimmten Geldbetrag an $\mathrm{C}$ zu überweisen. Wir wollen annehmen, daß A dies tut, um eine Kaufpreisforderung zu tilgen, die $\mathrm{C}$ wegen der Lieferung eines Kühlschranks gegen ihn hat. Die Bank führt den Auftrag aus und belastet das Konto des A. Stellt sich nun heraus, daß der Kaufvertrag zwischen A und $\mathrm{C}$ unwirksam ist, stellt sich die Frage, ob A von $\mathrm{C}$ kondizieren kann. Prima facie möchte man meinen, dies sei nicht der Fall: Stellt man naiv darauf ab, wer an wen eine Leistung erbracht hat, scheint es so, als habe B an C ,geleistet“. Daran ändert sich vorderhand auch nichts, wenn man mit den Einheitstheoretikern auf die ,unmittelbare Vermögensverschiebung“ abstellt, denn die hat offenbar zwischen B und C stattgefunden. Nach einhelliger Auffassung kann A jedoch bei C kondizieren, nicht jedoch die Bank den gezahlten Betrag zurückfordern. Dies kann sie im übrigen auch dann nicht, wenn sie nach Ausführung des Überweisungsauftrags feststellt, daß sie auf dem Konto des A keine Deckung findet. Um die Wende des 19. zum 20. Jahrhundert ist das $R G$ mit Bereicherungsklagen des Postfiskus beschäftigt worden, der jeweils per Postanweisung von einem untreuen Postbeamten zur Bezahlung von dessen Privatschulden veranlaßt worden war und nun die gezahlten Beträge von ihren Empfängern zurückforderte. Das $R G$ hat die Klagen abgewiesen, und zwar einerlei, ob sie auf das gemeine Recht oder das BGB gestützt wurden. ${ }^{310}$ Der Post bzw. der Bank sei der Empfänger ebenso gleichgültig wie das Valutaverhältnis zwischen dem Empfänger und dem Anweisenden; sie interessiere allein das Deckungsverhältnis. In diesem Deckungsverhältnis zum Kontoinhaber sei auch der Bereicherungsausgleich durchzuführen.

306 Jakobs, NJW 1992, 2524, zu Martinek, JZ 1991, 395 und Canaris, NJW 1992, 868; beide wiederum zu der Entscheidung BGHZ 113, 62 = NJW 1991, 919; zu dieser Entscheidung auch noch Flume, NJW 1991, 2521, 2523.

307 Jakobs, NJW 1992, 2524, 2529.

308 Martinek, NJW 1902, 3141, 3142.

309 Canaris, NJW 1992, 3143, 3145.

310 RG SeuffA 44 (1889), Nr. 257; RGZ 60, 24, 27 ff. 
cc) Von diesen Entscheidungen des $R G$ ist es nur ein winziger Schritt zum „,modernen“ Leistungsbegriff, wie ihn von Caemmerer verstanden hat. ${ }^{311} \mathrm{Nach}$ seiner Auffassung ,,verbietet sich jede schematisierende Lösung. Es ist vielmehr nach dem konkreten oder durchschnittlichen Willen der Parteien, nach den von ihnen verfolgten und zum Ausdruck kommenden Zwecken und der Lagerung ihrer Interessen zu prüfen, welches die sachgerechte Behandlung ist". ${ }^{312}$ Dabei ließen sich bestimmte Fallgruppen als „Grundtypen“ herausheben. Eine solche ist die Anweisung, die er wie folgt beurteilt: „Der Angewiesene setzt eine Kausalbeziehung nur dem Anweisenden gegenüber voraus. Die Leistung an den Begünstigten soll von ihr jedoch unabhängig sein. Zahlender und Zahlungsempfänger gehen davon aus, daß jeder von ihnen die Zahlung nur mit dem Anweisenden abzurechnen hat, daß also die Zahlung als Leistung des Anweisenden und als Leistung an diesen gelten soll. Um das Valutaverhältnis kümmert sich der Angewiesene grundsätzlich nicht. " ${ }^{313}$ Folgerichtig kann bei Mängeln des Deckungsverhältnisses der Angewiesene nur beim Anweisenden kondizieren, und bei Mängeln des Valutaverhältnisses vollzieht sich der Bereicherungsausgleich zwischen Anweisendem und Zahlungsempfänger.

dd) Gegenüber einer solchen Begründung kann sicher nicht der Vorwurf der „Begriffsjurisprudenz“ erhoben werden. ${ }^{314}$ Wenn überhaupt, trifft er den Standpunkt von Reuter/Martinek, die das allseits konsentierte Ergebnis - Kondiktion nur in den jeweiligen Kausalverhältnissen - damit begründen, die ,tatsächliche ,Leistung، “ im Verhältnis B/C werde ,im Wege der Empfangsermächtigung des C durch A nach $\S 362$ II, 185 BGB sowie der Tilgungs- und Zweckbestimmung des B gegenüber A nach $\S 366$ BGB analog zu einer rechtlichen Leistung B - A und im Wege der Tilgungs- und Zweckbestimmung des A gegenüber C nach $\$ \S 267$, 366 BGB analog zu einer rechtlichen Leistung A - C. “315 Reuter/Martinek sind sich der Gefahren ihres konstruktivistischen Ansatzes allerdings durchaus bewußt, meinen diese jedoch in Kauf nehmen zu müssen, um der Praxis einfache und klare Regeln an die Hand geben zu können, die sich ihrerseits an den Wertungen der Rechtsgeschäftslehre und des Erfüllungsrechts orientieren. Die so gewonnenen Regeln sollen sich dann auch gegenüber Wertungen durchsetzen, die von Caemmerer angedeutet und die Canaris ausgearbeitet hat: „Die Verteilung der Einwendungs- und Insolvenzrisiken ist prinzipiell nicht Aufgabe, sondern Folge der Regelung des Bereicherungsausgleichs. "316 Die Autoren fügen allerdings sofort hinzu: „Erst wenn und soweit hinsichtlich der Verteilung der Einwendungs- und Insolvenzrisiken ein Widerspruch zu gesetzlichen Wertungen droht, zwingt die Einheit

$311 \mathrm{Zu}$ dem von ihm verwandten Bündel von Entscheidungskriterien bereits oben C. III. 2; übereinstimmend König, Ungerechtfertigte Bereicherung, 1985, S. 181.

312 von Caemmerer, JZ 1962, 385, 386.

313 von Caemmerer, JZ 1962, 385, 386.

314 So aber, gegenüber dem „,modernen Leistungsbegriff“ allgemein Wilhelm (Fn. 260), S. 111, 132; ähnlich auch MünchKommBGB-Lieb (Fn. 273), § 812 Rn. 27; wie hier Esser/Weyers, Schuldrecht II/2 (Fn. 51), § 48 II, S. 44.

315 Reuter/Martinek (Fn. 220), § 11 II 1, S. 413; grundlegend zur Konstruktion der Erklärungen ,übers Eck“ Reuter/Martinek (Fn. 220), § 10 I 2, S. $388 \mathrm{ff}$.

316 Reuter/Martinek (Fn. 220), § 11 III, S. 426. 
der Rechtsordnung [...] zu einer entsprechenden Anpassung des Bereicherungsausgleichs." Umgekehrt verwendet Canaris in seinem Schuldrechtslehrbuch viel Mühe darauf, die mit Hilfe von Wertungen gewonnenen Ergebnisse konstruktiv zu untermauern, Entscheidungsregeln zu bestimmten Fallgruppen zu entwickeln und letztere wieder in drei „Hauptentscheidungsregeln“ zusammenzufassen. ${ }^{317}$

ee) Wilhelm als einer der schärfsten Kritiker des modernen Leistungsbegriffs hat nicht nur den Vorwurf der Begriffsjurisprudenz erhoben, sondern diesen auch dahin erweitert, es werde doktrinäres Begriffsdenken mit ,bloßer Billigkeitsentscheidung" kombiniert. ${ }^{318}$ Das trifft den Gegner sicherlich besser, doch müssen sich die Anhänger der Einheitslehre die Frage gefallen lassen, wie sie die Dreipersonenverhältnisse nach Art der Anweisungsfälle bewältigen wollen, ohne die eigenen Prämissen preiszugeben. - Nach Kupisch liegt tatsächlich eine Leistung der Bank an den Empfänger vor, doch der Bereicherungsausgleich soll sich gleichwohl zwischen der Bank und dem Anweisenden sowie zwischen diesem und dem Empfänger vollziehen. Erreicht wird dieses allseits konsentierte Ergebnis durch eine analoge Anwendung des $\S 812$ BGB! ${ }^{1319}$ Dazu hat Canaris mit Recht bemerkt: „Daß indessen eine Generalklausel (!) wie $§ 812$ BGB für einen so elementaren Fall wie den der Anweisung eine Lücke (!) enthält und also erst im Wege der Analogie anwendbar zu machen ist, erscheint methodologisch von vornherein unplausibel." ${ }^{2} 20$ Wilhelm hingegen leugnet eine Leistung des Angewiesenen an den Leistungsempfänger mit der Begründung, die Disposition des Anweisenden über den Leistungsgegenstand und die Befolgung dieser Disposition durch den Angewiesenen sei einem , dinglichen Durchgang durch das Vermögen des Anweisenden vermögensmäßig“ gleich zu erachten. ${ }^{321}$ Dagegen ist nichts einzuwenden außer dem Hinweis, daß sich das Kriterium der ,unmittelbaren Vermögensverschiebung“ offenbar genauso normativieren läßt wie der Leistungsbegriff.

ff) Damit zeigt sich: Die eigentliche Aufgabe besteht nicht in der Anwendung des „Begriffs“ der Leistung oder des Begriffs der Vermögensverschiebung, sondern in der normativ begründeten Zurechnung der Leistungen zu den einzelnen Akteuren. Ganz folgerichtig wird die Rechtsprechung nicht müde zu betonen, daß bei der Leistungskondiktion gar nichts aus Begriffen deduziert werden dürfe, denn es verbiete ,sich bei der bereicherungsrechtlichen Behandlung von Vorgängen, an denen mehr als zwei Personen beteiligt sind, jede schematische Lösung“. Vielmehr seien ,in erster Linie die Besonderheiten des einzelnen Falles für die sachgerechte bereicherungsrechtliche Abwicklung [...] zu beachten. " ${ }^{322}$ Blickt man auf ein Jahrhundert bereicherungsrechtliche Diskussion zurück, wird niemand leugnen wollen, daß über die wahren normativen Gründe für die Sachgerechtigkeit bereicherungsrechtlicher Entscheidungen heute wesentlich klarere Vorstellungen

317 Larenz/Canaris (Fn. 31), S. 199 ff.; zusammenfassend S. 246 ff.; zur Regelbildung im Bereicherungsrecht vgl. auch Canaris, NJW 1992, 3143, 3145.

318 Wilhelm (Fn. 220), S. 132.

${ }^{319}$ Kupisch, Gesetzespositivismus im Bereicherungsrecht, 1978, S. $19 \mathrm{ff}$.

320 Larenz/Canaris (Fn. 31), S. 251.

321 Wilhelm (Fn. 260), S. 116.

322 BGHZ 72, 246, 250; 82, 28, 30. 
bestehen als bei Inkrafttreten des BGB. Nachdem die maßgeblichen Wertungskriterien offen diskutiert sind, hat bei einigen Fallgruppen bereits ein Prozeß der „Redogmatisierung“ eingesetzt. Dieser vollzieht sich allerdings innerhalb des Leistungsbegriffs und nicht außerhalb. ${ }^{323}$ In der Tat ist der Leistungsbegriff als Rahmen für eine normativ fundierte Dogmatik der Dreiecksverhältnisse aus mehreren Gründen besser geeignet als die Kategorie der ,unmittelbaren Vermögensverschiebung": Der Leistungsbegriff kann die Wertungen des Vertragsrechts viel leichter aufnehmen, weil er eine dogmatische Verknüpfung zum Erfüllungsrecht und damit auch zu den Kausalverhältnissen herstellt, und weil der Leistungszweckbestimmung das Grundprinzip des Vertragsrechts eingeschrieben ist: die Privatautonomie. $^{324}$

\section{Umfang des Bereicherungsanspruchs und die Saldotheorie}

Der Streit um die dogmatischen Grundlagen des Bereicherungsrechts setzt sich fort, wenn es um die Bestimmung von Gegenstand und Umfang des Bereicherungsanspruchs geht.

\section{Gegenstand des Bereicherungsanspruchs}

Ein klassisches Thema des Bereicherungsrechts ist die Frage, ob sich der Herausgabeanspruch auf das „Erlangte“ oder auf die „Bereicherung“ richtet. Die Anhänger der gegenständlichen Betrachtungsweise beziehen den Bereicherungsanspruch auf das Erlangte, während die vermögensmäßige Betrachtungsweise den Bereicherungsanspruch von vornherein auf die Differenz zweier Vermögenslagen gerichtet sieht. $^{325}$

Nach Flume und seinen Schülern wird die „Bereicherung nach abstrakter Vermögensrechnung bemessen“. ${ }^{326}$ Auch die Leistungskondiktion sei ,von der Gegenständlichkeit des indebite-Erwerbs gelöst" zugunsten einer Orientierung am Vermögen des Empfängers. ${ }^{327}$ Wo es nicht zu einer Bereicherung gekommen sei, da könne gar kein Anspruch aus $§ 812$ BGB entstehen; der Anspruch falle nicht mit $§ 818$ Abs. 3 BGB weg, sondern er entstehe erst gar nicht. Für diese Auffassung sprechen die Materialien zum BGB, denn in den Motiven heißt es, bei der Prüfung der Bereicherung sei ,,in concreto auf die gesamte Vermögenslage des Empfängers Rücksicht zu nehmen“, ${ }^{328}$ und in den Protokollen wird aufgeführt: „Der Empfänger solle danach ohne Unterschied, ob ihm ein Verschulden zur Last falle oder nicht, frei werden, wenn er das Erlangte in solcher Art verloren habe,

\footnotetext{
323 Übereinstimmend Larenz/Canaris (Fn. 31), S. 248 f., 252f.; Schlechtriem, Schuldrecht Besonderer Teil (Fn. 302), Rn. 770; Medicus (Fn. 23), Rn. 724 f.

324 So schon von Caemmerer, FS Dölle (Fn. 21), S. 141: Leistungszweckbestimmung, als nicht wegzudenkender Teil der schuldrechtlichen Parteiautonomie“; übereinstimmend König, Ungerechtfertigte Bereicherung, 1985, S. 212.

325 Zum Streitstand und seiner Entwicklung vgl. Reuter/Martinek (Fn. 220), § 14 I, S. 516 ff.

326 Flume, FS Niedermair, 1953, S. 103, 148, 153 f.

327 Flume (Fn. 326), S. 153.

328 Mot. II (Fn. 4), S. 837.
} 
daß der Werth seinem Vermögen nicht zu Gute gekommen sei““.329 Die Umsteuerung der bereicherungsrechtlichen Dogmatik in Richtung Gegenstandsorientierung ist wiederum von Caemmerer zu danken. In der Festschrift für Rabel aus dem Jahr 1954 hat er lapidar festgestellt, die Bereicherungsansprüche des BGB gingen „,nicht primär auf, die Bereicherung“, sondern, wie die $\$ \S 818$ Abs. 1, 2, 819 und 820 BGB erweisen, auf das Erlangte oder seinen Wert“. Das sei , der normale Anspruchsinhalt“. ${ }^{330}$ Diese Auffassung hat Esser seiner Darstellung des Bereicherungsrechts ebenso zugrunde gelegt ${ }^{331}$ wie Larenz; ${ }^{332}$ sie ist heute ganz herrschend geworden. ${ }^{333}$ Nach Auffassung von Lieb entspricht sie am besten der Systematik des Gesetzes, das den Bereicherungsschuldner in $\S 812$ Abs. 1 ausdrücklich und primär zur Herausgabe des „Erlangten“ verpflichtet, die Wertersatzpflicht in $\S 818$ Abs. 2 BGB nur für den Fall der Unmöglichkeit der Herausgabe anordnet und diese dann in $\S 818$ Abs. 3 BGB durch den Entreicherungseinwand relativiert. ${ }^{334}$

Der Streit um Gegenstands- oder Vermögensorientierung des Bereicherungsanspruchs klingt sehr dogmatisch, und er scheint von geringer praktischer Bedeutung. Das Gegenteil hat der Flugreisefall bewiesen. ${ }^{335}$ - Ein Minderjähriger hatte sich ohne Flugschein an Bord einer Linienmaschine der Deutschen Lufthansa geschmuggelt und war mit dieser nach New York geflogen, wo er von der amerikanischen Grenzpolizei aufgegriffen und postwendend zurückgeschickt wurde. Die Lufthansa verlangte Ersatz der Kosten für den Hinflug. ${ }^{336}$ Der $B G H$ gelangte nur mit großer Mühe zu einem Bereicherungsanspruch, weil er von der Prämisse ausging, daß ,,von einer Bereicherung im Sinne der $\$ \S 812$ ff. BGB in der Regel nur gesprochen werden kann, wenn und soweit der Bereicherte eine echte Vermögensvermehrung und sei es allein durch die Ersparnis von Aufwendungen erfahren hat. "337 Es müsse dem ,,allgemein anerkannten obersten Grundsatz des Bereicherungsrechts immer Geltung verschafft werden [...], wonach die Herausgabepflicht des Bereicherten keinesfalls zu einer Verminderung seines Vermögens über den Betrag der wirklichen Bereicherung hinaus führen darf". ${ }^{338}$ Folgerichtig lehnt der Senat die gegenständliche Betrachtungsweise, nach der schlicht die von dem Minderjährigen erlangten Dienstleistungen als erlangtes Etwas anzusehen sind, so daß der Schuldner gemäß $§ 818$ Abs. 2 BGB zum Wertersatz verpflichtet ist, ausdrücklich ab. ${ }^{339}$ Vor dem Hintergrund dieser mit fast pathetischen Formulierungen begründeten Weichenstellung muß es überraschen, wenn der Senat eine Seite spä-

\footnotetext{
329 Prot. II, S. 706.

330 von Caemmerer (Fn. 246), S. 333, 368.

331 Esser, Schuldrecht (Fn. 18), S. 818.

332 Larenz, 5. Aufl. 1962 (Fn. 70), S. 346 f.; 12. Aufl. 1981 (Fn. 21), S. 576 f.

333 Vgl. Medicus (Fn. 23), Rn. 672 ff.; Esser/Weyers, Schuldrecht II/2 (Fn. 51), § 51 I 2, S. $97 \mathrm{f}$.

334 MünchKommBGB-Lieb (Fn. 273), § 812 Rn. 340.

335 BGHZ 55, $128 \mathrm{ff} .=\mathrm{JZ}$ 1971, 556 ff. mit Anm. Canaris.

336 Der Erstattungsanspruch wegen der Kosten des Rückflugs wurde auf Geschäftsführung ohne Auftrag gestützt; dazu BGH NJW 1971, 609, 612.

337 BGHZ 55, 128, 131.

338 BGHZ 55, 128, 131.

339 BGHZ 55, 128, 133.
} 
ter ausführt, die Fälle des Wegfalls und der (mangelnden) Entstehung der Bereicherung müßten gleich behandelt werden, mit der Folge, daß dem bösgläubigen Bereicherungsschuldner die Berufung darauf versagt wird, es sei eine Vermögensmehrung niemals eingetreten und ein Bereicherungsanspruch zu keinem Zeitpunkt entstanden. ${ }^{340}$ Im Ergebnis , gilt" der bösgläubige Empfänger einer Leistung also als bereichert, obwohl er es nach der vermögensbezogenen Betrachtung ,an sich" nicht ist.

Schon die bloße Schilderung des Lösungswegs des BGH macht verständlich, warum Lieb dem Gericht sofort in einem Beitrag für die NJW entgegengetreten ist. ${ }^{341}$ Nach seiner Auffassung ist die gegenständliche Betrachtungsweise nicht nur bei der Leistung von Sachen, also körperlichen Gegenständen, angemessen, sondern genauso auch bei Dienstleistungen. Da diese gegenständlich nicht herausgegeben werden können, ist gemäß $§ 818$ Abs. 2 BGB ihr Wert zu vergüten, und dabei bleibt es, wenn der Bereicherungsschuldner gemäß $§ 818$ Abs. 4, 819 BGB verschärft haftet und sich nicht auf den Wegfall der Bereicherung gemäß $\S 818$ Abs. 3 BGB berufen darf.

Die zuletzt gewählte - weithin übliche - Formulierung, der bösgläubige Bereicherungsschuldner dürfe sich nicht auf den Wegfall der Bereicherung berufen, täuscht ein wenig darüber hinweg, daß $§ 818$ Abs. 4 BGB auf die $§ \S 292,989$, 990 BGB verweist und damit eine verschuldensabhängige Schadensersatzhaftung anordnet, während es in Konstellationen nach Art des Flugreisefalls um eine vom Schadenseintritt auf seiten des Gläubigers unabhängige Wertersatzhaftung des bösgläubigen Bereicherungsschuldners geht. ${ }^{342}$ Diese Asymmetrie in Tatbestand und Rechtsfolge ist in jüngster Zeit von Canaris herausgearbeitet worden, ${ }^{343}$ der freilich auch gleich den Schlüssel für die Lösung mitgeliefert hat: In den Materialien zu $\S 818$ Abs. 3 BGB heißt es, der Eintritt der Rechtshängigkeit des Rückforderungsanspruchs sei die ,entscheidende Zeit für die Fixierung der Verpflichtung des gutgläubigen Empfängers in dem Sinne, daß hiermit die bezeichnete, von den allgemeinen Grundsätzen abweichende, bevorzugte Stellung des Empfängers aufhört". ${ }^{344}$ Eine entsprechende Erklärung findet sich auch in den Motiven zum heutigen $\S 819$ BGB. ${ }^{345}$ Warum aber hat der Gesetzgeber die Regel, daß die Berufung auf $\S 818$ Abs. 3 BGB ab Rechtshängigkeit des Bereicherungsanspruchs bzw. Bösgläubigkeit des Bereicherungsschuldners ausscheidet, nicht deutlicher ausgesprochen? - Die Antwort liegt vermutlich darin, daß die Gesetzesväter, und zumal die Verfasser des ersten Entwurfs, die Leistungskondiktion nach rechtsgrundloser Lieferung einer Sache vor Augen hatten. ${ }^{346}$ Legt man diesen Fall zugrunde, kann das Problem der Flugreise-Entscheidung gar nicht auftreten, denn wenn die Sache noch

\footnotetext{
340 BGHZ 55, 128, 135.

341 MünchKommBGB-Lieb (Fn. 273), § 812 Rn. 358 ff.; ders., NJW 1971, 1289, $1290 \mathrm{ff}$.

342 Zum hier nicht weiter verfolgten Problem des bösen Glaubens Minderjähriger Larenz/ Canaris (Fn. 31), S. 312 ff.; MünchKommBGB-Lieb (Fn. 273), § 819 Rn. 7.

343 Larenz / Canaris (Fn. 31), S. 319 f.

344 Mot. II (Fn. 4), S. 838; aus der Rechtsprechung: BGHZ 72, 252, 256 f.

345 Mot. II (Fn. 4), S. 841.

346 Vgl. Mot. II (Fn. 4), S. $836 \mathrm{ff}$.
} 
unversehrt existiert, ist sie samt der Nutzungen zurückzugeben $(\S \S 812,818$ Abs. 1 BGB), und wenn sie beschädigt oder zerstört wurde, haftet der bösgläubige oder verklagte Bereicherungsschuldner auf Schadensersatz ( $\$ 819,818$ Abs. 4, 282, 989, 990 BGB). Zu einer ,,bereicherungs- und schadensunabhängigen Wertersatzhaftung “ ${ }^{\text {‘47 }}$ kann es also nur bei Dienstleistungen bzw. sonstigen unkörperlichen Vermögensgegenständen kommen, und auf diese Konstellation sind die Wertungen der zitierten Vorschriften zu übertragen: Der bösgläubige oder verklagte Bereicherungsschuldner haftet auf Wertersatz, ohne daß es auf den Eintritt eines kongruenten Schadens auf seiten des Bereicherungsgläubigers ankommt. Der Entwicklung eines eigenständigen Kondiktionstyps bedarf es dafür nicht. ${ }^{348}$

\section{Saldotheorie}

\section{a) Zweikondiktionen-vs. Saldolehre}

Die Alternative aus Gegenstands- und Vermögensbezug der Bereicherungshaftung liefert die Grundlage für Aufstieg und Niedergang einer weiteren Rechtsfigur, die die bereicherungsrechtliche Diskussion im 20. Jahrhundert beherrscht hat, nämlich die sogenannte „Saldotheorie“. Der Stand der Dogmatik vor Beginn des Zweiten Weltkriegs wird im „Palandt“ aus dem Jahr 1939 prägnant zusammengefaßt: „Nach der Zweikondiktionen-Lehre hat jeder Vertragsteil [einen] selbständigen Anspruch auf Herausgabe des Empfangenen oder [des] Wertes. [Ein] Ausgleich wäre nur durch Aufrechnung oder Zurückbehaltungsrecht möglich [...]. Nach herrschender Saldo-Lehre besteht auch in diesem Falle nur ein Anspruch, der Ausgleichsanspruch, der auf Herausgabe des Überschusses der Aktiv- über die Passivposten gerichtet ist. Der Bereicherungsanspruch steht also nur einem Teil zu. Bei Errechnung des Saldos ist als Abzugsposten auch die Gegenleistung zu berücksichtigen. [...]. [Der] Unterschied der beiden Lehren wird praktisch, wenn [die] Gegenleistung untergegangen ist. "349

$\mathrm{Zu}$ dem Streit um Zweikondiktionen- und Saldotheorie konnte es nur kommen, weil das Gesetz selbst ambivalent ist. In $\S 812$ Abs. 1 S. 1 BGB wird der Bereicherungsanspruch auf Herausgabe des ,,erlangten Etwas“ - also auf einen Gegenstand - gerichtet, während $\S 818$ Abs. 3 BGB eine Vermögensbetrachtung erfordert. In den Motiven zum späteren $\S 818$ Abs. 3 BGB ( $\$ 739$ Abs. 2 Erster Entwurf) heißt es einerseits, daß ,,bei der Prüfung, ob und in welchem Umfange eine solche [Bereicherung] vorhanden ist, in concreto auf die gesamte Vermögenslage des Empfängers Rücksicht zu nehmen ist",,350 andererseits steht wenig später zu lesen: „Der Anspruch auf Herausgabe oder Wertvergütung kann auch im Wege der Kompensation gegen eine Forderung des Empfängers geltend gemacht werden. Hier entsteht die Frage, welcher Zeitpunkt für die Begrenzung der Befugnis

347 Larenz/Canaris (Fn. 31), S. 319.

348 Anders Larenz/Canaris (Fn. 31), S. 320: „Quasi-Vertragskondiktion“; wie hier MünchKommBGB-Lieb (Fn. 273), § 812 Rn. 129, $156 \mathrm{f}$.

349 Palandt-Pinzger (Fn. 92) § 818 Anm. 6 C; vgl. auch Enneccerus-Lehmann (Fn. 232), § 224 II, S. $753 \mathrm{f}$.

${ }^{350}$ Mot. II (Fn. 4), S. 837. 
des Empfängers der Nichtschuld, sich auf den Wegfall oder die Minderung der Bereicherung zu berufen, maßgebend ist. Diese Frage ist nicht durch das Gesetz zu lösen. “351 Die Kompensationsbefugnis wäre sinnlos, wenn von vornherein nur ein einziger, auf den Saldo gerichteter Bereicherungsanspruch bestünde.

\section{b) Entwicklung der Saldotheorie in der Rechtsprechung des $R G$}

Tatsächlich hat das RG bereits im Jahre 1903 unter Berufung auf seine Judikatur unter dem Gemeinen Recht ${ }^{352}$ den Wortlaut des $\S 812$ BGB, der einen Anspruch auf Herausgabe des ,Erlangten“ gibt, zur Seite geräumt und eine vermögensbezogene Betrachtung an dessen Stelle gesetzt. Unter dem nach $\S 812$ BGB herauszugebenden ,etwas“ dürfe ,nicht etwa ein beliebiger einzelner aus dem Vermögen des Einen in das des Anderen hinübergeflossener Wert, sondern nur die Gesamtheit des Hinübergelangten unter gleichzeitiger Berücksichtigung der dafür gegebenen Werte und der auf dem Empfangenen ruhenden Lasten verstanden werden“..353 Mit der Erklärung der Aufrechnung oder der Geltendmachung eines Zurückbehaltungsrechts habe dies nichts zu tun; die Gegenansprüche des Bereicherungsschuldners bildeten ,nur unselbständige Glieder bei Feststellung des wiederherzustellenden früheren Zustands der dem Beklagten grundlos zugeflossenen Bereicherung“. ${ }^{354} \mathrm{Im}$ Ergebnis sah das $R G$ den Bereicherungsanspruch als einen quasi-Abrechnungsanspruch, der das „Gesamtergebnis dieser Tätigkeit [des Bereicherungsschuldners] ins Auge [faßt]“. ${ }^{355}$ Waren die wechselseitigen Bereicherungsansprüche ungleichartig, war der Bereicherungsgläubiger gehalten, Zug um Zug gegen Befriedigung des eigenen Rückgewähranspruchs die von ihm empfangene Gegenleistung anzubieten. ${ }^{356}$ Diese Judikatur belegte das $R G$ selbst mit dem Begriff ,Saldotheorie“. 357

\section{c) Literatur in der ersten Hälfte des 20. Jahrhunderts}

In der zeitgenössischen Literatur hat das $R G$ wohl überwiegend Zustimmung, von prominenter Seite aber auch Widerspruch erfahren. Neben Oertmann ${ }^{358}$ hat vor allem von Tuhr die Kritik in der Festgabe für Immanuel Bekker aus dem Jahr 1907 auf den Punkt gebracht, indem er dem RG die Widersprüchlichkeit seiner Konstruktion vorhielt: „Der Käufer ist bereichert erst in dem Moment, in dem ihm das Eigentum zugewendet wird; daß er aber durch Zahlung des Kaufpreises sein Vermögen vermindert, ist juristisch eine Folge nicht des Eigen-

351 Mot. II (Fn. 4), S. 838.

352 RGZ 44, 136, 144: „Andererseits findet die Verpflichtung ihre Begrenzung aber wieder in der Bereicherung, und wenn die grundlose Leistung gleichzeitig einen Nachteil mit sich gebracht hat, so bleibt nur insoweit, als dieser Nachteil überwogen wird, eine wahre Bereicherung zurück."

353 RGZ 54, 137, 141.

354 RGZ 54, 137, 142.

355 RGZ 60, 284, 291.

356 RGZ 137, 324, 337.

${ }^{357}$ RGZ 129, 307, 310; eingehende Schilderung der Rechtsprechung des RG bei Weintraud, Die Saldotheorie, 1931, S. $31 \mathrm{ff}$.

358 Oertmann, DJZ 1915, $1063 \mathrm{ff}$. 
tumserwerbs an der Kaufsache, sondern des vorausgegangenen Umstands, daß er eine Verpflichtung übernommen hat oder übernommen zu haben glaubt; die Zahlung des Kaufpreises erfolgt causa solvendi, nicht causa acquirendi“. ${ }^{359}$ Aus dieser Klarstellung folgert von Tuhr, aus der Erfüllung eines unwirksamen Kaufvertrags entstehe „,ür jeden Kontrahenten eine Rückforderung der von ihm vorgenommenen Leistung: zwischen beiden Ansprüchen besteht Retention bzw. Aufrechnung“".360

Schließlich hat von Tuhr in dem erwähnten Beitrag ein Szenario vorgeführt, das in der Nachkriegszeit viel Staub aufwirbeln sollte, nämlich den Fall, daß der Käufer den Kaufvertrag wegen arglistiger Täuschung anficht und vom Verkäufer gemäß $§ 812,818$ BGB Rückzahlung des Kaufpreises verlangt, nachdem die Kaufsache bei ihm untergegangen ist. Nach der Rechtsprechung des $R G$ dürfe der Verkäufer den Wert der (mangelhaften) Kaufsache als Minderung seiner Bereicherung von dem zurückzuzahlenden Kaufpreis abziehen. Demgegenüber erscheint es von Tuhr selbst richtiger, „daß der Verkäufer den ganzen Kaufpreis, soweit er ihn noch hat, zurückgibt und von der Kaufsache nur das zurückbekommt, was sich beim Käufer noch vorfindet. “361

\section{d) Nachkriegsliteratur}

In der Literatur der Nachkriegszeit wurde die Kritik an der Saldotheorie stärker. In seinem bereits mehrfach erwähnten Beitrag für die Rabel-Festschrift kam von Caemmerer zu der lapidaren Feststellung: „Man wird zugeben können, daß die so genannte Zweikondiktionentheorie, für die insbesondere von Tuhr und Oertmann eingetreten sind, ursprünglich dem Gesetz entsprach."362 Gleichwohl sei die Saldierung von Leistung und Gegenleistung für die Rückabwicklung gegenseitiger Verträge richtig, wenn auch nicht wegen der "Saldotheorie“, sondern wegen des Synallagmas: „Deshalb wird es dem Vertragspartner nicht erlaubt, seine eigene Leistung isoliert zurückzuverlangen, wenn er selbst das Empfangene wegen Wegfalls der Bereicherung nicht mehr herausgeben könnte. " ${ }^{363}$ Ganz ähnlich begründet Esser die Saldotheorie mit der „, wirtschaftlichen Verbundenheit“ von Leistung und Gegenleistung. ${ }^{364}$ Wird die Verknüpfung der wechselseitigen Bereicherungsansprüche in dieser Weise als Fortwirkung des Synallagmas in der Rückabwicklung begründet, dann läßt sich auch ganz zwanglos erklären, warum die Rechtsprechung im Rahmen der Eingriffskondiktion nach $\S \S 951$ Abs. 1, 812 Abs. 1 S. 1 Alt. 2 BGB oder nach $\S 816$ Abs. 1 S. 1 BGB anders entscheidet und es dem

359 von Tuhr, FS Bekker, 1907, S. 291, 309; genauso Flume, FS Niedermeyer, 1953, S. 103, 162; Wilburg (Fn. 238), S. 156; vgl. auch den untauglichen Rettungsversuch von Weintraud (Fn. 357), S. $66 \mathrm{ff} .:$ wirtschaftlicher Zusammenhang zwischen Leistung und Gegenleistung statt Kausalzusammenhang zwischen herauszugebendem Vorteil und erlittenem Nachteil.

360 von Tuhr (Fn. 359), S. 291, 309.

361 von Tuhr (Fn. 359), S. 291, 309.

362 von Caemmerer (Fn. 246), S. 385; genauso Flume, FS Niedermeyer (Fn. 359), S. 163; vgl. auch Wilburg (Fn. 238), S. $156 \mathrm{f}$.

363 von Caemmerer (Fn. 246), S. 385, 386.

364 Esser, Schuldrecht (Fn. 18), S. 822. 
Beklagten nicht gestattet, dem Bereicherungsanspruch des Eigentümers den für die Sache an einen Dritten gezahlten Kaufpreis zum Zwecke der Saldierung entgegen zu halten..$^{365}$

Diesem Standpunkt schloß sich Larenz in seinem Lehrbuch zum Schuldrecht an: Die Saldotheorie sei „eine von der Rechtsprechung aus Billigkeitsgründen vorgenommene „Gesetzeskorrektur“. ${ }^{366}$ Sie sei zwar als eine „,der Sachlage angemessene richterliche Rechtsfortbildung anzuerkennen“, allerdings nicht wegen irgendwelcher Eigenarten des Bereicherungsrechts, sondern als „Auswirkung des Synallagmas". ${ }^{367}$ Als solche sei die Saldotheorie auf die Abwicklung gegenseitiger Verträge zu beschränken, und selbst in diesem legitimen Bereich unterliege sie Einschränkungen, wenn durch ihre Anwendung ,ein vorrangiger Grundsatz der Rechtsordnung beeinträchtigt werden würde" .368

Indessen hat die Saldotheorie auch in dieser elaborierten Form Widerspruch erregt, am deutlichsten bei Flume, der den Finger in ihre zwei großen Wunden legte. Zum einen sei es „einfach nicht haltbar“ danach zu unterscheiden, ob die Leistungen bereits ausgetauscht sind oder nicht: „Hat bei einem nichtigen Kaufvertrag der Verkäufer die Ware geliefert, der Käufer aber noch nicht bezahlt und ist die Ware beim Käufer untergegangen, so soll nach der herrschenden Meinung der Verkäufer die Gefahr tragen. Hat der Käufer aber den Kaufpreis gezahlt, so trägt nach der Saldo-Theorie er die Gefahr. Es hat noch niemand dargelegt, wie diese unterschiedliche Entscheidung hinsichtlich der Gefahrtragung gerechtfertigt werden könnte." ${ }^{369}$ Weiter wirft Flume der Saldotheorie vor, sie verstoße gegen den gesetzlich gewollten Minderjährigenschutz, wenn sie auch dem Geschäftsunfähigen oder in der Geschäftsfähigkeit Beschränkten den Anspruch auf Rückzahlung des Preises versage, soweit er die empfangene Leistung nicht herausgeben könne..$^{370}$ Statt dessen plädiert Flume für eine offene Allokation der Sachgefahr zum Käufer bzw. Leistungsempfänger mit Hilfe der Figur der ,,vermögensmäßigen Entscheidung". Indem der Bereicherungsschuldner den empfangenen Leistungsgegenstand im Tausch gegen die selbst erbrachte Gegenleistung seinem Vermögen einverleibe, übernehme er die Sachgefahr. ${ }^{371}$ Folgerichtig schuldet der Käufer, der den Kaufpreis noch nicht bezahlt, die Kaufsache aber bereits erhalten hat und bei dem diese untergegangen ist, dem Verkäufer Wertersatz mindestens in Höhe des Werts der Gegenleistung (des Kaufpreises), obwohl hier nichts zu saldieren ist. ${ }^{372}$ Umgekehrt wird der Minderjährige vor der Überwälzung der Sachgefahr geschützt, weil er eine „vermögensmäßige Entscheidung“ nicht wirksam treffen kann. ${ }^{373}$ Fährt also

365 RGZ 106, 4, 7; BGHZ 9, 333, 335 f.; 14, 7, 9 f.; 47, 128, 129 f.; 55, 176, 179 f.; PalandtSprau (Fn. 56), § 818 Rn. 43.

366 Larenz, 5. Aufl. (Fn. 70), S. 292; eine der Saldotheorie wohler gesonnene Akzentuierung findet sich noch in der 2. Aufl. (Fn. 59), S. 252.

367 Larenz (Fn. 59), S. 322 f., im Anschluss an von Caemmerer (Fn. 362).

368 Larenz (Fn. 70), S. 292.

369 Flume (Fn. 359), S. 162.

370 Flume (Fn. 359), S. 163.

371 Flume (Fn. 359), S. 165.

372 Flume (Fn. 359), S. 168 f.

373 Flume (Fn. 359), S. 174. 
ein Sechzehnjähriger das ihm übereignete Fahrrad zu Schrott, kann er den Kaufpreis gleichwohl vom Verkäufer herausverlangen, obwohl die Saldierung hier möglich wäre.

Die Lehre von der ,,vermögensmäßigen Entscheidung“ als solche hat sich nicht durchsetzen können. Die von Flume erbarmungslos aufgedeckten Schwächen der Saldotheorie sind heute jedoch Allgemeingut; sie finden sich praktisch unverändert im Schuldrechts-Lehrbuch von Medicus. ${ }^{374}$ In seiner Kommentierung des Bereicherungsrechts im Münchener Kommentar hat Lieb zwar nicht das Kriterium der vermögensmäßigen Entscheidung, wohl aber dessen normativen Gehalt sowie die Kritik an der Saldotheorie aufgegriffen. ${ }^{375}$ Konsequenterweise fordert Lieb nicht nur die Rückkehr zur Zweikondiktionentheorie, sondern darüber hinaus deren Ergänzung durch eine ,bereicherungsunabhängige Wertersatzpflicht“ des Bereicherungsschuldners in den Fällen der Rückabwicklung gegenseitiger Verträge. ${ }^{376}$

Canaris hat in seinem Schuldrechts-Lehrbuch die „Re-Dogmatisierung“ dieser Wertungen betrieben. Diese nimmt als Prämissen, daß der berechtigte Kern der Saldotheorie in der Berücksichtigung des Synallagmas bei der Rückabwicklung gegenseitiger Verträge liegt, daß sie dieses Anliegen in den Vorleistungsfällen aber nicht erreicht und zudem die von der Rechtsprechung zugelassenen Ausnahmen nicht verarbeiten kann. „Die entscheidende Schwäche der Saldotheorie liegt dabei nicht darin, daß sie eine Reihe von Ausnahmen konzedieren muß - Ausnahmen sind bei fast jeder juristischen Theorie unvermeidlich -, sondern darin, daß sie kein Kriterium aufweist, mit dessen Hilfe sich diese erklären lassen. “377 Die Lösung von Canaris besteht deshalb nicht darin, die Saldotheorie auf eine neue dogmatische Grundlage zu stellen, wie von Caemmerer dies versucht hatte, sondern sie ganz zu verabschieden. ${ }^{378}$ An ihre Stelle tritt eine Kombination dreier Elemente: (1) Die Einschränkung des $§ 818$ Abs. 3 BGB im Wege der teleologischen Reduktion bei der Rückabwicklung gegenseitiger Verträge unter Berücksichtigung der Wertungen des Rücktrittsrechts, nach denen der Verkäufer das Zufallsrisiko, der Käufer aber das Risiko verschuldeten Untergangs der Sache trägt ( $\S 350,351 \mathrm{BGB}$ aF). (2) Die Gewährung einer „Gegenleistungskondiktion“ zugunsten des vorleistenden Verkäufers, mit der er den Wert der Kaufsache liquidieren kann ( $\$ 818$ Abs. 2 BGB), falls sie durch Verschulden des Käufers bei diesem untergegangen ist. (3) Normativ motivierte Einschränkungen beider Regeln - also der Einschränkung des $\S 818$ Abs. 3 BGB und der Verpflichtung zum Wertersatz in Vorleistungsfällen gemäß $\S 818$ Abs. 2 BGB - in geeigneten Fällen, insbesondere zu-

374 Medicus (Fn. 23), Rn. 695; ähnlich auch Brox/Walker (Fn. 23), § 39 Rn. $14 \mathrm{ff}$.

375 MünchKommBGB-Lieb, 1. Aufl. (Fn. 263), § 818 Rn. 98 ff.; 4. Aufl. (Fn. 273), § 818 Rn. 75 f., $114 \mathrm{ff}$.

376 MünchKommBGB-Lieb, 1. Aufl. (Fn. 263), § 818 Rn. 99 ff.; 4. Aufl. (Fn. 273), § 818 Rn. $123 \mathrm{ff}$.

377 Canaris, FS Werner Lorenz, 1991, S. 19, 58; im Anschluß an Flume, NJW 1970, 1161: „Was ist das für eine seltsame, Theorie“, die einen Begriff der Bereicherung, nämlich Bereicherung $=$ Saldo, aufstellt, um, wenn er nicht passend erscheint, diesen Begriff wieder aufzugeben“. Genauso Honsell, MDR 1970, $717 \mathrm{f}$.

378 Zur Abgrenzung gegen von Caemmerer, Canaris (Fn. 377), S. 59 f. 
gunsten minderjähriger Bereicherungsschuldner sowie nach Maßgabe des Schutzzwecks der Nichtigkeitsnorm. ${ }^{379}$

Nachdem die $\S \S 350,351$ BGB a.F. durch $\S 346$ BGB ersetzt worden sind und der aufgrund Gesetzes zum Rücktritt Berechtigte gemäß § 346 Abs. 3 S. 3 BGB Wertersatz für die bei ihm zerstörte oder verschlechterte Sache nur schuldet, wenn er gegen die Sorgfalt in eigenen Angelegenheiten verstoßen hat, stellt sich die Aufgabe der Abstimmung von Rücktritts- und Bereicherungsrecht aufs Neue. Sie wird wesentlich dadurch erschwert, daß die Neuregelung des $§ 346$ BGB sofort zum Gegenstand heftiger Kontroversen geworden ist, die die Rechtslage noch unübersichtlicher machen, als sie es vor der Schuldrechtsreform gewesen ist. Der Streit rührt daher, daß der Gesetzgeber das durch $\S 350$ BGB a. F. bewirkte und vielfach kritisierte „Rückspringen“ der Sachgefahr auf den Verkäufer mit der Neuregelung des $\S 346$ Abs. 3 S. 1 Nr. 3 BGB noch ausgeweitet hat, denn nunmehr schadet dem Käufer und Rücktrittsgläubiger sogar die leicht fahrlässige Zerstörung des Kaufgegenstands nicht, wenn er nur die Sorgfalt beachtet hat, die er in eigenen Angelegenheiten zu beachten pflegt. In der Literatur wird diese Regelung vielfach als verfehlt empfunden und deshalb vorgeschlagen, § 346 Abs. 3 S. 1 Nr. 3 BGB nach Kenntniserlangung vom Rücktrittsgrund teleologisch zu „,korrigieren“380 oder um eine allgemeine Fahrlässigkeitshaftung auf der Grundlage von $\S \S 346$ Abs. 4, 280 Abs. 1 BGB $^{381}$ zu ergänzen. ${ }^{382}$ Vor diesem Hintergrund ist es nur zu verständlich, wenn Lieb im Münchener Kommentar zögert, die Wertungen des neuen Rücktrittsrechts auch für das Bereicherungsrecht - also für die Einschränkung des $\S 818$ Abs. 3 BGB - zu übernehmen. ${ }^{383}$ Mit Lieb wird man sich allerdings zu der Einschätzung durchringen müssen, daß die Harmonisierung von Rücktritts- und Bereicherungsrecht trotz $\S 346$ Abs. 3 S. 1 Nr. 3 BGB „,vorzugswürdig sein dürfte“: ${ }^{384}$ Es kann keinen Unterschied machen, ob der enttäuschte Käufer den von $\S \S 437$ Nr. 2, 346 ff. BGB vorgezeichneten Weg des Gewährleistungsrechts nimmt und vom Kaufvertrag zurücktritt oder ob er sich auf Irrtum ( $\$ 119$ BGB) oder Täuschung ( 123 BGB) beruft und Rückabwicklung nach Bereicherungsrecht begehrt (\$§ 142 Abs. 1, 812 Abs. 1 S. 1 Alt. 1, $818 \mathrm{BGB}) . .^{385}$

379 Larenz/Canaris (Fn. 31), S. 323 ff.; ausführlich ders. (Fn. 377), S. 26 ff.

380 Hager, FS Musielak, 2004, S. 195, 202; Schwab, JuS 2002, 630, 635; Thier, FS Heldrich, 2005, S. 439, $446 f$.

381 Gaier, in: Münchener Kommentar zum BGB, Bd. 2a, 4. Aufl. 2003, § 346 Rn. $61 \mathrm{ff}$; Palandt-Heinrichs (Fn. 56), § 346 Rn. 15 ff.; ders., FS Schmidt, S. 164 ff.; Bamberger/Roth-Grothe, BGB, 2003, § 346 Rn. 35 ff.; wohl auch Canaris, Schuldrechtsreform 2002, S. XLVII; Faust, in: Huber/Faust, Schuldrechtsmodernisierung, 2002, § 10 Rn. $46 \mathrm{ff}$.

382 Eingehend Wagner, FS Ulrich Huber, 2006, S. $618 \mathrm{ff}$.

383 MünchKommBGB-Lieb (Fn. 273), § 818 Rn. $134 \mathrm{f}$.

384 MünchKommBGB-Lieb (Fn. 273), § 818 Rn. 135 aE.

385 von Caemmerer, FS Larenz, 1973, S. 625; S. Lorenz, in: Schulze/Schulte-Noelke, S. 346 f.; Larenz/Canaris (Fn. 31), S. 324f., S. 327f.; Hager, in: Ernst/Zimmermann, Zivilrechtswissenschaft und Schuldrechtsreform, S. 429, 442f. m. w. N. in Fn. 66; U. Huber, JuS 1972, 439, 444. 


\section{e) Zum heutigen Stand der Saldotheorie}

Nach 1945 hat der BGH die vom RG entwickelte Saldotheorie übernommen. ${ }^{386}$ Soweit Lieb und Canaris die Saldotheorie in den Ruhestand schicken wollten, ist ihnen der $B G H$ bisher nicht gefolgt. Das Gericht betont in ständiger Rechtsprechung, die bereicherungsrechtliche Rückabwicklung gegenseitiger Verträge habe „,nach den Grundsätzen der sogenannten Saldotheorie zu erfolgen“. ${ }^{387}$ Auf der anderen Seite kann der BGH die Arbeiten von Canaris zustimmend zitieren, weil er die dort erarbeiteten normativen Einschränkungen mehr oder weniger komplett übernommen bzw. vorweggenommen hat. ${ }^{388}$ So hat der BGH den Klagen arglistig getäuschter Käufer von Gebrauchtwagen, die mit ihrem Fahrzeug einen - verschuldeten oder unverschuldeten - Unfall erlitten hatten und nunmehr nach Anfechtung des Kaufvertrags ( $§ 123,142$ Abs. 1 BGB) vom Verkäufer aufgrund Bereicherungsrechts Rückzahlung des Kaufpreises verlangten, stattgegeben, ${ }^{389}$ obwohl er sie bei strikter Anwendung der Saldotheorie hätte abweisen müssen. ${ }^{390}$ Das Gericht hat sich allerdings nicht dazu durchringen können, die Saldotheorie offen $\mathrm{zu}$ verabschieden, sondern hat lediglich die Notwendigkeit wertender Korrekturen betont: Es könne ,,bei besonderer Fallgestaltung, abweichend von der Saldotheorie, als billig ein Ausgleich angesehen [werden], bei dem der Untergang des Gegenstands, den der Bereicherungsgläubiger empfangen hat, auf Gefahr des Bereicherungsschuldners geht. " ${ }^{391}$ Darüber hinaus ist in der heutigen Rechtsprechung anerkannt, daß die Saldotheorie keine Anwendung zu Lasten von Geschäftsunfähigen findet ${ }^{392}$ und daß der sittenwidrig übervorteilte Verkäufer die erbrachte Leistung zurückfordern darf, weil die Anwendung der Saldotheorie dem Schutzzweck der Nichtigkeitsnorm ( $\$ 138$ BGB) widerspricht. ${ }^{393}$

Wie ein Blick in die Rechtsprechung des RG zeigt, ist diese Flexibilität innerhalb der Saldotheorie eigentlich gar nichts Neues, sondern war ihr von Anfang an inhärent. Das RG hat den Fall, daß die Kaufsache beim Käufer zerstört oder verschlechtert worden war und der Käufer nunmehr auf Rückzahlung des Kaufpreises klagte, im Jahr 1918 entschieden. ${ }^{394}$ Der Käufer von 7960 Pfund dänischem Goudakäse klagte auf Rückzahlung von drei Viertel des Kaufpreises, nachdem er die Ware wegen angeblichen Verderbs hatte versteigern lassen und dabei weniger als ein Viertel des Preises erlöst hatte. Das $R G$ hielt dafür, im Fall der Rückabwicklung eines beiderseits erfüllten Kaufvertrags entspreche es „,dem natürlichen Rechtsgefuihlt und der Billigkeit" bei der Saldierung nicht nur das Schicksal der

\footnotetext{
386 BGHZ 1, 75, 81.

387 Vgl. etwa BGH NJW 2000, 3064; 2001, 1863, 1864; ZIP 2001, 747, 751.

388 Vgl. BGH ZIP 2001, 747, 762.

389 BGHZ 53, 144; 57, 137

390 BGHZ 53, 144, $147 \mathrm{ff}$; 57, 137, $148 \mathrm{ff}$. (mit analoger Anwendung des § 254 BGB!); dazu die Besprechungen von von Caemmerer (Fn. 385), S. 621; Flessner, NJW 1972, 1777; Flume, NJW 1970, 1161; Honsell, MDR 1970, 717; U. Huber, JuS 1972, 439; Weitnauer, NJW 1970,

391 BGHZ 53, 144, 147; 57, 137, 148.

392 BGHZ 126, 105, 107, mit umfassenden Nachweisen des einhelligen Schriftums.

393 BGH ZIP 2001, 747, 752.

394 RGZ 94, 253.
} 636. 
von dem Bereicherungsschuldner empfangenen Leistung, sondern auch das Schicksal der von ihm erbrachten Gegenleistung zu berücksichtigen. ${ }^{395}$ Gleichwohl gab es der Klage auf Rückzahlung des Kaufpreises in vollem Umfang statt, weil ,nach Bereicherungsgrundsätzen“ der Verkäufer das Risiko des Verderbs oder Verschlechterung der gelieferten Ware zu tragen habe. ${ }^{396}$ Eine weitere Entscheidung aus dem Jahr 1915 beurteilt die Frage, ob der Käufer trotz Unmöglichkeit der Rückgabe der Kaufsache den dafür gezahlten Preis herausverlangen kann, anhand der Wertungen der $\S \S 818$ Abs. 3, 4, 819 BGB - und gerade nicht durch Deduktion aus der Saldotheorie. ${ }^{397}$

Die Verengung der Debatte auf das Problem der Gefahrtragung bei der Rückabwicklung gegenseitiger Verträge hat vielleicht auch eine Überreaktion des $B G H$ provoziert. In der bereits erwähnten Entscheidung zur Rückabwicklung eines wegen Verstoßes gegen $\S 138$ Abs. 1 BGB nichtigen Kaufvertrags hat das Gericht der Rechtsnachfolgerin der Verkäuferin gestattet, die noch unversehrt vorhandene Kaufsache von den Erwerbern zurückzufordern, ohne die Rückgabe des empfangenen Kaufpreises anzubieten und ihren Klageantrag entsprechend auf die Verurteilung Zug um Zug zu beschränken. ${ }^{398}$ Genauso, wie eine ,implizite“ Allokation der Gefahrtragung durch eine naiv und mechanisch angewendete Saldotheorie kritisiert worden ist, ist es auch kritikwürdig, wenn der $B G H$ den Bereicherungsausgleich zwischen den Parteien auch dort atomisiert, wo Probleme der Gefahrtragung nicht zur Debatte stehen, weil der Leistungsgegenstand noch unversehrt vorhanden ist. ${ }^{399}$ Die konsequente Anwendung der Saldotheorie und also die Verurteilung zur Rückabwicklung Zug um Zug wäre hier die einzig sachgerechte Lösung gewesen.

\section{Europäisierung des Bereicherungsrechts}

Insgesamt läßt sich festhalten, daß das deutsche Bereicherungsrecht im 20. Jahrhundert eine Fülle grundlegender Klärungsprozesse durchlaufen hat, die das Verständnis des Rechtsinstituts stark gefördert haben. Die dabei gefundenen Ergebnisse bzw. die Standpunkte der heute ,herrschenden Meinung“ werden natürlich nicht jeden überzeugen. Es ist aber schwer vorstellbar, daß man ein Bereicherungsrecht konzipieren könnte, daß an den geschilderten Weichenstellungen einfach vorbei ginge. Insofern scheint das deutsche Bereicherungsrecht für das Projekt der Europäischen Rechtsvereinheitlichung gut gerüstet zu sein. In den Worten von Reinhard Zimmermann ausgedrückt, hat die Erziehung des vernachlässigten Hinterhofkindes in Deutschland deutliche Fortschritte gemacht. ${ }^{400}$ Als ein

\footnotetext{
395 RGZ 94, 253, 254f.

396 RGZ 94, 253, 255.

397 RG JW 1915, 711, 712.

398 BGH ZIP 2001, 747, 751.

399 So mit Recht Flume, ZIP 2001, 1621, 1622f., im Anschluß an ders. (Fn. 262), S. 537 f.

${ }^{400}$ So, mit Bezug zum englischen Bereicherungsrechts und ein Diktum von Peter Birks aufgreifend, Zimmermann (Fn. 66), S. 892f.: „Bedevilled by historical accident and legalistic fiction, the law of restitution has remained something of a backward child of the legal family."
} 
Beleg für diese optimistische These mag man anführen, daß sich das englische Bereicherungsrecht zunehmend auf die ,deutsche“ - besser: civilistische - Tradition zu entwickelt ${ }^{401}$ und Peter Birks als der bis zu seinem Tod führende Bereicherungsrechtler Englands, ,,partly by the power of comparative analysis“, die Kategorie des enrichment by subtraction auf der Basis verschiedener unjust-grounds zugunsten des Konzepts der Leistungskondiktion bei Rechtsgrundlosigkeit aufgegeben hat. ${ }^{402}$ Darüber informiert in Deutschland zuverlässig und regelmäßig die bei Beck verlegte Zeitschrift für Europäisches Privatrecht. ${ }^{403}$ Ein Pendant zu dem rechtsvergleichenden Werk von Bars zum Deliktsrecht ist ebenfalls bereits erschienen, wenn auch nicht im Hause Beck, sondern bei Mohr Siebeck. ${ }^{404}$

\section{Geschäftsführung ohne Auftrag}

\section{Ein Rechtsinstitut ohne feste Grundlage}

Anders als das Vertragsrecht, so heißt es bei Reinhard Zimmermann, sind Regelungen über die Geschäftsführung ohne Auftrag kein notwendiger Bestandteil eines entwickelten Rechtssystems. ${ }^{405}$ Der Anwendungsbereich der $\$ \S 677 \mathrm{ff}$. BGB ist deshalb weniger klar definiert als derjenige des Vertrags- und des Deliktsrechts. Auf die Rechtsprechung übt die Geschäftsführung ohne Auftrag deshalb eine ,,geradezu magische Anziehungskraft" aus, wie ein ehemaliger Bundesrichter freimütig eingeräumt hat. ${ }^{406}$ Die wissenschaftliche Diskussion kreist um Fallgruppen, die die Rechtsprechung mit Hilfe der Geschäftsführung ohne Auftrag gelöst hat, wobei sich der Streit regelmäßig darum dreht, ob dieser Weg zu Recht beschritten oder das Rechtsinstitut bloß usurpiert wurde.

\section{Dogmatische Alternativentwürfe}

„,Vor diesem Hintergrund wird der Wunsch verständlich, einen möglichst aussagekräftigen Grundgedanken für die $\$ \S 677$ ff. kennenzulernen, der als eine Art Leitfaden die Orientierung in diesem offensichtlich nicht unproblematischen Bereich erleichtert. “407 Dies schreibt Seiler als „Münchener Kommentator“ der Geschäftsführung ohne Auftrag, um sofort hinzuzufügen: „Der Wunsch kann leider nicht erfüllt werden. “ ${ }^{408}$ In der Literatur ist seit dem Ende des 19. Jahrhunderts immer wieder nachdrücklich dafür plädiert worden, die Geschäftsführung ohne Auftrag

401 Zimmermann, in: ders. (Hrsg.), Grundstrukturen eines Europäischen Bereicherungsrechts, 2005, S. $31 \mathrm{ff}$.

402 Birks, Unjust Enrichment, 2003, S. 40; und dazu Zimmermann (Fn. 401), S. 40f.; Visser, ZEuP 2005, 118 (125f.).

403 Visser, ZEuP 2005, 118; Zimmermann, ZEuP 1999, 713; Sonja Meier, ZEuP 1998, 716.

404 Schlechtriem, Restitution und Bereicherungsausgleich in Europa, Bd. I, 2000; Bd. II, 2001; gleiches gilt für den Band von Zimmermann (Hrsg.), Grundstrukturen eines Europäischen Bereicherungsrechts, 2005.

405 Zimmermann (Fn. 66), S. 435.

406 Hauß, FS Weitnauer, 1983, S. 333.

407 Seiler, JuS 1987, 368.

408 Seiler, JuS 1987, 368. 
auf Akte der Menschenhilfe im Freundeskreis zu begrenzen. ${ }^{409}$ Damit ließe sich in der Tat eine einigermaßen feste dogmatische Grundlage gewinnen, doch diese Auffassung hat sich gleichwohl nicht durchgesetzt. Am anderen Ende des Spektrums steht der induktive Ansatz von Wollschläger, der auf der Basis einer umfassenden Auswertung der seit dem 19. Jahrhundert veröffentlichten Rechtsprechung der Geschäftsführung ohne Auftrag einen denkbar weiten Anwendungsbereich erschließen will. ${ }^{410}$ Im Vordergrund der Praxis zu den $§ \S 677 \mathrm{ff}$. BGB stehe der Aufwendungsersatzanspruch des $§ 683$ BGB und das ,,auch-fremde“ Geschäft, das mit Hilfe des Kriteriums des Geschäftsführungswillens nicht zu bewältigen sei, sondern eine Dogmatik des objektiv fremden Geschäfts erfordere. Diese Voraussetzung der Geschäftsführung ohne Auftrag sei auf die Funktion auszurichten, die ,vermögensmehrenden und -mindernden Folgen vertretungsweisen Handelns auf denjenigen zu übertragen, der endgültig dafür zuständig“, weil ,näher daran“ sei, die damit verbundenen wirtschaftlichen Lasten zu tragen. ${ }^{411}$

Auf den dezidiert extensiven Ansatz Wollschlägers antwortete Wittmann mit seiner in den Münchener Universitätsschriften veröffentlichten Habilitationsschrift. ${ }^{412}$ Wittmann wählte nicht die Rechtsprechung des 19. und 20. Jahrhunderts zum Ausgangspunkt, sondern das klassische römische Recht. ${ }^{413}$ Er verwarf den Begriff des objektiv fremden Geschäfts und stellte ganz auf das subjektive Kriterium des Geschäftsführungswillens $a b,{ }^{414}$ und er wandte sich gegen die Mobilisierung der Geschäftsführung ohne Auftrag bei Rettungshandlungen im Interesse von Leib und Leben anderer. ${ }^{415}$ Allerdings schreckte er davor zurück, sich der Theorie der Menschenhilfe zu verschreiben, ${ }^{416}$ und plädierte dafür, den Begriff des Geschäftsführungswillens anhand des ,,sozialen Sinns“ des Verhaltens des Geschäftsführers zu ermitteln - und damit doch wieder zu objektivieren. ${ }^{417}$

\section{Wertungsjurisprudenz im Recht der GoA}

Die Rechtsprechung hat sich über weite Strecken von den Angriffen der Literatur völlig unbeeindruckt gezeigt. Erst in jüngster Vergangenheit ist ein gewisser Trend $\mathrm{zu}$ einem restriktiven Gebrauch der $\$ \S 677 \mathrm{ff}$. BGB zu verzeichnen, wenn etwa quasi-vertragliche Ausgleichsansprüche von Erbensuchern verneint werden ${ }^{418}$ oder einer Behörde versagt wird, an dem Pflichtengefüge und den Kostenregelungen des Polizeirechts vorbei auf einen Störer zuzugreifen. ${ }^{419}$ Der restriktive Ansatz

\footnotetext{
409 So insbesondere J. Kohler, JherJb. 25 (1887), 1, 42 ff.; Rabel, RheinZ 1919/1920, 89, $94 \mathrm{ff.}$

410 Wollschläger, Die Geschäftsführung ohne Auftrag, 1976.

411 Wollschläger (Fn. 410), S. 57, 66.

412 Wittmann, Begriff und Funktion der Geschäftsführung ohne Auftrag, 1981.

413 Wittmann (Fn. 412), S. $4 \mathrm{ff}$.

414 Wittmann (Fn. 412), S. 18 ff., 53 ff.; eingehende Begründung bei Gursky, AcP 185 (1985), $13,14 \mathrm{ff}$.

415 Wittmann (Fn. 412), S. $65 \mathrm{ff}$.

416 Wittmann (Fn. 412), S. $16 \mathrm{f}$.

417 Wittmann (Fn. 412), S. 30.

418 Siehe Fn. 434.

419 Siehe Fn. 444.
} 
Wittmanns ist in der Literatur zwar auf viel Sympathie gestoßen, hat aber wenig direkte Gefolgschaft evoziert: Larenz versucht der Forderung nach Begrenzung der Geschäftsführung ohne Auftrag mit einem eigenen, pragmatischen Vorschlag gerecht zu werden, ${ }^{420}$ während Seiler im Münchener Kommentar den Finger in die Wunde legt, wenn er auf die erhebliche Diskrepanz verweist, die zwischen der Überzeugungskraft der Kritik als solcher und der Überzeugungskraft der Alternativvorschläge besteht. ${ }^{421}$ Seiler plädiert deshalb mit vollem Recht für eine Orientierung am Bereicherungsrecht, nämlich für die Ersetzung begrifflich orientierter Dogmatik durch eine an zentralen schuldrechtlichen Wertungen orientierte Wertungsjurisprudenz. ${ }^{422}$ Die dadurch zunächst zu verzeichnende Einbuße an Rechtssicherheit wird aufgefangen durch eine auf Fallgruppen bezogene Regelbildung, die den Sachproblemen viel näher ist als eine begrifflich-deduktive Dogmatik und die gleichwohl den Bezug zu den „obersten Prinzipien“ des Privat-, aber auch des öffentlichen Rechts zu wahren imstande ist.

\section{Das „auch-fremde“ Geschäft}

\section{Selbst verpflichteter Geschäftsführer}

Ein Hauptkriegsschauplatz der Auseinandersetzung um den Anwendungsbereich der Geschäftsführung ohne Auftrag ist seit jeher das ,,auch-fremde“ Geschäft. Ein gutes Beispiel ist der Fall des Fuldaer Dombrandes: ${ }^{423}$ Bei einer BonifaziusJubelfeier im Jahre 1905 in Fulda wurde ein Feuerwerk abgebrannt, das die Türme des Doms in Brand setzte, wodurch der Nordturm schwer in Mitleidenschaft gezogen wurde. Das Land Preußen hatte aufgrund einer ihm obliegenden Baulast den Dom instand gesetzt und verlangte nun von den verantwortlichen Mitgliedern des Festausschusses Kostenerstattung. - Das RG gab der Klage auf der Grundlage der Geschäftsführung ohne Auftrag statt. Zwar sei es dem klagenden Fiskus zuerst um die Erfüllung seiner eigenen Pflicht aus der öffentlich-rechtlichen Baulast gegangen, doch habe er die Aufwendungen auch in der Absicht gemacht, ,sich wegen ihrer bei dem an letzter, endgültiger Stelle verpflichteten Schädiger wieder zu erholen“. ${ }^{424}$ Bereits Ernst Rabel warf dem RG vor, es habe mit dieser Rechtsprechung ,das Institut der auftraglosen Geschäftsführung entstellt und teilweise [ge]sprengt". ${ }^{425}$ Auch Larenz hat die Entscheidung des RG mit der Begründung abgelehnt, im Hinblick auf die eigene Verpflichtung des Fiskus fehle es an der Fremdgeschäftsführung für den Schädiger. Diese Kritik richtete sich allerdings nicht gegen das vom $R G$ erzielte Ergebnis, das Larenz zu erreichen suchte, indem er dem Fiskus aus $§ 242$ BGB einen Anspruch gegen die Kirche auf Abtretung des Schadensersatzanspruchs gegen den Schädiger einräumte. ${ }^{426}$

${ }^{420}$ Larenz, Schuldrecht, Besonderer Teil, Bd. II/1, 13. Aufl. 1986, S. 442 f.

${ }^{421}$ MünchKommBGB-Seiler, Bd. 4, 4. Aufl. 2005, § 677 Rn. 13 ff.

422 MünchKommBGB-Seiler (Fn. 421), § 677 Rn. 24.

423 RGZ 82, 206; RG, JW 1915, 325.

${ }^{424}$ RGZ 82, 206, 214; RG JW 1915, 325, 326.

425 Rabel, RheinZ 1919/1920, 89, 96.

426 Larenz, Schuldrecht, Bd. I, Allgemeiner Teil , 14. Aufl. 1987, S. 567. 
Die Kategorie des ,,auch-fremden“ Geschäfts entfaltet ihre ganze Dynamik vor allem wegen der Unterscheidung zwischen objektiv und subjektiv fremdem Geschäft sowie die daran geknüpfte Vermutung des Fremdgeschäftsführungswillens beim objektiv fremden Geschäft. Obwohl sich die Erste Kommission in den Motiven zum BGB explizit gegen die im Gemeinen Recht verbreitete Unterscheidung zwischen objektiv und subjektiv fremdem Geschäft ausgesprochen hat, ${ }^{427}$ ist sie von der Rechtsprechung wiederbelebt worden und beherrscht heute die Lehrbuch- und Kommentarliteratur. ${ }^{428}$ Kombiniert man die Vermutung des Fremdgeschäftsführungswillens beim objektiv fremden Geschäft mit der Kategorie des „,auch-fremden“ Geschäfts, so wird bei einem als „objektiv auch-fremd“ qualifizierten Geschäft der Fremdgeschäftsführungswille ebenfalls vermutet. De facto ist der Anwendungsbereich der Geschäftsführung ohne Auftrag also bereits mit der Feststellung eröffnet, für die jeweilige Aufgabe sei ,,auch“ ein anderer zuständig gewesen. Im Schrifttum ist dementsprechend vorgeschlagen worden, das „,auch-fremde“ Geschäft zu verabschieden und den pflichtgebundenen Geschäftsführer aus den $\$ \S 677 \mathrm{ff}$. BGB herauszunehmen. ${ }^{429} \mathrm{Ob}$ damit der gordische Knoten durchschlagen oder nicht vielleicht doch das Kind mit dem Bade ausgeschüttet wird, ist eine offene Frage. Folgerichtig plädiert Seiler im Münchener Kommentar nicht für eine Radikallösung, sondern für die Einschränkung der Geschäftsführung ohne Auftrag in diesen Fällen durch Entwicklung von Regeln mittlerer Reichweite, die fallgruppenspezifisch die Wertungen der übrigen Rechtsordnung zur Geltung bringen. ${ }^{430}$ Was dies bedeutet, soll im folgenden am Beispiel einer besonders neuralgischen Fallgruppe demonstriert werden, nämlich der Anwendung der Geschäftsführung ohne Auftrag bei gescheiterten Vertragsverhältnissen.

Der $B G H$ qualifiziert in ständiger Rechtsprechung Dienstleistungen, die aufgrund nichtiger Dienst-, Werk oder Geschäftsbesorgungsverträge erbracht werden, als Führung eines ,,auch-fremden“ Geschäfts. ${ }^{431}$ Die praktische Konsequenz dieser Rechtsprechung liegt darin, daß die $\S \S 812 \mathrm{ff}$. BGB als Abwicklungsregime durch die Geschäftsführung ohne Auftrag ersetzt werden. Die in der Literatur mitunter in den Vordergrund gerückte Einsicht, der Leistende führe kein fremdes Geschäft, sondern sein eigenes, ist nur von sekundärem Gewicht. ${ }^{432}$ Wie Seiler im Münchener Kommentar hervorhebt, ist statt dessen der Gesichtspunkt entscheidend, daß die Rechtsprechung die Wertungen des Bereicherungsrechts, insbesondere die Kondiktionssperren der $\S \S 814,817$ S. 2 BGB sowie den Entreicherungseinwand des $§ 818$ Abs. 3 BGB umgeht, wenn sie die Rückabwicklung nichtiger Verträge

427 Mot. II (Fn. 4), S. 855.

428 Vgl. nur Medicus (Fn. 23), Rn. 614f.; Brox/Walker (Fn. 23), § 35 Rn. 10 ff.; Palandt-Sprau (Fn. 56), § 677 Rn. 4 ff.; wegen der Gesetzesmaterialien dagegen etwa Schmidt, JuS 2004, 862; zur Auffassung Wittmanns bereits oben Fn. 414.

429 Schubert, NJW 1978, 687; ders., AcP 178 (1978), 425, $435 \mathrm{f}$.

430 MünchKommBGB-Seiler (Fn. 421), § 677 Rn. 20, 24.

431 BGHZ 37, 258, 262f.; 101, 393, 398; 111, 308, 311; BGH NJW 1997, 47, 48.

432 Vgl. S. Lorenz, NJW 1996, 883, 885: „Dieser in der Literatur immer wieder vorgebrachte Einwand stößt jedoch in der ständigen Rechtsprechung des BGH seit jeher auf taube Ohren." 
dem Anwendungsbereich der Geschäftsführung ohne Auftrag zuordnet. ${ }^{433}$ Diesen Überlegungen hat sich der III. Zivilsenat des BGH in einem Urteil aus dem Jahr 1999 angenähert, als er die auf Geschäftsführung ohne Auftrag gestützten Vergütungsansprüche eines gewerblichen „Erbensuchers“ gegen den begünstigten Erben mit folgender Begründung zurückwies: „Eigene Aufwendungen im Vorfeld eines Vertragsschlusses bleiben aber, sofern es nicht zu einem Abschluß kommt, nach den Regeln des Privatrechts unvergütet; jede Seite trägt das Risiko eines Scheiterns der Vertragsverhandlungen selbst. Diese im Gefüge der Vertragsrechtsordnung angelegte und letztlich auf die Privatautonomie zurückzuführende Risikoverteilung würde durch Zulassung von Aufwendungsersatzansprüchen aus Geschäftsführung ohne Auftrag unterlaufen". ${ }^{434} \mathrm{Zu}$ kritisieren ist der III. Zivilsenat lediglich dafür, daß er diese Argumentation ausdrücklich nicht auf die Rückabwicklung nichtiger Verträge angewandt hat. ${ }^{435}$ In Wahrheit liegt es dort genauso, nur entstammt die dort maßgebliche Risikoverteilung nicht dem Vertrags-, sondern dem Bereicherungsrecht.

\section{Geschäftsführung ohne Auftrag durch Verwaltungsträger}

Wie weit die $\S \S 677$ ff. BGB bei Anerkennung des ,,auch-fremden“ Geschäfts ausgreifen, zeigt insbesondere die Entwicklung der Geschäftsführung ohne Auftrag im Bereich des öffentlichen Rechts. Hier lassen sich auf der Grundlage von $§ 683$ BGB Regreßansprüche der Behörde gegen private Verursacher der Gefahrenlage auch dort begründen, wo spezialgesetzliche Kostenerstattungsregeln fehlen. So hat die Rechtsprechung Kostenersatz auf der Grundlage der $\$ \S 677$ ff. BGB zugesprochen, wenn ein Verwaltungsträger im Bereich der Gefahrenabwehr tätig geworden ist, beispielsweise eine Behörde eine durch Funkenflug verursachte Feuersbrunst gelöscht, ${ }^{436}$ Straßen gereinigt, ${ }^{437}$ umgestürzte Tanklastzüge wieder aufgerichtet, das ausgetretene Mineralöl aufgefangen und Gewässerkontaminationen verhindert bzw. ${ }^{438}$ eingedämmt oder in einer Bundeswasserstraße über Bord gegangene Lukendeckel geortet und eingesammelt hat. ${ }^{439}$ Ausnahmsweise kann die Annahme einer Geschäftsführung ohne Auftrag in Fällen der Gefahrenabwehr auch zugunsten eines Privaten wirken, soweit nämlich die Aufgabe von der Behörde grob unsachgemäß durchgeführt worden ist. In diesem Fall hat der Verwaltungsträger dem Bürger seinen Schaden gemäß $§ \$ 677,680$ BGB zu ersetzen. ${ }^{440}$

In der Literatur ist die Rechtsprechung zur öffentlich-rechtlichen Geschäftsführung ohne Auftrag auf Kritik gestoßen. Maurer hält dem BGH in seinem bei Beck erschienenen „Allgemeinen Verwaltungsrecht“ entgegen, er habe der Geschäfts-

433 MünchKommBGB-Seiler (Fn. 421), § 677 Rn. 48, im Anschluß an Wollschläger (Fn. 410),

S. $207 \mathrm{ff}$; Canaris, NJW 1985, 2404, 2405; Gursky, AcP 185 (1985), 13, $31 \mathrm{f}$.

434 BGH NJW 2000, 72, 73; dazu Falk, JuS 2003, 833, 838.

435 BGH NJW 2000, 422, 424.

436 BGHZ 40, 28, $30 \mathrm{ff}$.

437 BGHZ 65, 354, $356 \mathrm{ff}$.

438 BGHZ 63, 167, $168 \mathrm{f}$.

${ }^{439} \mathrm{BGHZ} 65,384,389 \mathrm{f}$.

440 BGHZ 63, 167, $171 \mathrm{ff}$. 
führung ohne Auftrag einen ,sehr zweifelhaften Bereich“ erschlossen, indem er das Verwaltungshandeln zugleich als eine privatrechtliche Geschäftsführung im Interesse eines anderen qualifiziert habe. ${ }^{441}$ Ossenbühl fügt in seinem ebenfalls im Beck-Verlag erschienenen Lehrbuch zum „Staatshaftungsrecht“ hinzu, der Sache nach unterlaufe die Geschäftsführung ohne Auftrag die speziellen Ermächtigungsgrundlagen und Kostenerstattungsnormen des öffentlichen Sicherheitsrechts. ${ }^{442}$ Es fehle im übrigen sowohl an der Fremdheit des Geschäfts für den Verwaltungsträger, der einer öffentlich-rechtlichen Handlungspflicht unterliege, als auch am Fremdgeschäftsführungswillen, weil sich der Verwaltungsträger nicht dem Interesse des (privaten) Geschäftsherrn unterordnen wolle. ${ }^{443}$

In jüngster Zeit hat die Problematik erheblich an Brisanz verloren. Zum einen hat der Gesetzgeber mittlerweile in den allermeisten Verwaltungsgesetzen spezielle Kostenerstattungsregelungen getroffen, die den Rückgriff auf die $\$ \S 677 \mathrm{ff}$. BGB entbehrlich machen. Auf dieses immer dichter werdende Geflecht öffentlichrechtlicher Gebührentatbestände und Kostenerstattungsnormen reagierte der BGH in einer Entscheidung jüngeren Datums durch eine Rücknahme seiner Rechtsprechung zur Geschäftsführung ohne Auftrag. ${ }^{444}$ In dem zugrundeliegenden Fall war einem Viehhändler ein Rind entwischt, das die Autobahn unsicher machte. Nachdem es bereits zu Verkehrsunfällen gekommen war, wußte sich der das Tier verfolgende Polizist nicht anders zu helfen, als die Kreatur durch mehrere Schüsse aus seiner Pistole niederzustrecken. Dabei erlitt er ein Knalltrauma an beiden Ohren und war zeitweise arbeitsunfähig krank. Sein Dienstherr verlangte von dem Viehhändler aufgrund von $\S 683$ BGB Erstattung der Krankheitskosten. Damit scheiterte er vor dem $B G H$, der die Vorschriften des bayerischen Polizeirechts über die Kostentragungspflicht des Zustandsstörers für abschließend hielt. ${ }^{445} \mathrm{Ob}$ sich diese Sichtweise allgemein durchsetzen wird, bleibt abzuwarten.

\section{Hilfe in Notlagen und Selbstaufopferung im Straßenverkehr}

Der $B G H$ hatte dem Nothelfer, der dem Opfer einer Vergewaltigung beigesprungen war und dabei selbst schwere Verletzungen erlitten hatte, einen Anspruch aus Geschäftsführung ohne Auftrag gegen die Krankenversicherung des Opfers eingeräumt. ${ }^{46}$ Diese Judikatur hat sich erledigt, nachdem Nothelfer in den Schutzbereich der gesetzlichen Unfallversicherung einbezogen worden sind; vgl. jetzt $\S 2$ Nr. 13 lit. c) SGB VII. Der Zweck dieser sozialversicherungsrechtlichen Vorschrift ist natürlich derselbe wie derjenige der Geschäftsführung ohne Auftrag, nämlich Anreize zum altruistischen Handeln in Notlagen freizusetzen. Eine Angelegenheit der Unfallversicherungsträger ist heutzutage auch der vom $R G$ ent-

441 Maurer, Allgemeines Verwaltungsrecht, 15. Aufl. 2004 Auflage, § 28 Rn. 12.

442 Ossenbühl, Staatshaftungsrecht, 5. Aufl. 1998, S. 343; genauso MünchKommBGB-Seiler (Fn. 421), Vor $§ 677$ Rn. 31; ausführlich Maurer, JuS 1970, 561, $563 \mathrm{ff}$.

443 Scherer, NJW 1989, 2724, 2728.

444 BGH NJW 2004, 513.

445 BGH NJW 2004, 513, $514 \mathrm{f}$.

446 BGHZ 33, 251, $254 \mathrm{ff}$. 
schiedene Fall geworden, daß ein Retter in ein Gewässer springt, um eine dort um Hilfe schreiende Person vor dem Ertrinken zu retten, dabei aber selbst zu Tode kommt. ${ }^{447}$ Hier besteht heute Sozialversicherungsschutz gemäß $\S 2$ Nr. 13 lit. a) SGB VII.

Nach wie vor außerhalb des Schutzbereichs der sozialen Unfallversicherung liegt die Selbstaufopferung im Straßenverkehr. In diesen Fällen steuert ewa ein Autofahrer seinen Wagen in den Graben, um den Aufprall auf einen anderen Verkehrsteilnehmer zu vermeiden, der letzterem womöglich das Leben kosten, jedenfalls aber schwere Personenschäden verursachen würde. Sofern der durch Ausweichen abgewendete Unfall für den Kraftfahrer ein unabwendbares Ereignis im Sinne des $\S 7$ Abs. 2 StVG a. F. gewesen wäre, soll er sich nach der Rechtsprechung des $B G H$ wegen der selbst erlittenen Schäden aufgrund Geschäftsführung ohne Auftrag bei dem ,begünstigten“ Verkehrsteilnehmer erholen können. ${ }^{448}$ Wiederum hat die Literatur dem $B G H$ vorgeworfen, die Geschäftsführung ohne Auftrag für disfunktionale Aufgaben heranzuziehen. Wittmann hält eine Geschäftsführung ohne Auftrag zugunsten des Geretteten bei entsprechendem Fremdgeschäftsführungswillen grundsätzlich für möglich, läßt sie in casu jedoch an den Erwägungen scheitern, der Kraftfahrer sei gemäß $\S 823$ BGB ohnehin zum Ausweichen verpflichtet gewesen und ein Grund für die „Haftpflicht“ des Geretteten nicht ersichtlich. ${ }^{449}$ In der Tat handelt es sich regelmäßig um zwei „unschuldige“ Parteien, so daß sich starke Gründe für die Risikozurechnung in die eine oder andere Richtung nicht finden lassen. Das Interesse an der Aufrechterhaltung von Anreizen $\mathrm{zu}$ altruistischem Verhalten auch außerhalb der sozialen Unfallversicherung spricht für die „Versicherung“ des Retters über die $\$ \S 677 \mathrm{ff}$. BGB. ${ }^{450}$

Allerdings ist zweifelhaft, ob die geschilderte Rechtsprechung das am 1. August 2002 in Kraft getretene Zweite SchadensersatzrechtsänderungsG überlebt hat. Seither ist in $\S 7$ Abs. 2 StVG der Entlastungsgrund des unabwendbaren Ereignisses durch denjenigen der höheren Gewalt ersetzt worden. Um höhere Gewalt handelt es sich aber nicht, wenn ein Radfahrer direkt vor dem herannahenden Fahrzeug ausschert, so daß dessen Fahrer den Wagen in den Graben steuert, um einen Aufprall zu vermeiden. ${ }^{451}$ Dank der Beck'schen „Neuen Zeitschrift für Verkehrsrecht" sind die Konsequenzen dieser Änderung für die Geschäftsführung ohne Auftrag bereits ausführlich erörtert worden. ${ }^{452} \mathrm{Ob}$ es wirklich dem Opferschutz dient, wenn Ersatzansprüche des ausweichenden Kraftfahrzeugführers verneint werden, steht freilich auf einem anderen Blatt. ${ }^{453}$

447 RGZ 167, 85, 87.

448 BGHZ 38, 270, $273 \mathrm{ff}$.

449 Wittmann (Fn. 412), S. $78 \mathrm{ff}$.

${ }^{450} \mathrm{Im}$ Ergebnis genauso MünchKommBGB-Seiler (Fn. 421), § 683 Rn. 23; eingehend zur Anreizwirkung der $\$ \S 677 \mathrm{ff}$. Kötz, FS Großfeld, 1999, S. 583, $584 \mathrm{ff}$.

451 So der Fall BGHZ 38, 270.

452 Friedrich, NZV 2004, 227, 229.

453 Vgl. MünchKommBGB-Seiler (Fn. 421), § 683 Rn. 23; Friedrich, NZV 2004, 227, 229. 


\section{Ausdehnung der $\$ 683,670$ BGB auf Schadensersatz}

Die bisherigen Darlegungen haben bereits anklingen lassen, was nunmehr und abschließend erörtert werden soll, nämlich die Ausdehnung des $§ 683$ BGB auf Schadensersatzansprüche. Ausweislich des $§ 683$ S. 1 BGB kann der zur Geschäftsführung berechtigte Geschäftsführer die traditionsreiche actio negotiorum gestorum contraria erheben, also vom Geschäftsherrn Ersatz seiner Aufwendungen verlangen ( $\$ 670$ BGB). Unter Aufwendungen werden herkömmlich freiwillige Vermögensopfer im Interesse eines anderen verstanden, während es für Schäden kennzeichnend ist, daß sie unfreiwillig erlitten werden. ${ }^{454} \mathrm{Nach}$ seinem Wortlaut deckt $\S 683 \mathrm{~S} .1$ BGB Schadensersatzansprüche des Geschäftsführers gegen den Geschäftsherrn also nicht.

In einem Fall, in dem ein Passant versucht hatte, das Leben einer Ertrinkenden zu retten und dabei sein eigenes Leben eingebüßt hatte, war das $R G$ der Auffassung, bei dieser Rechtslage lasse ,sich nicht stehen bleiben“. ${ }^{455}$ Derjenige, der sich selbst aufgeopfert hat, müsse auf der Grundlage von $\S \S 683$ S. 1, 670 BGB Schadensersatz verlangen können, und im Falle des Todes seien den Hinterbliebenen die Ansprüche der $\S \S 844,845$ BGB zuzubilligen. ${ }^{456}$ Diese Judikatur hat der $B G H$ übernommen und bis heute an ihr festgehalten. ${ }^{457}$ Die Literatur folgt der Rechtsprechung im Ergebnis, ${ }^{458}$ hat sich jedoch um eine genauere Profilierung der Anspruchsgrundlage bemüht, weil die Ausdehnung der $\S \S 683$ S. 1, 670 BGB auf Schäden verbreitet als unglücklich empfunden wird. Der Alternativvorschlag Wollschlägers, an die Stelle der Ausdehnung bzw. analogen Anwendung der $§ \S 683$ S. 1, 670 BGB einen Aufopferungs-Ausgleichsanspruch auf ,,billige Verteilung der Unglücksfolgen“"zu setzen und diesen als Ergänzung des Sozialversicherungsschutzes zugunsten von Nothelfern zu verstehen, ${ }^{459}$ hat keine Gefolgschaft gefunden. Besser erging es dem Vorschlag von Canaris, der den Schadensersatzanspruch des Geschäftsführers auf den Zurechnungsgrund der „Risikohaftung bei Tätigkeit in fremdem Interesse“ stützen will. ${ }^{460}$

Die Rechtsprechung hat bisher keinen Anlaß gesehen, von dem Ansatz bei $\S 670$ BGB abzuweichen, obwohl sie diese Variante des „Aufwendungsersatzes“ den sonst nur für Schadensersatzansprüche geltenden Vorschriften der $\$ \S 254$, 844f. BGB unterwirft. Der eigentliche Grund dafür könnte sein, daß das Festhalten an der Anspruchsgrundlage des $§ 670$ BGB und die Qualifikation als Aufwendungsersatz es dem BGH erleichtert, einen Anspruchsübergang auf Sozialversicherungsträger gemäß $\S 116$ SGB X auszuschließen, der schwer von der Hand zu weisen ist, wenn der Anspruch offen als Schadensersatzanspruch angesprochen wird. ${ }^{461}$

454 MünchKommBGB-Seiler (Fn. 421), § 683 Rn. 18.

${ }^{455}$ RGZ 167, 85, 89.

${ }^{456}$ RGZ 167, 85, 89.

${ }_{457}$ BGHZ 33, 251, 257; 38, 270, 271; BGH NJW 1993, 2234, 2235.

458 MünchKommBGB-Seiler (Fn. 421), § 683 Rn. 18 ff.; Larenz (Fn. 420), S. 449f.; Medicus (Fn. 23), Rn. 425, 626; Brox/Walker (Fn. 23), § 35 Rn. 45.

459 Wollschläger (Fn. 410), S. 295 ff., 299; ablehnend etwa Larenz (Fn. 420), S. 449 Fn. 51.

460 Canaris, RdA 1966, 41, 43; Larenz (Fn. 420), S. 449 f.

${ }^{461}$ BGHZ 92, 270, 271 f.; anders noch RGZ 167, 85, 90; BGHZ 33, 251, 258. 


\section{Europäisierung}

Obwohl die Geschäftsführung ohne Auftrag längst nicht allen europäischen Rechtsordnungen geläufig ist ${ }^{462}$, ist sie von den Bemühungen um Rechtsvereinheitlichung bereits voll erfaßt worden. Die Study Group on a European Civil Code hat von ihren „Principles of European Law“ einen ersten Band veröffentlicht, der den Prinzipien eines Europäischen Gestionsrechts gewidmet ist ${ }^{463}$. Dieser Schritt kam insoweit etwas überraschend, als das Bedürfnis für die Geschäftsführung ohne Auftrag als Institution eines zukünftigen Europäischen Schuldrechts eigentlich erst dann abgeschätzt werden kann, wenn die übrigen Teile des Systems - Vertragsrecht, Deliktsrecht, Bereicherungsrecht - feststehen. Die Geschäftsführung ohne Auftrag ist primär Regreßinstrument und im übrigen Lückenbüßer. Solange man nicht weiß, welche Regreßfragen noch offen und welche Lücken zu schließen sind, lassen sich Aussagen über die Ausgestaltung des Rechtsinstituts kaum treffen. Aus diesen Gründen ist zu erwarten, daß die $§ \S 677 \mathrm{ff}$. BGB noch auf längere Sicht erhalten bleiben werden.

462 Oben, IV 1.

463 von Bar, Benevolent Intervention in Another's Affairs, 2006. 